\title{
Distribución relativa de genotipos de virus papiloma humano en muestras de carcinoma escamoso de laringe
}

\author{
Relative distribution of human papilloma virus in laryngeal squamous cell carcinoma
}

Mariela Torrente $\mathrm{A}^{1}$, Loreto Yeomans $\mathrm{A}^{2}$, Maritza Abud P³, José Manuel Ojeda F².

\begin{abstract}
RESUMEN
Introducción: La relación entre virus papiloma humano (VPH) y cáncer escamoso de la vía aéreo-digestiva superior está claramente establecida en la literatura.

Objetivo: El objetivo del presente trabajo es conocer la frecuencia de identificación de ADN de VPH y la distribución relativa de genotipos en muestras de carcinoma escamoso de laringe.

Material y método: Se extrajo ADN desde muestras fijadas en formalina e incluidas en parafina, de biopsias de carcinoma escamoso de laringe de pacientes operados en el Servicio de Otorrinolaringología del Hospital San Juan de Dios. La detección de ADN viral se realizó mediante $P C R$ con partidores de consenso MY09/11, y la genotipificación se realizó mediante endonucleasas de restricción Rsal. La calidad de la muestra se controló mediante amplificación de B-globina.

Resultados: Se incluyeron 90 casos. En 24 de ellos (27\%) se identificó la presencia de ADN de VPH. Los genotipos más frecuentes fueron VPH18 (7/24), VPH16 (5/24), VPH54 (2/ 24). En 3 casos no se logró identificar el genotipo. No se detectaron infecciones múltiples.

Conclusiones: La presencia de genotipos de VPH de alto riesgo oncogénico sugieren que el virus papiloma humano tendría un rol en la etiopatogenia de un subgrupo de pacientes portadores de carcinoma escamoso de laringe.
\end{abstract}

Palabras clave: VPH, genotipificación, virus papiloma humano.

\begin{abstract}
Introduction: Human papillomaviruses (HPV) have been detected in benign and neoplastic laryngeal lesions, with variable frequency (20-60\%). These viral agents are proposed as an adjuvant or cofactor in head and neck carcinogenesis because of their oncogenic properties.

Aim: The aim of this study was to identify HPV in laryngeal carcinoma samples and to describe their genotype distribution.

Material and method: Tumor samples from patients with newly diagnosed laryngeal carcinomas were collected, fixed in formalin and paraffin-embedded. HPV genome was identified by use of polymerase chain reaction (PCR) using primers complementary to the conserved region L1 (MYO9-11). Genotyping was accomplished by restriction fragment length polymorphism.

Results: 24 of the 90 samples were positive for HPV DNA (27\%), all of the samples were positive for human B-globin. The genotypes identified were HPV 16 (5 cases), HPV 18 (7 cases), and HPV 39, 45, 51, 58, 59, 61, and 66 (1 case each).

Conclusions: High-risk HPV genotypes were identified, suggesting a role of human papilloma virus in the etiology of a subgroup of laryngeal squamous cell carcinomas.

Key words: HPV, genotyping, human papilloma virus.
\end{abstract}

\footnotetext{
Departamento de Otorrinolaringología, Facultad de Medicina Universidad de Chile, Hospital San Juan de Dios.

2 Centro de Oncología Preventiva, Campus Occidente, Facultad de Medicina Universidad de Chile.

3 Departamento de Anatomía Patológica, Hospital San Juan de Dios.
} 


\section{INTRODUCCIÓN}

El carcinoma escamoso de laringe constituye aproximadamente $2 \%$ de los casos nuevos de neoplasias malignas al año en Estados Unidos ${ }^{1}$, y 4.500 personas mueren por esta enfermedad al año. La mayoría de los pacientes son hombres (relación 8:1 entre hombres y mujeres), los factores de riesgo más conocidos son el hábito tabáquico y el consumo de alcohol'1. En los últimos años se ha reconocido el rol del virus papiloma humano (VPH) en el proceso carcinogénico de un grupo de tumores escamosos de la vía aéreo digestiva superior. Los VPH son virus icosahédricos de doble hebra de ADN, que contienen aproximadamente 8.000 pares de bases. Su genoma se distribuye en genes de expresión temprana (E) y tardía (L).

Entre los genes de expresión temprana se reconocen los oncogenes virales E6 y E7, cuyas proteínas interfieren con el normal funcionamiento de las proteínas celulares p53 y pRb, respectivamente. De esta forma se pierde el control de la progresión del ciclo celular con la consecuente proliferación descontrolada e inmortalización celular. Esto permite además la acumulación de eventos relacionados con inestabilidad genética que contribuyen a la carcinogénesis².

Entre los genes de expresión tardía cabe destacar L1 cuya secuencia génica posee regiones altamente constantes en los distintos genotipos virales, lo que permite su utilización en los ensayos para identificar la presencia de ADN viral.

A la fecha se han descrito más de 100 tipos distintos de VPH (genotipos), los que se agrupan en genotipos de alto y bajo riesgo oncogénico según su relación epidemiológica con el cáncer cérvico-uterino. Los genotipos de alto riesgo (HR VPH) más frecuentes son VPH 16 y 18, los que se detectan en $60 \%$ a $70 \%$ de los casos de cáncer de cérvix. Cabe destacar que la distribución relativa de los genotipos de alto riesgo presenta una variación étnico-geográfica ${ }^{3}$.

En carcinomas invasores de laringe la prevalencia de VPH varía entre $8 \%$ y $58,8 \% \%^{4-12}$. Esta dispersión puede explicarse por la diferencia entre técnicas empleadas para la identificación del ADN viral y por la escasa cantidad de pacientes y muestras clínicas incluidas en los estudios. La distribución relativa de genotipos no ha sido estu- diada en carcinomas escamosos de laringe, sólo hay reportes que incluyen algunos genotipos más prevalentes en poblaciones anglosajonas ${ }^{4,13} 0$ donde se entrega la información total para tumores de cabeza y cuello sin detallar por zona anatómica ${ }^{14}$. VPH 16 parece ser el más frecuente, al igual que en carcinoma cérvico-uterino.

En publicación previa de nuestro grupo se describen los resultados de un número reducido de pacientes $^{12}$. El objetivo del presente trabajo fue evaluar la presencia de ADN de VPH en muestras de cáncer escamoso de laringe, y establecer la distribución relativa de los genotipos identificados incluyendo una casuística mayor.

\section{MATERIAL Y MÉTODO}

\section{Material de biopsias}

Se incluyeron en el estudio las biopsias de 90 pacientes con diagnóstico de carcinoma escamoso de laringe, tratados en el Servicio de Otorrinolaringología del Hospital San Juan de Dios entre los años 2000 y 2005. De ellos, 30 casos se reportaron previamente $^{12}$. Todas las muestras se encontraban fijadas en formalina e incluidas en parafina.

\section{Extracción de ADN}

Se realizó extracción de la parafina mediante tratamiento con xilol y etanol. Se sometió a digestión con proteinasa $\mathrm{K}$ por 3 horas a $55^{\circ} \mathrm{C}$. El pellet resultante se purificó mediante extracción orgánica con una secuencia de fenol, cloroformo y alcohol isopropílico.

\section{Detección ADN de VPH por PCR (MY09/11)}

La detección de VPH se realizó usando los partidores de consenso MY09/MY11 que hibridan con regiones genómicas correspondientes al gen L1 de VPH.

El producto de PCR se analizó por electroforesis en gel de agarosa al 1,5\% con bromuro de etidio incorporado. Se visualizó la banda amplificada de aproximadamente $450 \mathrm{pb}$ en un transiluminador U.V. (Vilber Lourmart), y se fotografiaron las imágenes usando una cámara digital Nikon Coolpix 4500. 


\section{Genotipificación de VPH mediante uso de endonucleasas de restricción}

La tipificación de los VPH se realizó de acuerdo a la técnica previamente descrita ${ }^{12}$, que consiste en digerir con la endonucleasa de restricción Rsa I el producto amplificado por PCR de la región L1. Los patrones de digestión por Rsa I de la mayoría de los VPH son característicos para cada genotipo viral. Esto permite realizar un procedimiento de genotipificación "abierto" a todos los genotipos descritos, y no limitado a los más frecuentes como sería al utilizar hibridación con marcadores específicos.

El producto de digestión fue analizado por electroforesis en gel de agarosa al 1,5\% con bromuro de etidio incorporado. Posteriormente se visualizaron las bandas digeridas por medio de un transiluminador U.V. (Vilber Lourmart) y se compararon al patrón de las mismas con los estándares obtenidos por Villiers y cols.

\section{PCR para B-globina humana}

Para verificar la calidad del ADN obtenido, a cada muestra se le determinó la presencia de B-globina humana mediante PCR.

\section{Análisis estadístico}

Los resultados son analizados en forma descriptiva. Se incluyeron todos los pacientes del período de estudio, es decir, se trabajó con el universo muestral del período.

\section{RESULTADOS}

Se incluyeron 90 casos de pacientes portadores de carcinoma escamoso de laringe, cuyas características se observan en la Tabla 1. Se detectó genoma de VPH en 24 de las 90 carcinomas estudiados (27\%), 20 casos fueron pacientes de sexo masculino y 4 de sexo femenino. No hubo diferencias significativas con respecto a la presencia viral y edad, hábito tabáquico y estadio tumoral (Tabla 1).

La Figura 1 muestra la presencia de ADN de VPH amplificado mediante PCR usando los partidores MY09/11. Las muestras positivas muestran la presencia de fragmentos de 450 pares de base (bp), el que no se observa en las muestras negativas. Todas las muestras fueron adecuadas para el ensayo ya que permitieron la amplificación del gen de B-globina.

La Figura 2 muestra la presencia de genotipos de VPH en los carcinomas laríngeos estudiados. El perfil de los fragmentos producto de la digestión con la enzima de restricción Rsa1 permite visualizar la presencia de genotipos como VPH18 por su correspondencia con los fragmentos generados utilizando el ADN de células HeLa que contiene ADN de VPH18.

La Figura 3 muestra la distribución de los genotipos de VPH en los carcinomas escamosos.

Tabla 1. Características epidemiológicas de los pacientes incluidos

\begin{tabular}{|lrrr|}
\hline & VPH + & VPH & Total \\
& n: 24 & n: 66 & n: 90 \\
& $(27 \%)$ & $(73 \%)$ & $(100 \%)$ \\
\hline Sexo & & & \\
Femenino & $4(17 \%)$ & $10(15 \%)$ & $14(16 \%)$ \\
Masculino & $20(83 \%)$ & $56(85 \%)$ & $76(84 \%)$ \\
Tabaco & & & \\
$\quad$ Sí & $19(79 \%)$ & $52(79 \%)$ & $71(79 \%)$ \\
No & $5(21 \%)$ & $14(21 \%)$ & $19(21 \%)$ \\
Edad (años) & & & \\
$\quad$ Rango & $29-85$ & $30-86$ & $29-86$ \\
Mediana & 62 & 65 & 65 \\
Estadio & & & $28(31 \%)$ \\
$\quad$ Inicial (I y II) & $7(29 \%)$ & $21(32 \%)$ & $62(69 \%)$ \\
Avanzado (III y IV) & $17(71 \%)$ & $45(68 \%)$ & \\
\hline
\end{tabular}




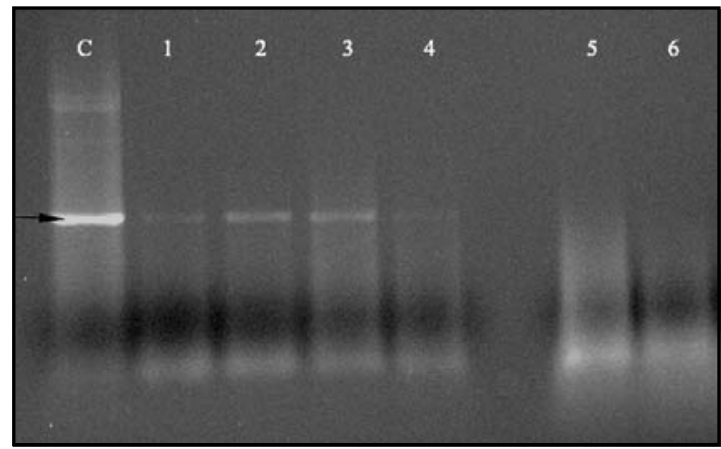

Figura 1. Detección de ADN de VPH en muestras de carcinomas laríngeos correspondientes a 6 casos. Gel de agarosa al 1,5\% mostrando la presencia del producto de PCR correspondiente a la región L1 del genoma de VPH usando partidores MY09/11. La flecha indica la banda de 450 bp en el control (C) y en los casos 1 al 4 . Los casos 5 y 6 son negativos.

Los genotipos más frecuentes fueron VPH18 (7/ 24), VPH16 (5/24), VPH54 (2/24). En 3 casos no se logró identificar el genotipo. No se detectaron infecciones múltiples.

\section{DISCUSIÓN}

El rol de VPH en la carcinogénesis de los tumores escamosos de la vía aéreo-digestiva superior ha sido claramente establecido en los últimos años, incluso se ha demostrado su rol como factor de buen pronóstico ${ }^{15}$.

La literatura reporta una prevalencia en torno al $25 \%$ de VPH en tumores de cabeza y cuello, pero esta cifra puede variar entre $8 \%$ y $58 \%$. Esto se explica por las diferentes técnicas usadas para la detección viral y por el número de casos incluidos. Sólo tres series reportadas incluyen más de 50 pacientes ${ }^{4,13,14}$. En la primera de ellas, para un total de 103 pacientes, la prevalencia de VPH fue de $6,8 \%{ }^{13}$, pero los autores emplearon PCR selectivo para genotipos VPH 16, 18, 31, 33 y 45; excluyendo de esta forma otros genotipos, por lo cual la prevalencia real de VPH podría estar subestimada. En un segundo estudio se incluyeron 86 casos con una prevalencia de $19 \%$ para $\mathrm{VPH}^{14}$. Finalmente un tercer estudio incluyó 91 casos con una prevalencia de $13 \%{ }^{4}$. De un total de 5.046 casos agrupados en un metaanálisis ${ }^{16}$, la prevalencia de VPH fue de 24\% (IC 21,8-26,3).

En este trabajo escogimos una técnica basada en PCR ya que es el método más sensible. Como partidores utilizamos MY09/11 que corresponden

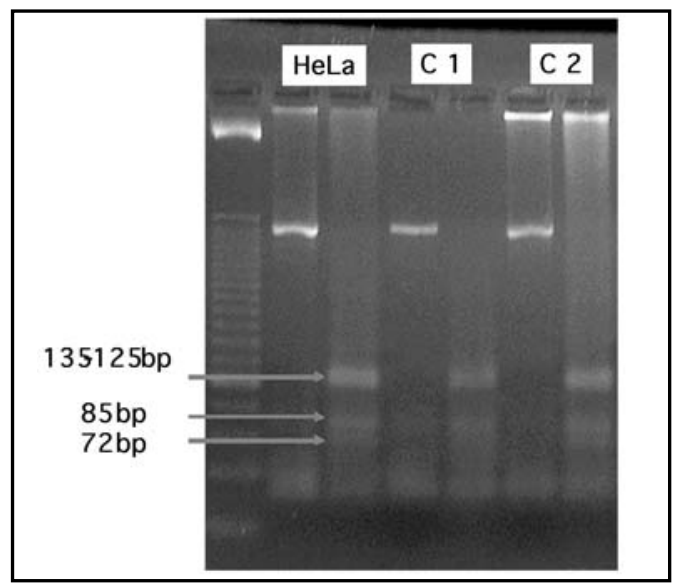

Figura 2. Identificación de genotipos de VPH en muestras de carcinomas laríngeos mediante técnica de endonucleasas de restricción. Gel de agarosa al $1,5 \%$ donde se observa el resultado de la digestión del amplificado de L1 con la endonucleasa Rsa1. El primer carril corresponde al patrón de tamaño. Se muestra el resultado del control (HeLa) y de dos casos (1 y 2), para todos ellos el primer carril corresponde al amplificado de L1 sin digerir. El control corresponde a ADN de células HeLa lo que permite identificar la presencia de VPH 18, con bandas en 135-125 bp, 85 bp y 72 bp. En los dos casos incluidos se observa el mismo patrón de bandas que el correspondiente al ADN de células HeLa.

a partidores genéricos y se ha demostrado que amplifican en forma confiable un gran número de genotipos de VPH, incluyendo todos los de alto riesg $0^{17}$. La limitación de esta técnica puede ser el tamaño del fragmento a amplificar: $450 \mathrm{bp}$. Las muestras se encuentran fijadas en formalina lo que fragmenta el ADN y dificulta la extracción de fragmentos de más de 200 bp. Sin embargo, la 


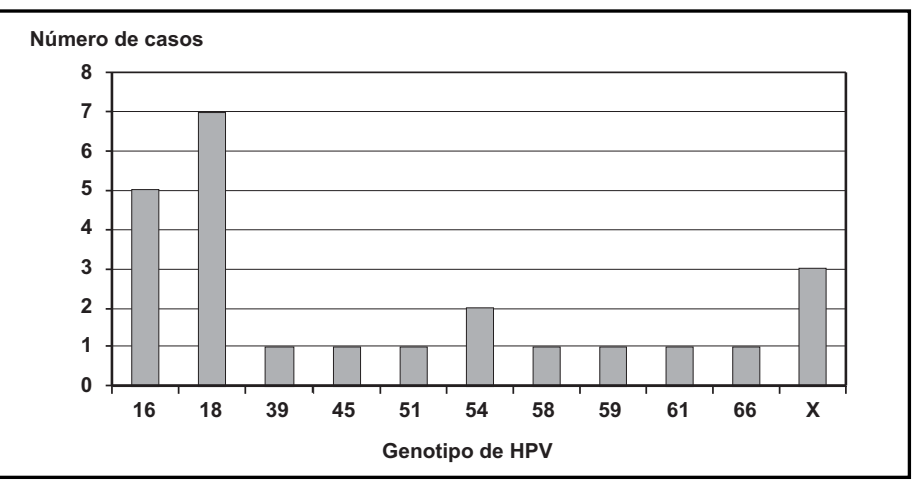

Figura 3. Distribución de genotipos de VPH en carcinomas laríngeos. VPHX: no identificado.

cifra obtenida en este experimento es muy cercana al $25 \%$ que reporta el metaanálisis de Kreimer $^{16}$.

Con respecto a la distribución de genotipos de VPH en tumores de cabeza y cuello existen pocos reportes, y la mayoría utilizan técnicas que detectan los genotipos de alto riesgo más prevalentes. En nuestra serie llama la atención que el genotipo más frecuente fue VPH18 (7 casos, 33\%), al contrario que en otras series publicadas donde el genotipo más frecuente es VPH16 (en nuestra serie corresponde a 5 casos, 24\%). Sin embargo, son series donde se incluyen tumores de la vía aéreodigestiva superior, analizando en conjunto orofaringe, hipofaringe y laringe, lo cual podría tener un efecto en la distribución de genotipos.

La variación en la distribución relativa de genotipos también puede estar determinada por factores étnico-geográficos. En carcinomas escamosos de cuello uterino el genotipo más frecuente a nivel mundial es el VPH $16^{18}$. Sin embargo, al realizar un análisis por continente, Ios genotipos más prevalentes de VPH pueden presentar variaciones ${ }^{18,19}$. La prevalencia de VPH16 y VPH18 en carcinomas de cuello uterino en Europa y Norteamérica es semejante ( $74 \%$ y $76 \%$ respectivamente); en cambio, en Centro y Sudamérica es más parecida a la de Asia (65\% y $67 \%$, respectivamente), siendo la de África de distribución intermedia $(70 \%)$. Siendo los genotipos de VPH 16 y 18 los más prevalentes en los carcinomas de cuello uterino a nivel mundial, la frecuencia y distribución de los otros genotipos presenta una mayor variación en cuanto a distribución y frecuencia por continentes.
Si entendemos la fuente de infección de la vía aéreo-respiratoria fundamentalmente de origen genital, es comprensible que la distribución de genotipos sea semejante a la del carcinoma cérvico-uterino.

El estudio de la distribución de genotipos también resulta relevante en el contexto de la vacuna profiláctica de VPH. En el comercio están disponibles dos vacunas: Cervirax ${ }^{\mathrm{TM}}$ (que protege contra VPH 16 y 18) y Gardasil ${ }^{\mathrm{TM}}$ (que protege para VPH $6,11,16$ y 18).

El presente trabajo demuestra la factibilidad de realizar estudios de identificación de VPH en muestras fijadas en formalina e incluidas en parafina en nuestro medio. La frecuencia de identificación viral es similar a lo reportado en la literatura ${ }^{16}$. Con respecto a los genotipos identificados, esta serie incluye un número considerable de pacientes con patología tumoral de un solo origen en la vía aéreodigestiva superior (la laringe) en comparación con otros estudios, lo que consolida la relación etiopatogénica de ciertos VPH en los carcinomas escamosos de laringe.

\section{BIBLIOGRAFÍA}

1. Miluion R, Cassisi N, Clark J. Cancer of the head and neck. In: V.T. De Vita, S. Hellman, and S.A. Rosemberg (eds), Cancer: Principles and Practice of Oncology, pp. 488-590. Philadelphia: J.B. Lippincott Co.; 1989.

2. Mckaig RG, Baric RS, Losan AF. Human papillomavirus and head and neck cancer: 
Epidemiology and molecular biology. Head Neck 1998, 20: 250-65.

3. Muñoz N, Bosch X, de Sanjose S, Herrero R, Castellsague $X$, Shah K et als. Epidemiologic classification of human papillomavirus types associated with cervical cancer. $N$ Engl J Med 2003; 348: 518-27.

4. Gorgoulis VG, Zacharatos $P$, Kotsinas A, Kyroudi A, Rassidakis A, IKonomopoulos J et als. Human Papilloma Virus (HPV) is possibly involved in laryngeal but not in lung carcinogenesis. Hum Pathol 1999; 30:,274-83.

5. Simith eM, Summersgill KF, Allen J, et als. Human papillomavirus and risk of laryngeal cancer. Ann Otol Rhinol Laryngol 2000; 109: 1069-86.

6. Almadori G, Cadoni G, Cattani P, Galli J, Bussu F, FerRandina G, et als. Human papillomavirus infection and epidermal growth factor receptor expression in primary laryngeal squamous cell carcinoma. Clin Can Res 2001; 7: 3988-93.

7. Atula S, Grenman R, Kujari h, Syruänen S. Detection of human papillomavirus (HPV) in laryngeal carcinoma cell lines provide evidence for a heterogeneic cell population. Eur J Cancer 1999; 35: 825-32.

8. Venuti A, Manni V, Morello R, De Marco F, Marzetti F, Marcante ML. Physical state and expresión of human papillomavirus in laringeal carcinoma and surrounding normal mucosa. $J$ Med Virol 2000; 60: 396-402.

9. Brandwein MS, Biller H, Nuovo GJ. Analysis of prevalence of human papilloma virus in laryngeal carcinomas. Ann Otol Rhinol Laryngol 1993; 102: 309-13.

10. Lie ES, Karlsen F, Holm R. Presence of human papilloma virus in squamous cell laryngeal carcinomas. A study of thirty-nine cases using polymerasa chain reaction and in situ hybridization. Acta Otolaryngol (Stockh) 1996; 116: $900-5$.

11. Pérez-Ayala M, Ruiz-Cabello F, Esteban F, Concha A, Redendo M, Oliva MR, et als. Presence of HPV 16 sequences in laringuela carcinomas. Int $J$ Cancer 1990; 46: 8-11.

12. Torrente M, Abud $S$, Abud M, OJeda JM. Molecular detection and genotyping of human papillomavirus in laryngeal carcinoma specimens. Acta Otolaryngol 2005; 125: 88893.

13. Fouret P, Monceaux G, Temam $S$, Lacourreye L, LACAU St GuILY J. Human papillomavirus in head and neck squamous cell carcinomas in nonsmokers. Arch Otolaryngol Head Neck Surg 1997; 123: 513-16.

14. Gillison ML, Koch WM, Capone RB, Spafford M, Westra WH, Wu L, et ALs. Evidence for a causal association between human papillomavirus and a subset of head and neck cancers. J Natl Cancer Inst 2000; 92: 709-20.

15. Fakhry C, Gillison ML. Clinical implications of human papillomavirus in head and neck cancers. J Clin Oncol 2006; 24: 2606-11.

16. Kreimer AR, Clifford GM, Boyle P, Franceschi S. Human papillomavirus types in Head and Neck Squamous Cell Carcinomas Worldwide: A Systematic Review. Cancer Epidemiol Biomarkers Prev 2005; 14: 467-75.

17. Qu W, Jiang G, Cruz Y, Chang CJ, Ho G, Klein R, ET ALS. PCR detection of human papillomavirus: Comparison between MY09/11 and GP5+/ GP6+ primer systems. J Clin Microbiol 1997; 35: 1304-10.

18. Smith J, Lindsay L, Hoots B, Keys J, Franceschi S, Winer R. Human papillomavirus type distribution in invasive cervical cancer and high-grade cervical lesions: A meta-analysis update. Int J Cancer 2007; 121: 621-32. 
Tabla 3. Motivos de repetición de exámenes

\begin{tabular}{|lcc|}
\hline Motivo & $\mathrm{n}$ & $\%$ \\
\hline Caducidad $^{\star}$ & 69 & 45,1 \\
Alteración de exámenes iniciales $_{\text {Controles programados u otras causas ** }}^{*}$ & 50 & 32,5 \\
Total exámenes repetidos $^{*}$ & 34 & 22,5 \\
\end{tabular}

Se incluyen en esta tabla exámenes de rutina y propiamente $\mathrm{ORL}$.

*Definido arbitrariamente 6 meses de duración. ${ }^{* *}$ En caso de controles audiométricos programados 0 duda clínica de diagnóstico o indicación quirúrgica.

Tabla 4. Exámenes preoperatorios propiamente otorrinolaringológicos

\begin{tabular}{|lcccc|}
\hline Examen ORL & $\begin{array}{c}\text { Número total } \\
(\bar{x} \text { por paciente })\end{array}$ & $\begin{array}{c}\text { Una } \\
\text { repetición* }\end{array}$ & $\begin{array}{c}\text { Dos } \\
\text { repeticiones * * }\end{array}$ & $\begin{array}{c}\text { Pertinencia } \\
\text { del examen } \\
\text { solicitado }\end{array}$ \\
\hline Nasofaringolaringoscopía & $15(0,11)$ & $0 \%$ & $0 \%$ & $60 \%$ \\
Audiometría & $36(0,26)$ & $63,2 \%$ & $26,3 \%$ & $52,8 \%$ \\
Impedanciometría & $34(0,24)$ & $70,6 \%$ & $29,4 \%$ & $50 \%$ \\
Total & 85 & & & \\
\hline
\end{tabular}

*Porcentaje de pacientes a los que se repitió el examen al menos una vez. ${ }^{*}$ Porcentaje de pacientes a quienes se les realizó el examen una tercera vez.

el porcentaje restante no se encontró algún fundamento clínico explícito en la ficha clínica que avalara la decisión de repetir el examen.

Con respecto al resultado de los exámenes de rutina, podemos ver en la Tabla 5, como fueron necesarios 70 exámenes de rutina (con un costo de $\$ 703.500$ pesos chilenos) para encontrar una alteración clínicamente relevante. Esto, permitió detectar 2 casos de enfermedad de von Willebrand, Io que modificó su manejo como ya se expuso.

Ningún EP alterado se asoció a alguna complicación perioperatoria.

Más aún, dentro de los casos inicialmente determinados sin mayor riesgo (con exámenes preoperatorios normales) hubo 4 complicaciones (2,9\% del total de la muestra), todos ellos sangrados posoperatorios en adeno-amigdalectomías.

No es posible calcular razón de momios (odds ratio) para la comparación de complicaciones según alteración de EP debido a la ausencia de casos en alguna de las categorías.
Al evaluar en conjunto los casos donde se necesitó una acción médica, y las complicaciones observadas, como resultados que demandaron un cambio en el manejo del paciente, observamos una razón de momios de 7,87 con un intervalo de confianza sobre 1, y un valor de $\chi^{2}$ asociado a un $p<0,05$. Esto podría reflejar, que los EP obligan a intervenir con más frecuencia en casos con resultados alterados en comparación a pacientes sin alteración en sus exámenes, sin embargo, sin impacto en la tasa de complicaciones.

Por otro lado, aunque los EP no ayudaron a prever complicaciones, sí se asociaron significativamente a mayor número de consultas médicas, mayor número de días de hospitalización (principalmente debido a la necesidad de repetir exámenes y visitas anestésicas).

En términos de costo-efectividad, se necesitaron 70 exámenes de rutina para encontrar una patología que motivó un cambio de conducta dentro del manejo del paciente (2 casos de EvW). 
Tabla 5. Exámenes alterados y resultados

\begin{tabular}{|c|c|c|c|}
\hline & $\begin{array}{l}\text { Exámenes } \\
\text { alterados }\end{array}$ & $\begin{array}{l}\text { Exámenes } \\
\text { normales }\end{array}$ & Significancia estadística \\
\hline $\begin{array}{l}\text { Número } \\
\text { (\% del total) }\end{array}$ & $\begin{array}{c}10 \\
(7,1 \%)\end{array}$ & $\begin{array}{c}130 \\
(92,8 \%)\end{array}$ & \\
\hline $\begin{array}{l}\text { Patología confirmada que requirió } \\
\text { acción médica (\% del total) }\end{array}$ & $\begin{array}{c}2 \\
(1,4 \%)\end{array}$ & $\begin{array}{c}0 \\
(0 \%)\end{array}$ & $\begin{array}{l}\text { - Se requieren } 70 \text { exámenes } \\
\text { de rutina para encontrar } 1 \\
\text { patología. } \\
\text { - Ninguna alteración en } \\
\text { exámenes preoperatorios } \\
\text { asoció una complicación }\end{array}$ \\
\hline $\begin{array}{l}\text { Complicaciones perioperatorias } \\
\text { ( } \% \text { del total) }\end{array}$ & $\begin{array}{c}0 \\
(0 \%)\end{array}$ & $\begin{array}{c}4 \\
(2,9 \%)\end{array}$ & \\
\hline $\begin{array}{l}\text { Total de situaciones con repercusión } \\
\text { en el manejo** }\end{array}$ & $\begin{array}{c}2 \\
(1,4 \%)\end{array}$ & $\begin{array}{c}4 \\
(2,9 \%)\end{array}$ & $\begin{array}{l}\text { Odds Ratio }=7,87 \\
(1,25-49,67)^{\star * *} \\
2^{2}=7,095 ; p<0,008\end{array}$ \\
\hline $\begin{array}{l}\text { Suspensiones de la cirugía } \\
\text { (\% por paciente } \pm \text { desv. estándar) }\end{array}$ & $\begin{array}{c}0,78 \\
(\mathrm{DE} \pm 0,92)\end{array}$ & $\begin{array}{c}1,1 \\
(\mathrm{DE} \pm 0,876)\end{array}$ & $\begin{array}{l}\text { p-value }=0,284 \\
\text { (t-student) }\end{array}$ \\
\hline $\begin{array}{l}\text { Número de consultas médicas } \\
\text { (x por paciente } \pm \text { desv. estándar) }\end{array}$ & $\begin{array}{c}4,4 \\
(\mathrm{DE} \pm 1,17)\end{array}$ & $\begin{array}{c}2,53 \\
(\mathrm{DE} \pm 0,97)\end{array}$ & $\begin{array}{l}{ }^{*} p \text {-value }=0,0002 \\
\text { (t-student) }\end{array}$ \\
\hline $\begin{array}{l}\text { Días de hospitalización } \\
\text { (\% por paciente } \pm \text { desv. estándar) }\end{array}$ & $\begin{array}{c}2,5 \\
(\mathrm{DE} \pm 3,37)\end{array}$ & $\begin{array}{c}1,77 \\
(\mathrm{DE} \pm 0,49)\end{array}$ & $\begin{array}{l}{ }^{*} p \text {-value }=0,025 \\
\text { (t-student) }\end{array}$ \\
\hline
\end{tabular}

*Estadísticamente significativo. * ${ }^{\star}$ Para el análisis de Odds Ratio y $\chi^{2}$ se consideraron en conjunto las patologías que requirieron acción médica y las complicaciones como eventos que cambiaron el manejo del paciente y cuyo reconocimiento era el objetivo del examen preoperatorio. ${ }^{* \star \star}$ Valor de Odds Ratio e intervalo con $95 \%$ de confianza.

El costo-oportunidad (definido como los recursos ocupados en una tarea que podrían ser invertidos en otro servicio) de realizar EP de rutina (incluyendo el costo del examen en sí mismo y el aumento en número de consultas y días de hospitalización que se asocia a su interpretación y repeticiones) es de $\$ 28.608,29$ pesos chilenos en promedio por paciente operado. Extrapolado a la totalidad de pacientes ASA I operados anualmente en el Servicio de Otorrinolaringología del Hospital San Juan de Dios (718 pacientes en 2006), el costo-oportunidad anual de los exámenes de rutina alcanza los $\$ 20.540 .748,12$ pesos chilenos, lo que equivale a los costos asociados a realizar 162 amigdalectomías con 0 sin adenoidectomías, con sus días de hospitalización y consultas médicas correspondientes contabilizadas (este número corresponde al $27 \%$ de todas las amigdalectomías realizadas en un año en este centro).

El costo-oportunidad asociado a la realización de nasofaringolaringoscopías (NFL) no pertinen- tes es de $\$ 963$ chilenos por paciente, que extrapolado al total de operados anuales alcanza $\$ 134.880$ chilenos. El costo-oportunidad asociado a la realización de audiometrías e impedanciometrías no pertinentes es de $\$ 12.814$ por paciente, que extrapolado equivale a $\$ 461.320$ anuales.

\section{DISCUSIÓN}

Se suelen solicitar exámenes preoperatorios a todos los pacientes que serán sometidos a cirugía, sin embargo, las razones solamente tienen fundamentos teóricos o legales. En Chile, la Sociedad de Anestesiología sugiere: "La solicitud de exámenes complementarios no debiera ser un acto médico de rutina, sino que éstos debieran solicitarse según los hallazgos de la historia, el examen físico y las características de la cirugía que se va a realizar"14. 
Esta postura también es adoptada por la Academia Americana de Otorrinolaringología y Cirugía de Cabeza y Cuello ${ }^{15}$ y la Agencia Nacional de Acreditación y de Evaluación en Salud en Francia ${ }^{16}$.

En nuestro trabajo los EP de rutina, en pacientes ASA I, tuvieron baja utilidad en cuanto a su impacto en el manejo clínico de los pacientes, se requirió de un elevado número de exámenes al azar para detectar una patología que ameritara cambios en la conducta. Los exámenes que con mayor frecuencia presentaron alteraciones fueron en relación a la hemostasia, sin embargo se ha descrito que los tiempos de coagulación no predicen la presentación de hemorragia perioperatoria ${ }^{14}$. En nuestra serie, los casos en los que se llegó al diagnóstico de enfermedad de von Willebrand, la patología de la hemostasia más frecuente, su determinación sí influyó en el manejo del paciente y determinó una estadía más prolongada y mayores costos, justificados en un mayor riesgo de sangrado, motivo por el cual los costos no se incluyeron en el cálculo de costo-eficiencia.

Este resultado, en particular, estimula a realizar un estudio controlado, con pacientes a los que se realicen exámenes de rutina (grupo control) y a quienes no se les realicen (grupo experimental), comparando la tasa de complicaciones reales que existan entre ambos grupos, y no sólo la necesidad teórica-clínica de realizar una intervención. Experiencias internacionales apoyan dicho análisis, no habiendo encontrado diferencias estadísticas entre estos grupos s., $^{2,7,9,10}$, especialmente si se realiza tamizaje clínico previo con encuestas como la expuesta en el Anexo $1^{16}$. En nuestro contexto nacional, el presente trabajo justifica y motiva la realización de tal estudio.

Tampoco existe un fundamento científico para respaldar la premisa de caducidad de los EP si no ha habido ningún cambio en el estado clínico del paciente. Incluso, se ha mencionado que solamente $0,4 \%$ de los EP repetidos al momento de la cirugía serían anormales ${ }^{18}$. En otros estudios tampoco se ha encontrado que los exámenes preoperatorios cambien significativamente si no ha habido una diferencia en el estado clínico de los pacientes al menos durante cuatro meses ${ }^{19}$.

En nuestra revisión no hubo ningún examen caducado que haya cambiado sus resultados. Esto resulta de alto impacto si consideramos que 22,1\% de los exámenes realizados son por repetición.
Otro aspecto importante se refiere al control de la pertinencia clínica de la realización de exámenes. Casi la mitad de las indicaciones de NFL, audiometrías e impedanciometrías carecían de cualquier propósito razonable, más allá de la indicación avalada por la duda. Es tarea de cada médico el cuestionarse la necesidad de realizar un examen 0 no, considerando el costo acumulativo de ellos. El costo anual asociado a los exámenes de rutina superó en casi 40 veces al mal uso de exámenes otorrinolaringológicos. Así, una medida de mayor impacto sería el transferir el costooportunidad de los exámenes de rutina hacia una prestación de mayor utilidad.

Cabe considerar que el costo-oportunidad calculado, deja de lado el análisis de factores de más difícil objetivación, como es el costo social. En promedio, cada paciente pierde 2,49 días laborales debido a la realización de exámenes de rutina (sea por consulta médica o día de hospitalización). Al extrapolarlo a la población operada anualmente, alcanza a la pérdida de 1.785 días laborales anuales (un año de trabajo para 7,4 personas) sólo por motivo de exámenes de rutina para cirugía otorrinolaringológica en el Hospital San Juan de Dios.

Queremos constatar algunos sesgos en este estudio, la mayoría secundarios a su diseño retrospectivo, se debió excluir a 20 de los pacientes elegibles por falta de registros completos (12,5\%), y no se pudo calcular la incidencia real de eventos. Además no se contó con información sobre pacientes en los que se decidió no realizar la cirugía en forma permanente, y el impacto de exámenes preoperatorios en dicha decisión. Lo anterior invita a realizar un nuevo estudio prospectivo del tema.

En síntesis, realizar EP rutinarios en pacientes clínicamente sanos es una práctica cuestionable. Diferentes estudios evalúan la utilidad de cuestionarios estandarizados basados en datos clínicos relevantes, los cuales han eliminado la necesidad de EP de rutina. Ésta parece ser una política más racional que la tradicional, en la cual se solicitan EP independientemente del estado de salud del paciente.

La limitación de los EP puede significar un ahorro sustancial para las instituciones de salud. Salvo, los 2 casos detectados de enfermedad de von Willebrand, las anormalidades en los exámenes preoperatorios no se asociaron a incremento en la frecuencia de complicaciones perioperatorias 
o en el tiempo de estadía hospitalaria. El análisis de costo-efectividad mostró que los exámenes preoperatorios en pacientes adultos jóvenes clínicamente sanos es una práctica costosa y poco eficiente.

\section{BIBLIOGRAFÍA}

1. Smetana GW, Macpherson DS. The case against routine preoperative laboratory testing. Med Clin N Am 2003; 87: 7-40.

2. FISCHER SP. Cost-effective preoperative evaluation and testing. Chest 1999; 115: 96-100.

3. Morales C, Mata M, Cárdenas LE. Costo-beneficio de los exámenes preoperatorios de rutina en cirugía electiva. Cir Ciruj 2005; 73: 25-30.

4. RoIzen MF. Cost-effective preoperative laboratory testing. JAMA 1994; 271: 319-20.

5. Narr BJ, Warner ME, Schroeder SR, Warner MA. Outcomes of patients with no laboratory assessment before anesthesia and a surgical procedure. Mayo Clin Proc 1997; 72: 505-9.

6. Narr BJ, Hansen TR, Warner MA. Preoperative laboratory screening in healthy Mayo patients: cost-effective elimination of tests and unchanged outcomes. Mayo Clin Proc 1991; 66: 155-9.

7. Gathe-Ghermay JC, LIU LL. Preoperative programs in anesthesiology. Anesthiol Clin N Am 1999; 17: 335-53.

8. Van Klel WA, Moons KGM, Rutten Clg, Schuurhuis A, Knape JTA, Kalkman C, Grobbee D. The effect of outpatient preoperative evaluation of hospital in patients on cancellation of surgery and length of hospital stay. Anesth Analg 2002; 94: 644-9.

9. Roizen MF, Coalson D, Hayward RS, Schmittiner J, Thisted RA, Apfellbaum Jl, Stocking CV, Cassel CK, Pompel P, Ford DE, Steinberg EP. Can patients use an automated questionnaire to define their current health status? Med Care 1992; 30: MS74-84.

10. Tremper KK. Paper "Preoperative computer". Anesthesiology 2000; 92: 1212.
11. Roizen MF, Kaplan EB, Sheiner LB, et al. Elimination of unnecessary laboratory tests by preoperative questionnaire [abstract]. Anesthesiology 1984; 61: A455.

12. Fondo Nacional de Salud. Arancel Modalidad Atención Institucional. Disponible en www.fonasa.cl [Consultado el 20 de marzo de 2009].

13. Breinbauer $H$, Castillo $C$, Arancibia M. Análisis epidemiológico en 12 años de cirugía otorrinolaringológica en el hospital San Juan de Dios. Presentado en el LXV Congreso Chileno de Otorrinolaringología y Cirugía de Cabeza y CueIlo, 2 al 6 de diciembre 2008, Pucón, Chile.

14. Sociedad de Anestesiología de Chile. Recomendaciones en la evaluación preoperatoria pediátrica. Disponible en: http:// www.sachile.cl/medicos/recomendaciones/ pre_anestesica/evaluacion_nino.php [Consultado el 20 de marzo de 2009].

15. Asaf T, Reuveni H, Yermiahu T et al. The need for routine pre-operative coagulation screening tests (prothrombin time PT/partial thromboplastin time PTT) for healthy children undergoing elective tonsillectomy and/or adenoidectomy. Int $\mathrm{J}$ Ped Otorhinolaryngol 2001; 61: 217-22.

16. Agence Nationale d'Accreditation et d'Évaluation en Santé, Service des recommandations et références professionnelles. Les examens préopératoires systématiques. Paris, Diciembre 1998.

17. DeRkay CS. A Cost-effective Approach for Preoperative Hemostatic Assessment in Children Undergoing Adenotonsillectomy. Arch Otolaryngol Head Neck Surg 2000; 126: 688.

18. Macpherson DS, Snow R, Lofgren RP. Preoperative screening: value of previous tests. Ann Intern Med 1990; 113: 969-73.

19. Shah SA, Sajid SA, Asif M, et al. Significance and cost effectiveness of pre-operative routine laboratory investigations in young healthy patients undergoing elective ear, Nose \& throat Surgery. J Ayub Med Coll Abbottabad 2007; 19(2): 3-6. 


\title{
Utilidad clínica de los tests de Rinne y Weber en el diagnóstico de hipoacusia
}

\section{Clinical usefulness of Rinne and Weber tests for diagnosing hearing loss}

\author{
Pedro Badía V1, Claudio Callejas C¹, Claudia González G', Pilar Gajardo 0², José Luis Anabalón B², \\ Claudio Correa $\mathrm{G}^{3}$.
}

\begin{abstract}
RESUMEN
Introducción: Los tests de Rinne y Weber son considerados una herramienta diagnóstica importante. Frente a esto nos preguntamos ¿cuál es la sensibilidad, especificidad y utilidad de los tests de Rinne y Weber?

Objetivos: 1. Estudiar la sensibilidad y especificidad de los test de Rinne y Weber en el diagnóstico de hipoacusia. 2. Comparar la sensibilidad y especificidad de dichos tests realizados por un operador habitual y un operador ocasional.

Material y método: Estudio transversal y ciego. Se incluyeron pacientes mayores de 4 años de edad con indicación de audiometría por sospecha de hipoacusia. Todos los pacientes se estudiaron con tests de Rinne y Weber y se compararon con audiometría de tonos puros.

Resultados: Se estudiaron 85 pacientes. La sensibilidad del uso combinado de los tests de Rinne y Weber, por operador ocasional, fue 76,32\% y la especificidad 88,37\%. La sensibilidad del uso combinado de los tests de Rinne y Weber por operador habitual fue $75,76 \%$ y la especificidad $79,31 \%$. En comparación al operador habitual no se observó diferencias estadísticamente significativas.

Conclusión: Los tests de Rinne y Weber representan una herramienta útil en el diagnóstico de hipoacusia.
\end{abstract}

Palabras clave: Diapasón, Rinne, Weber, audiometría, sensibilidad, especificidad.

\begin{abstract}
Introduction: Rinne and Weber tests are considered an important diagnosis tool. The question arises as to what are the tests sensitivity, specificity and usefulness.

Aim: 1. To study the sensitivity and specificity of Rinne and Weber tests in diagnosing hearing loss. 2. To compare the sensitivity and specificity of the above mentioned tests when performed by an experienced vs an occasional practitioner.

Material and method: 85 patients were studied. Rinne and Weber test combined sensibility, performed by an occasional practitioner, was $76,32 \%$, and the specificity was $79,31 \%$. There were no statistically significant differences between experienced and occasional practitioners.

Conclusion: Rinne and Weber test represent useful tools for hearing loss diagnosis.

Key words: Tuning fork, Rinne, Weber, audiometry, sensitivity, specificity.

\footnotetext{
Otorrinolaringólogo, Departamento Otorrinolaringología, Facultad de Medicina, Pontificia Universidad Católica de Chile.

Médico Cirujano, Alumno Magister Inmunología, Universidad de Chile.

Tecnólogo Médico, Departamento Otorrinolaringología, Facultad de Medicina, Pontificia Universidad Católica de Chile.
} 


\section{INTRODUCCIÓN}

Los otorrinolaringólogos estamos familiarizados con el uso de los diapasones en el estudio de la hipoacusia. A continuación revisaremos los orígenes de estos tests.

La historia de estos tests comienza con J. B. Venturi, físico, quien en 1802, en Módena, Italia, habría demostrado que la percepción de la dirección desde la cual el sonido se aproxima, se debe al hecho que un oído es estimulado por el sonido más intensamente que el otro. Luego en 1827, C. T. Tourtual, médico, en Munster, Alemania, demostró que esto también era aplicable para el sonido conducido a través de los huesos del cráneo; utilizando un reloj como fuente de sonido, encontró que la oclusión de ambos conductos auditivos externos (CAEs) aumentaba la sensación sonora en ambos oídos por igual, pero la oclusión de un solo CAE aumentaba la sensación sonora sólo en el oído ocluido, dando la impresión que el sonido provenía de ese lado. En el mismo año, C. Wheatstone, físico londinense, mientras investigaba el modo de vibración de la membrana timpánica, utilizando un diapasón, observó el mismo fenómeno descrito por Tourtual. Finalmente, en 1834, en Leipzig, Alemania, Ernst Heinrich Weber, anatomista y fisiólogo, describió una vez más el fenómeno descrito por Tourtual y Wheatstone. El quería demostrar que el sonido conducido por vía aérea es percibido por el vestíbulo y los canales semicirculares, mientras que el sonido conducido por vía ósea es percibido por la cóclea. Ninguno de estos investigadores estaba pensando en un uso clínico de sus hallazgos, y no hicieron ningún comentario al respecto. Sino que fue E. Schalmz, un otólogo, en Dresden, Alemania, que introdujo a la otología los diapasones y este test llamado posteriormente Weber ${ }^{1}$.

En 1855, A. Rinne², médico, en Gottingen, Alemania, describió el test que más tarde llevaría su nombre, como un método para comparar la conducción aérea y ósea del sonido, en un elaborado tratado que describía la fisiología de la cóclea. Él quería demostrar que en los humanos y animales terrestres, a diferencia de los que viven en el agua, la conducción del sonido a través de los huesos del cráneo era sólo un efecto colateral, inevitable, de la percepción del sonido. El mencionó una aplicación clínica de su test sólo en una nota a pie de página y nunca lo utilizó de manera sistemática en la clínica. Sin embargo algunos años antes, en 1842, Polansky habría descrito el test y su uso práctico, pero su descripción aparentemente pasó al olvido. Tuvieron que pasar más de 25 años para que Lucae en $1880^{3}$ y Schwabach ${ }^{4}$ en 1885 confirmaran la utilidad del test y se comenzará a difundir su uso $0^{5}$.

Estos tests han sido considerados, por algunos, una herramienta diagnóstica fundamental en el estudio de la hipoacusia, dada su simpleza, rapidez y bajo costo. Sin embargo con el advenimiento de tests diagnósticos más sofisticados y modernos en la audiología, han ido perdiendo su lugar, y el clínico los ha abandonado en su práctica clínica diaria.

En virtud de lo anterior nos preguntamos: ¿cuál es la sensibilidad y especificidad de los tests de Rinne y Weber? y ¿cuál es su utilidad en nuestra aproximación inicial frente a un paciente que consulta por hipoacusia?

\section{HIPÓTESIS}

El uso de los tests de Rinne y Weber en el estudio de la hipoacusia, es una herramienta útil en el diagnóstico de la hipoacusia y no requiere gran entrenamiento por parte del operador que los realiza.

\section{OBJETIVOS}

1. Estudiar la sensibilidad y especificidad de los tests de Rinne y Weber en el diagnóstico de hipoacusia.

2. Comparar la sensibilidad y especificidad de dichos tests, realizados por un operador habitual y un operador ocasional.

\section{MATERIAL Y MÉTODO}

\section{Diseño}

Se diseñó un estudio transversal, ciego.

\section{Sujetos}

Se incluyeron pacientes adultos y niños mayores de 4 años de edad, con indicación de audiometría 
por sospecha de hipoacusia, que consultaron en el Centro ambulatorio de Otorrinolaringología de la Pontificia Universidad Católica de Chile, en el período de marzo a mayo de 2006.

\section{Examinadores}

Como operadores ocasionales, fueron definidos 3 otorrinolaringólogos de 5 , 3 y 2 años de experiencia. Como operadores habituales fueron definidos 2 tecnólogos médicos audiólogos de 10 y 20 años de experiencia.

\section{Intervención}

A todos los pacientes se les realizaron tests de Rinne y Weber, con diapasón de $512 \mathrm{~Hz}$ por un operador ocasional y un operador habitual, sucesivamente. Ambos examinadores desconocían la sospecha diagnóstica y el resultado de los tests realizados por el otro examinador. Luego todos los pacientes fueron sometidos a una audiometría de tonos puros, realizada por el tecnólogo médico.

\section{Análisis}

Los datos obtenidos fueron tabulados y analizados con ExcelMR de Microsoft" ${ }^{\mathrm{MR}}$. Se estudió la sensibilidad, especificidad, valor predictivo positivo (VPP), valor predictivo negativo (VPN), cuociente de probabilidad positivo $(\mathrm{LR}+)$ y cuociente de probabilidad negativo (LR-); de cada test y del uso combinado de éstos, con respecto a la audiometría de tonos puros, para cada operador por separado. Luego se compararon dichos parámetros entre cada operador, mediante el método de distribución muestral de diferencia de proporciones.

\section{Test de Rinne}

El test de Rinne fue estudiado por oído. Su resultado se analizó con respecto a la presencia 0 ausencia de hipoacusia de conducción (diferencia ósea/ aérea $\geq 10 \mathrm{~dB}$ ) en la audiometría de tonos puros.

\section{Test de Weber}

El test de Weber fue estudiado por sujeto. Su resultado se analizó con respecto a la presencia o ausencia de hipoacusia asimétrica (diferencia entre ambos oídos $\geq 10 \mathrm{~dB}$ ) en la audiometría de tonos puros.

\section{Uso combinado de tests de Rinne y Weber}

El uso combinado de estos tests fue estudiado por sujeto. Su resultado se analizó con respecto a la presencia 0 ausencia de hipoacusia de conducción, hipoacusia mixta 0 hipoacusia sensorioneural asimétrica en la audiometría de tonos puros, lo cual fue definido como audiometría anormal.

\section{RESULTADOS}

Fueron incluidos en el estudio 85 pacientes, cuya edad promedio fue 46,5 años; su desviación estándar (DS) $\pm 21,6$ años y su rango 5 a 87 años. Su distribución por géneros fue $56 \%$ femenino y $44 \%$ masculino. El grupo femenino tuvo una edad promedio de 47,9 años $\pm 21,0 \mathrm{DS}$. El grupo masculino tuvo una edad promedio de 44,7 años $\pm 22,8$ DS.

\section{Test de Rinne por operador habitual}

En el grupo de estudio, la prevalencia de hipoacusia de conducción (HC) fue 17,8\%. La sensibilidad del test de Rinne para identificar una HC correspondió a 58,62\%. La especificidad fue $99,25 \%$. El VPP correspondió a $94,44 \%$. EI VPN correspondió a $91,72 \%$. El LR+ fue 78,55 y el LRfue 0,42 (Tabla 1).

\section{Test de Rinne por operador ocasional}

En el grupo de estudio la prevalencia de $\mathrm{HC}$ fue $19,4 \%$. La sensibilidad del test de Rinne para identificar una $\mathrm{HC}$ correspondió a 48\%. La especificidad fue $96,15 \%$. El VPP correspondió a $75 \%$. El VPN correspondió a $88,5 \%$. El LR+ fue 12,48 y el LR- fue 0,54 (Tabla 1). Al comparar estos resultados con los obtenidos por el operador habitual no se observó diferencias estadísticamente significativas.

\section{Test de Weber por operador habitual}

En el grupo de estudio la prevalencia de hipoacusia asimétrica (HA) fue $41,5 \%$. La sensibilidad del test de Weber para identificar una HA correspondió a 
Tabla 1.

\begin{tabular}{|c|c|c|}
\hline $\begin{array}{l}\text { PERADOR } \\
\text { Por Oidos }\end{array}$ & Audiom & \\
\hline RINNE & Con Gap óseo/aéreo & Sin Gap óseo/aéreo \\
\hline Negativo & 17 & 1 \\
\hline Positivo & 12 & 133 \\
\hline & SENSIBILIDAD & ESPECIFICIDAD \\
\hline & $58,62 \%$ & $99,25 \%$ \\
\hline & $40,7 \%$ a $74,5 \%$ (IC $95 \%)$ & $95,9 \%$ a $99,9 \%$ (IC $95 \%)$ \\
\hline
\end{tabular}

\begin{tabular}{|c|c|c|}
\hline \multirow{2}{*}{$\begin{array}{c}\text { PPERADOR } \\
\text { Por Oidos } \\
\text { RINNE }\end{array}$} & \multicolumn{2}{|c|}{ Audiometria } \\
\hline & Con Gap óseo/aéreo & Sin Gap óseo/aéreo \\
\hline Negativo & 12 & 4 \\
\hline Positivo & 13 & 100 \\
\hline & SENSIBILIDAD & ESPECIFICIDAD \\
\hline & $48,00 \%$ & $96,15 \%$ \\
\hline & $30,0 \%$ a $66,5 \%$ (IC $95 \%)$ & $90,5 \%$ a $98.5 \%$ (IC $95 \%)$ \\
\hline
\end{tabular}

\begin{tabular}{|c|c|c|}
\cline { 3 - 3 } \multicolumn{2}{c|}{} & IC $95 \%$ \\
\hline VPP & $\mathbf{9 4 , 4 4 \%}$ & $74,2 \%$ a $99,0 \%$ \\
\hline VPN & $\mathbf{9 1 , 7 2} \%$ & $86,1 \%$ a $95,2 \%$ \\
\hline LR (+) & $\mathbf{7 8 , 5 5}$ & 10,88 a 566,93 \\
\hline LR (-) & $\mathbf{0 , 4 2}$ & 0,27 a 0,64 \\
\hline
\end{tabular}

\begin{tabular}{|c|c|c|}
\cline { 3 - 3 } \multicolumn{2}{c|}{} & IC $95 \%$ \\
\hline VPP & $\mathbf{7 5 , 0 0} \%$ & $50,5 \%$ a $89,8 \%$ \\
\hline VPN & $\mathbf{8 8 , 5 0} \%$ & $\mathbf{8 1 , 3 \%}$ a $93,2 \%$ \\
\hline LR (+) & $\mathbf{1 2 , 4 8}$ & 4,39 a 35,45 \\
\hline LR (-) & $\mathbf{0 , 5 4}$ & 0,37 a 0,80 \\
\hline
\end{tabular}

Tabla 2.

\begin{tabular}{|c|c|c|}
\hline & \multicolumn{2}{|c|}{ Audiometria } \\
\hline WEBER & Asimétrica & Simétrica \\
\hline Lateraliza & 27 & 7 \\
\hline No lateraliza & 7 & 41 \\
\hline & SENSIBILIDAD & ESPECIFICIDAD \\
\hline & $79,41 \%$ & $85,42 \%$ \\
\hline & $63.2 \%$ a $89,7 \%$ (IC $95 \%)$ & $72,8 \%$ a $92,8 \%$ (IC $95 \%)$ \\
\hline
\end{tabular}

\begin{tabular}{|c|c|c|}
\cline { 3 - 3 } \multicolumn{2}{c|}{} & IC $95 \%$ \\
\hline VPP & $\mathbf{7 9 , 4 1 \%}$ & $63,2 \%$ a $89,7 \%$ \\
\hline VPN & $\mathbf{8 5 , 4 2 \%}$ & $72,8 \%$ a $92,8 \%$ \\
\hline LR (+) & $\mathbf{5 , 4 5}$ & 2,69 a 11,03 \\
\hline LR (-) & $\mathbf{0 , 2 4}$ & 0,12 a 0,47 \\
\hline
\end{tabular}

$79,41 \%$. La especificidad fue $85,42 \%$. El VPP correspondió a $79,41 \%$. El VPN correspondió a $85,42 \%$. El LR+ fue 5,45 y el LR- fue 0,24 (Tabla 2).

\section{Test de Weber por operador ocasional}

En el grupo de estudio la prevalencia de HA fue $43,3 \%$. La sensibilidad del test de Weber para identificar una HA correspondió a $65,38 \%$. La especificidad fue $76,47 \%$. EI VPP correspondió a $68 \%$. EI VPN correspondió a 74,29\%. El LR+ fue 2,78 y el LR- fue 0,45 (Tabla 2). Al comparar estos resultados con los obtenidos por el operador habitual no se observó diferencias estadísticamente significativas.

\section{Uso combinado de tests de Rinne y Weber por operador habitual}

En el grupo de estudio la prevalencia de audiometría anormal (AA) fue 46,9\%. La sensibilidad

\begin{tabular}{|c|c|c|}
\hline & \multicolumn{2}{|c|}{ Audiometria } \\
\hline WEBER & Asimétrica & Simétrica \\
\hline Lateraliza & 17 & 8 \\
\hline No lateraliza & 9 & 26 \\
\hline & SENSIBILIDAD & ESPECIFICIDAD \\
\hline & $65,38 \%$ & $76,47 \%$ \\
\hline & $46.2 \%$ a $80,6 \%$ (IC $95 \%)$ & $60.0 \%$ a $87.6 \%$ (IC 95\%) \\
\hline
\end{tabular}

\begin{tabular}{|c|c|c|}
\cline { 3 - 3 } \multicolumn{2}{c|}{} & IC $95 \%$ \\
\hline VPP & $\mathbf{6 8 , 0 0 \%}$ & $48,4 \%$ a $82,8 \%$ \\
\hline VPN & $\mathbf{7 4 , 2 9 \%}$ & $57,9 \%$ a $85,8 \%$ \\
\hline LR (+) & $\mathbf{2 , 7 8}$ & 1,43 a 5,42 \\
\hline LR (-) & $\mathbf{0 , 4 5}$ & 0,26 a 0,80 \\
\hline
\end{tabular}

del uso combinado de los tests de Rinne y Weber para identificar una AA correspondió a $76,32 \%$. La especificidad fue $88,37 \%$. EI VPP correspondió a $85,29 \%$. EI VPN correspondió a $80,85 \%$. El LR+ fue 6,56 y el LR-fue 0,27 (Tabla 3).

\section{Uso combinado de tests de Rinne y Weber por operador ocasional}

En el grupo de estudio la prevalencia de AA fue $53,2 \%$. La sensibilidad del uso combinado de los tests de Rinne y Weber para identificar una $A A$ correspondió a $75,76 \%$. La especificidad fue $79,31 \%$. El VPP correspondió a $80,65 \%$. El VPN correspondió a $74,19 \%$. El LR+ fue 3,66 y el LRfue 0,31 (Tabla 3). Al comparar estos resultados con los obtenidos por el operador habitual no se observó diferencias estadísticamente significativas. 
Tabla 3.

\begin{tabular}{|c|c|c|}
\hline \multirow{2}{*}{ DIAPASONES } & \multicolumn{2}{|c|}{ Audiometria } \\
\hline & Anormal & Normal o HSN simétrica \\
\hline Alterado & 29 & 5 \\
\hline Normal & 9 & 38 \\
\hline & SENSIBILIDAD & ESPECIFICIDAD \\
\hline & $76,32 \%$ & $88,37 \%$ \\
\hline & $60,8 \%$ a $87,0 \%$ (IC $95 \%)$ & $75,5 \%$ a $94,9 \%$ (IC 95\%) \\
\hline
\end{tabular}

\begin{tabular}{|c|c|c|}
\cline { 3 - 3 } \multicolumn{2}{c|}{} & IC $95 \%$ \\
\hline VPP & $\mathbf{8 5 , 2 9} \%$ & $69,9 \%$ a $93,6 \%$ \\
\hline VPN & $\mathbf{8 0 , 8 5 \%}$ & $67,5 \%$ a $89,6 \%$ \\
\hline LR (+) & $\mathbf{6 , 5 6}$ & 2,83 a 15,25 \\
\hline LR (-) & $\mathbf{0 , 2 7}$ & 0,15 a 0,48 \\
\hline
\end{tabular}

\section{DISCUSIÓN}

El test de Rinne demostró un excelente rendimiento como prueba diagnóstica en cuanto a su especificidad $(99,25 \%)$ y a su $L R+(78,55)$, realizado por un operador habitual. Esto significa que $99 \%$ de los pacientes sin $\mathrm{HC}$ tiene Rinne positivo en el oído afectado, y que un Rinne negativo aumenta 78 veces la probabilidad que el paciente tenga HC. Por lo tanto un resultado alterado hace que el diagnóstico sea muy probable y constituye un excelente test para confirmar la sospecha diagnóstica, desde el punto de vista clínico.

El test de Weber demostró un buen rendimiento como prueba diagnóstica en cuanto a su especificidad $(85,42 \%)$ y a su $L R+(5,45)$, realizado por un operador habitual. Esto significa que $85 \%$ de los pacientes con audiometría simétrica no presenta lateralización del Weber, y que una lateralización del Weber aumenta 5 veces la probabilidad que el paciente tenga una audiometría asimétrica. Por lo tanto un resultado alterado hace que el diagnóstico sea muy probable y constituye un buen test para confirmar la sospecha diagnóstica, desde el punto de vista clínico.

El uso combinado de los tests de Rinne y Weber demostró un buen rendimiento en cuanto a su especificidad $(88,37 \%)$ y a su $\operatorname{LR}+(6,56)$, realizado por un operador habitual. Esto significa que el $88 \%$ de los pacientes con audiometría normal o HSN simétrica no presenta test combinado alterado, y que un test combinado alterado aumenta 6 veces la probabilidad que el paciente tenga una audiometría anormal. Por lo tanto un

\begin{tabular}{|c|c|c|}
\hline \multirow{2}{*}{ DIAPASONES } & \multicolumn{2}{|c|}{ Audiometría } \\
\hline & Anormal & Normal o HSN simétrica \\
\hline Alterado & 25 & 6 \\
\hline \multirow[t]{4}{*}{ Normal } & 8 & 23 \\
\hline & SENSIBILIDAD & ESPECIFICIDAD \\
\hline & $\mathbf{7 5 , 7 6 \%}$ & $79,31 \%$ \\
\hline & $59,0 \%$ a $87,2 \%$ (IC $95 \%)$ & $61,6 \%$ a $90,2 \%$ (IC $95 \%)$ \\
\hline
\end{tabular}

\begin{tabular}{|c|c|c|}
\cline { 3 - 3 } \multicolumn{2}{c|}{} & IC $95 \%$ \\
\hline VPP & $\mathbf{8 0 , 6 5 \%}$ & $63,7 \%$ a $90,8 \%$ \\
\hline VPN & $\mathbf{7 4 , 1 9 \%}$ & $56,8 \%$ a $86,3 \%$ \\
\hline LR (+) & $\mathbf{3 , 6 6}$ & 1,75 a 7,66 \\
\hline LR (-) & $\mathbf{0 , 3 1}$ & 0,16 a 0,57 \\
\hline
\end{tabular}

resultado alterado hace que el diagnóstico sea muy probable y constituye un buen test para confirmar la sospecha diagnóstica, desde el punto de vista clínico.

Los tests de Rinne y Weber individual y combinadamente demostraron un rendimiento regular a moderado en cuanto a su sensibilidad ( $58 \%$ a $79 \%)$ y LR- $(0,2$ a 0,4$)$, realizados por un operador habitual. Por lo tanto un resultado normal no nos permite descartar, con seguridad, la sospecha diagnóstica, lo que implica que no sean recomendables como test de screening.

Los tests de Rinne y Weber individual y combinadamente mostraron un mejor rendimiento cuando fueron realizados por el operador habitual, en comparación al operador ocasional. Sin embargo estas diferencias no fueron estadísticamente significativas.

En la literatura se describe para estos tests una sensibilidad entre $76 \%$ y $84 \%$ \%,5,-11 y una especificidad de $85 \% 5,6$, lo cual es similar a los resultados obtenidos en nuestro estudio.

Creemos importante destacar que tanto en nuestro estudio como en publicaciones anteriores se encontró un mejor rendimiento del test de Rinne cuando es realizado por operadores experimenta$\mathrm{dos}^{5}$, si bien este hallazgo no fue estadísticamente significativo en nuestro estudio. Junto con la experiencia del operador, Burkey describe que el usar enmascaramiento durante el test de Rinne y el considerar como negativos los resultados dudosos, aumentaría la sensibilidad del examen.

Nuestros resultados permiten sospechar que el otorrinolaringólogo general ha reducido el uso de 
estos importantes tests en su práctica clínica diaria. Considerando el buen rendimiento de éstos en cuanto a especificidad y $L R(+)$ creemos que el otorrinolaringólogo debiera incluirlos en la evaluación de un paciente que consulta por hipoacusia.

\section{CONCLUSIÓN}

Nuestros resultados confirman parcialmente nuestra hipótesis ya que los tests de Rinne y Weber representan una herramienta útil en el diagnóstico de la hipoacusia tomando en cuenta su especificidad y LR+, sin embargo, a la luz de nuestros resultados, creemos que es necesario el entrenamiento y uso habitual de estos tests para mejorar su rendimiento.

Los tests de Rinne y Weber, realizados e interpretados de manera correcta, junto con la clínica del paciente, pueden no sólo minimizar los errores de otros tests audiológicos sino que además nos entregan una visión global del estado auditivo de nuestro paciente en la consulta (previo a la audiometría), lo cual ningún otro test puede realizar.

\section{BIBLIOGRAFÍA}

1. Feldman $H$. History of the tuning fork. III: On the way to quantitative pure-tone measurement. Pictures from the history of otorhinolaryngology, represented by instruments from the collection of the Ingolstadt German Medical History Museum. Laryngorhinootologie 1997; 76(7): 428-34.

2. RINNE A. Beiträge zur Physiologie des menschlichen Ohres. Vierteljahrschrift für praktische Heilkunde, herausgegeben von der medicinischen Facultät in Prag. 12.Jg. 1. Bd. 1855; 71-123, 2 Bd, 45-72: 155-6.

3. LuCAE $A$. Die bei Schwerhörigen zu beobachtende gute Perception der tiefen musikalischen Töne und die physiologische und diagnostiche Bedeutung dieser Erscheinung; nebst Section zweier bei Lebzeiten beobachteten Fälle. Arch Ohrenheilk 15. 1880; 273-85.

4. Schwabach D. Ueber den Werth des Rinne'schen Versuches für die Diagnostik der Gehörkrankheiten. Z. Ohrenheilk 14. 1885; 61148.

5. HuIzING EH. The early descriptions of the socalled tuning-fork tests of Weber, Rinne, Schwabach, and Bing. III. The development of the Schwabach and Bing tests. ORL J Otorhinolaryngol Relat Spec 1975; 37(2): 92-6.

6. BuRkey JM, LipPy WH, Schuring AG, Rizer FM. Clinical utility of the $512-\mathrm{Hz}$ Rinne tuning fork test. Am J Otol 1998; 19(1): 59-62.

7. Browning GG, Swan IR, Chew KK. Clinical role of informal tests of hearing. J Laryngol Otol 1989; 103(1): 7-11.

8. Chole RA, Cook GB. The Rinne test for conductive deafness. A critical reappraisal. Arch Otolaryngol Head Neck Surg 1988; 114(4): 399-403.

9. VikRam KB, Naseeruddin K. Combined tuning fork tests in hearing loss: explorative clinical study of the patterns. J Otolaryngol 2004; 33(4): 22734.

10. MiltenbuRg DM. The validity of tuning fork tests in diagnosing hearing loss. J Otolaryngol 1994; 23(4): 254-9.

11. Browning GG, Swan IR. Sensitivity and specificity of Rinne tuning fork test. BMJ 1988; 297(6660): 1381-2. 


\title{
Hemangioma cavernoso gigante de seno maxilar. Reporte de un caso y revisión de la literatura
}

\section{Giant cavernous hemangioma of the maxillary sinus. Case report and literature review}

Alfredo Naser $\mathrm{G}^{1}$, Arturo Samith $\mathrm{M}^{1}$, Carlos Ríos $\mathrm{D}^{2}$.

\begin{abstract}
RESUMEN
Los hemangiomas son neoplasias vasculares benignas que se presentan de preferencia en la región cervicofacial, siendo raros en las fosas nasales y excepcionales en los senos paranasales, con pocos casos reportados. Se presenta un paciente de sexo masculino y 33 años de edad, que consultó por obstrucción nasal, aumento de volumen maxilar y exoftalmo izquierdo de 2 años de evolución. La tomografía computada con contraste mostraba una masa hipodensa con realce anular del contraste en maxilar izquierdo, con extensión a la cavidad nasal, con destrucción del piso de la órbita y la pared anterior del seno maxilar. Se tomó biopsia que se informó como hemangioma cavernoso, por lo que fue manejado con embolización y escleroterapia arterial supraselectiva previa a la resección. Se realizó una maxilectomía subtotal por abordaje de Weber-Ferguson, sin recidiva al seguimiento a 15 meses. Además se comparan los hallazgos y el manejo de nuestro paciente con revisiones extranjeras.
\end{abstract}

Palabras clave: Hemangioma cavernoso, tumor vascular, tumor de seno maxilar.

\begin{abstract}
Hemangiomas are benign vascular neoplasms that occur preferentially in the head and neck, being uncommon in the nasal cavities and exceptionally rare in the paranasal sinuses, with very few cases reported. We present the case of a 33 year old male, that consulted for nasal obstruction, maxillary enlargement and left exophthalmos of 2 years of evolution. Contrast enhanced computed tomography showed a hypodense mass with a ring enhanced lesion in the left maxilla, extending to the nasal cavity, with orbital floor and anterior wall of the maxillary sinus destruction. A biopsy sample was informed as cavernous hemangioma. Accordingly, it was treated by supraselective arterial embolization and sclerotherapy previous to surgical resection. A subtotal maxillectomy was performed following the Weber-Ferguson approach, with no recidives after a 15 month follow-up. In addition, we compare our findings and patient management with those reviewed in the literature.
\end{abstract}

Key words: Cavernous hemangioma, vascular tumor, maxillary sinus tumor.

Médico Otorrinolaringólogo, Servicio de Otorrinolaringología, Hospital Clínico de la Universidad de Chile.

2 Médico Cirujano, Universidad de Chile. 


\section{INTRODUCCIÓN}

Los hemangiomas son neoplasias vasculares benignas, se presentan con más frecuencia en la infancia y pueden presentarse en cualquier parte del cuerpo. En 1982, Mulliken y Glowacki propusieron una clasificación de lesiones vasculares, distinguiendo tumores vasculares de malformaciones vasculares basados en la apariencia clínica, características histopatológicas y comportamiento biológico. Los hemangiomas fueron identificados como tumores vasculares que experimentan una fase de crecimiento activo caracterizado por proliferación endotelial e hipercelularidad seguido por una fase de involución gradual que ocurre tras varios años. En contraste, las malformaciones vasculares fueron descritas como congénitas derivadas de la vasculatura de los capilares, venas, linfáticos, arterias o una combinación de éstos ${ }^{1}$. En 1996 esta clasificación fue modificada en el consenso de la sociedad internacional para el estudio de anomalías vasculares; expandiendo la categoría de tumores vasculares para incluir a los hemangioendoteliomas kaposiformes, angiomas en penacho, granulomas piógenos y hemangiopericitomas; que fueron clasificados como hemangiomas, pero demostraron tener distintas características clínicas e histopatológicas: siendo actualmente este sistema la clasificación estándar usada en el campo de anomalías vasculares². Además, Batsakis los clasificó histológicamente de acuerdo al tipo de vasculatura involucrada en la lesión; dependiendo del tamaño de los vasos que predominan en el tumor y los describió como: 1) capilares, que son frecuentemente vistos en la niñez y tienden a involucionar espontáneamente; 2) cavernosos, son frecuentes en adultos y no desarrollan involución espontánea; y 3) mixtos ${ }^{3}$. A la fecha, la patogénesis del hemangioma es poco conocida.

La región cervicofacial es un sitio común para la formación de hemangiomas en adultos siendo los labios, mejillas, frente y cuello los lugares más frecuentemente afectados ${ }^{4}$; cuando se presentan en la cavidad nasal, $85 \%$ es en el tabique nasal anterior y $15 \%$ en la pared lateral ${ }^{5}$; el tipo histológico predominante es capilar ${ }^{6,7}$. Son excepcionales en senos paranasales con pocos casos reportados a nivel mundial siendo la mayoría de tipo caverno- $\mathrm{so}^{8-12}$. Es por ello que presentamos este caso clínico, donde analizamos su manejo y realizamos una revisión de la literatura.

\section{CASO CLÍNICO}

Paciente de sexo masculino de 33 años de edad, sin antecedentes de importancia, que consulta por cuadro de 2 años de evolución, caracterizado por obstrucción nasal persistente, bilateral de predominio izquierdo, e infecciones sinusales recurrentes que cedían sólo parcialmente a tratamientos antibióticos adecuados. Al momento de consultar también presentaba algia facial izquierda, epifora, proptosis ipsilateral con movilidad ocular conservada, y aumento de volumen malar izquierdo de 2 meses de evolución. En la rinoscopía anterior de fosa nasal izquierda se observó desplazamiento hacia medial de la pared del seno maxilar con mucosa conservada. Se solicitó tomografía computada (TC) con contraste de cavidades perinasales, donde se visualizó lesión voluminosa que parecía originarse en la pared posterior del seno maxilar, con densidad de partes blandas (Figura 1), con realce anular del medio de contraste (Figuras 2a y 2b), y que protruye hacia la cavidad nasal, con desviación de la línea media y destrucción ósea (Figura 3).

Con la clínica y los hallazgos radiológicos descritos, se plantea el diagnóstico de tumor de

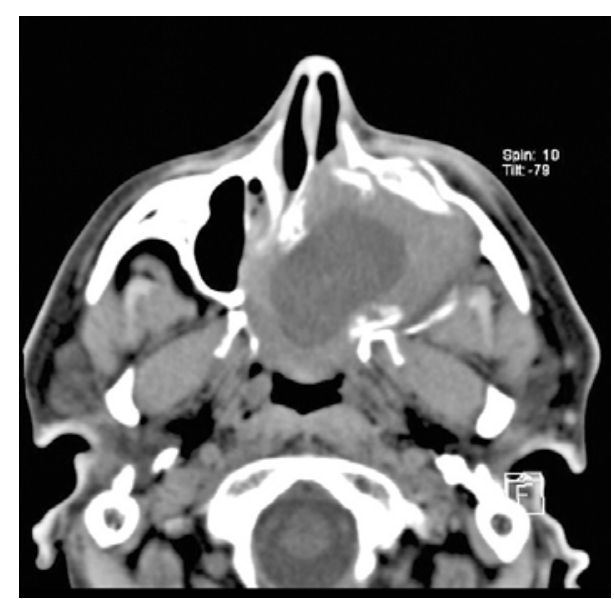

Figura 1. Tomografía computada con lesión expansiva del maxilar izquierdo. 


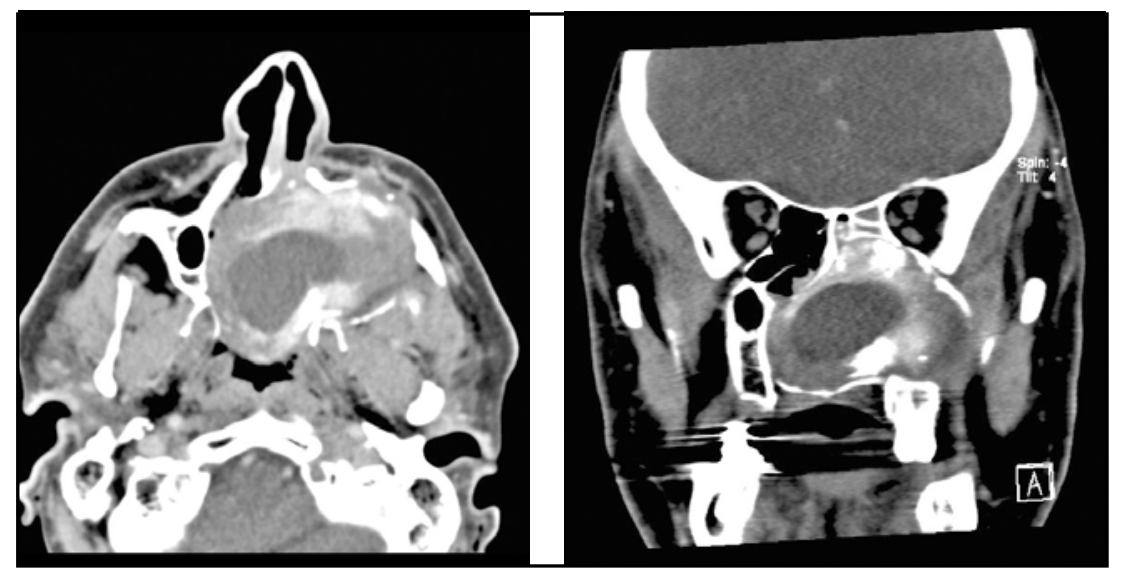

Figura 2a. TC (corte axial) con realce anular al medio de contraste, que delimita cavidad hipodensa central. $2 \mathrm{~b}$. TC corte coronal con realce del medio de contraste.

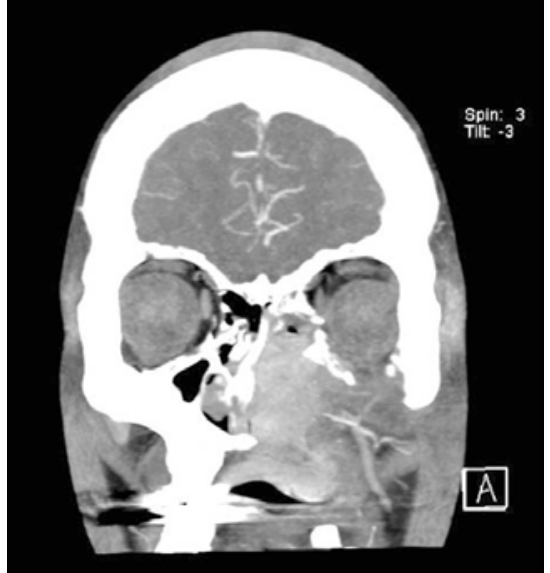

Figura 3. TC corte coronal evidencia destrucción ósea de piso de órbita y pared anterior maxilar.

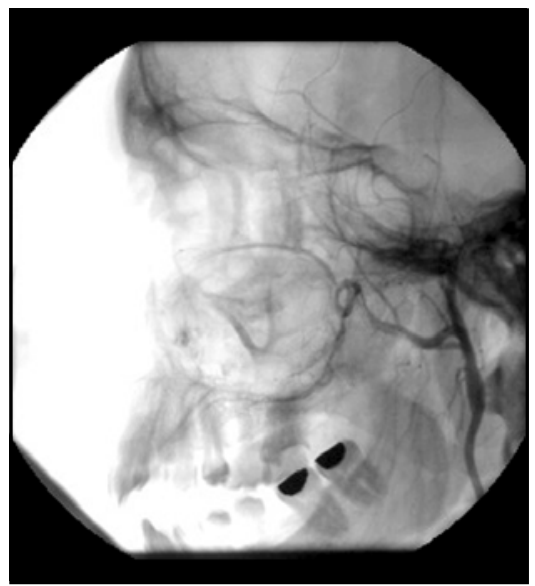

Figura 4. Angiografía: tumor vascularizado dependiente de arteria maxilar izquierda. seno maxilar, planteando inicialmente, que pudiese tratarse de un piomucocele, por lo que se planificó biopsia y posible drenaje en pabellón bajo anestesia general. Se intentó realizar el procedimiento por vía endoscópica produciéndose un sangrado profuso, que requirió complementar la técnica endoscópica con un abordaje vía Caldwell Luc para tomar una muestra de biopsia representativa y optimizar el control del sangrado, que cedió con un taponamiento posterior ipsilateral. En el posoperatorio evolucionó con anemia severa que se corrigió con transfusiones, sin presentar sangrado posterior. La biopsia se informó como hemangioma cavernoso. Once días después de la biopsia se realizó angiografía por vía femoral que mostró tumor maxilar izquierdo moderadamente vascularizado con aferentes de la arteria maxilar izquierda (Figura 4) que se embolizó en forma superselectiva. Tres días después de la embolización se intentó retirar el taponamiento posterior en pabellón, pero nuevamente se produce una hemorragia importante que requiere la reinstalación del taponamiento, se decide esclerosar la lesión de manera percutánea bajo visión angiográfica.

A los 5 días de realizada la escleroterapia se realizó la maxilectomía total por rinotomía lateral, sin incidentes. Una semana después se colocó prótesis obturadora sin dificultades. Se le dio el alta 15 días posmaxilectomía; la biopsia definitiva corroboró el diagnóstico de hemangioma cavernoso. Se le realizó TC poscirugía que evidenció tejido 
fibrogranuloso remanente, sin residuos de tumor (Figura 5). Al examen físico se evidenciaba una leve depresión infraorbitaria izquierda con movimientos oculares normales; a los 6 meses de la cirugía se realizó la reconstrucción del piso de la órbita con prótesis de titanio, con lo que mejoró su apariencia estética (Figura 6). Los controles hasta los 15 meses después de la cirugía no evidencian recidiva tumoral.

\section{DISCUSIÓN}

Los hemangiomas son lesiones endoteliales benignas que usualmente se ven en piel, mucosas y sistema esquelético; siendo la variante capilar mucho más frecuente que la cavernosa en localización nasosinusal5; así Fu y Perzin al estudiar 256 tumores no epiteliales, de cavidad nasal, senos paranasales y nasofaringe, encontraron 85 de estirpe vascular, entre ellos 30 hemangiomas capilares localizados en la parte anterior del tabique nasal, en menor número en cornetes y vestíbulo, encontrando sólo 2 casos a nivel maxilar ${ }^{14}$. También, Sciarreta y cols, dentro de su revisión de tumores benignos nasosinusales ${ }^{15}$ describen 13 casos de tumores vasculares, ninguno de ellos en seno maxilar ${ }^{16}$.

La mayoría de los hemangiomas tienen su origen primario en la mucosa que cubre al seno o la cavidad nasal, que es el sitio donde probablemente se inició en nuestro paciente. Los hemangiomas nasales son de tamaño limitado y pueden ser fácilmente detectados, mientras que los de cavidades perinasales, por su localización, son habitualmente diagnosticados cuando ya han formado una gran masa; por lo que los síntomas más frecuentemente reportados son epistaxis recurrente, obstrucción nasal, edema, dolor de mejilla y protrusión de globo ocular $^{17,18}$ (por destrucción ósea local); síntomas menos frecuentes como hemoptisis también han sido reportados ${ }^{19}$. Llama la atención que nuestro paciente no presentó epistaxis de manera espontánea, signo casi invariablemente presente en los casos reportados.

Dentro del diagnóstico diferencial de tumores en seno maxilar deben incluirse los papilomas invertidos, neuromas, osteomas, displasia fibrosa, angiofibroma juvenil, mucocele y tumores malignos de cualquier estirpe ${ }^{20,21}$; y dentro de los tumo-

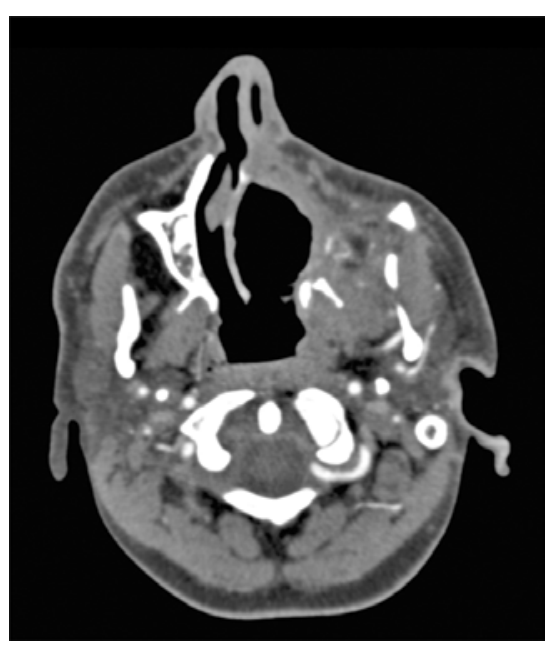

Figura 5. TC de control a los 8 meses poscirugía.

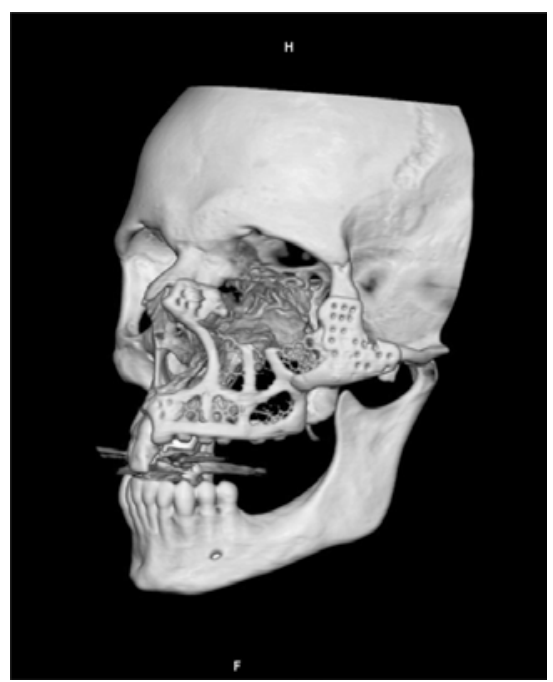

Figura 6. Reconstrucción tridimensional de TC posoperatoria con prótesis de titanio.

res vasculares, los hemangioendoteliomas (cuyo sitio de presentación es el seno maxilar en el 50\% de casos reportados ${ }^{22}$ ), los hemangiomas óseos ${ }^{23}$ y quistes óseos aneurismáticos ${ }^{24}$, deberían también estar presentes.

La TC y la resonancia magnética (RM) son usadas para delinear de mejor manera las estructuras vitales y la extensión tumoral al tejido blando, aunque su rol preoperatorio puede ser limitado $0^{17,25}$; la TC usualmente revela un aumento de la vascularización del tumor con el contraste; en 
algunos reportes se han descrito signos de erosión y destrucción ósea causada por este tipo de tumores, causando en algunos casos un diagnóstico erróneo de malignidad ${ }^{12,21,26,27}$; por su parte la RM demuestra una señal hiperintensa en T2. Ninguno de estos hallazgos es patognomónico; aunque algunos casos sugieren que la presencia de nódulos calcificados (flebolitos) dentro de la lesión podría considerarse como un signo muy sugerente de hemangioma ${ }^{28}$; sin embargo en la actualidad se prefiere a la angio-TC con reconstrucción tridimensional (3D), puesto que evidencia con más detalle las lesiones vasculares de cabeza y cuello, mostrando casi perfectamente la anatomía de este tipo de lesiones complejas ${ }^{29}$.

En cuanto al manejo, la mayoría de los reportes sugieren que la embolización de la arteria principal del tumor vascular debería ser realizado antes de la resección quirúrgica; siendo sus ventajas la disminución del tamaño tumoral y del riesgo de hemorragia durante el procedimiento quirúrgico ${ }^{11,18,19}$. En el tratamiento de la sinusitis crónica y de tumores benignos de cavidades perinasales, la cirugía endoscópica funcional ha reemplazado en la actualidad al abordaje abierto por su probada seguridad y efectividad; existiendo casos de hemangiomas maxilares de tamaño mediano resecados por vía endoscópica sin dificultades, con la ventaja de preservación de mucosa sana y estructuras óseas $18,19,25,27$. Esto no fue posible en nuestro paciente por el tamaño de la masa y la destrucción ósea ya existente; por lo que las ventajas de la vía endoscópica ya no fueron factibles y la vía de abordaje seleccionada fue la de Weber-Ferguson con resección total de la lesión sin presentar recidiva a 15 meses de seguimiento.

Los hemangiomas deberían ser considerados en el diagnóstico diferencial de tumores de seno maxilar. Ninguno de los signos, síntomas o resultados imagenológicos son patognomónicos de esta patología; aunque la presencia de flebolitos podría orientarnos en el diagnóstico de este tipo de lesiones. Una valoración angiográfica con embolización previa a la resección es lo más indicado; siendo el abordaje quirúrgico abierto 0 endoscópico individualizado, en función de la accesibilidad, extensión de la lesión, edad del paciente y consideraciones estéticas.

\section{BIBLIOGRAFÍA}

1. Mulliken JB, Glowack J. Hemangiomas and vascular malformations in infants and children: a classification based on endothelial characteristics. Plast Reconstr Surg 1982; 69: 412-22.

2. Adams D, Lucky A. Cervicofacial vascular anomalies. Hemangiomas and other benign vascular tumors. Semin Pediatr Surg 2006; 15(2): 124-32.

3. BatSAKIS J. Tumors of the Head and Neck: Clinical and Pathological Considerations. Baltimore: Editorial Williams and Wilkins; 1979: 291-312.

4. KAng G, Song C. Forty one cervicofacial vascular anomalies and their surgical treatmentRetrospection and Review. Ann Acad Med Singapore 2008; 37(3): 165-79.

5. Caylakli F, Can A, Hürcan C, Bal N, Kizllkilic 0, KIROgLU F. Cavernous hemangioma of the middle turbinate: A case report. ENT 2008; 87(1): 391-3.

6. Puxeddu R, Berlucchi M, Ledda GP, Parodo G, Farina D, Nicolal P. Lobular capillary hemangioma of the nasal cavity: A retrospective study on 40 patients. Am J Rhinol 2006; 20: 480-4.

7. Iwata N, Hattori $K$, Nakagawa $T$, Tsujimura $T$. Hemangioma of the nasal cavity: a clinicopathologic study. Auris Nasus Larynx 2002; 29: 335-9.

8. Sheppard L, Mickelson S. Hemangiomas of the nasal septum and paranasal sinuses. Henry Ford Hosp Med J 1990; 38(1): 25-7.

9. Lahoz M, Galvé A, Royo J, Valero J, Cámara F. Hemangioma cavernoso del seno maxilar. Acta Otorrinolaringol Esp 1990; 41(3): 197-9.

10. Amor J, Juiz P, Zubiarreta A. Hemangioma cavernoso del seno maxilar. Acta Otorrinolaring Esp 1998; 49(2): 165-7.

11. Raboso E, Rosell A, Plaza G, Martinez-Vidal A. Haemangioma of the maxillary sinus. $J$ Laryngol Otol 1997; 111: 638-40.

12. Engels $T$, Schörner W, Felix $R$, Witt H, Jahnke V. Cavernous hemangioma of the maxillary sinus. HNO 1990; 38(9): 342-4.

13. Dufour H, Fesselet J, Métellus P, FigarellaBranger D, Grisoli F. Cavernous hemangioma of 
the sphenoid sinus: Case report and review of the literature. Surg Neurol 2001; 55: 169-73.

14. Fu Y, Perzin K. Non epithelial tumors of the nasal cavity, paranasal sinuses and nasopharynx: a clinicopathologic study. Cancer 1974; 33: 1275-88.

15. Sciarretta V, Pasquini E, Frank G, Modugno G, Cantaroni C, Mazzatenta D, Farneti $G$. Endoscopic treatment of benign tumors of the nose and paranasal sinuses: A report of 33 cases. Am J Rhinol 2006; 20(1): 64-71.

16. Sciarretta V, Pasquini E, Farneti G, Frank $G$, Mazzatenta D, Calbucci F. Endoscopic sinus surgery for the treatment of vascular tumors. Am J Rhinol 2006; 20: 426-31.

17. Walch C, Anderhuber W, LuXenberger W, Humer-Fuchs $U$. Cavernous haemangioma in the infraorbital nerve canal: An unusual expansion en the maxillary sinus. J Laryngol Otol 1998; 112: 872-4.

18. Kanazana $T$, Inou $R$, Ohta $Y$, Watanabe $Y$, Iino $Y$. Maxillary haemangioma succesfully resected by endoscopic approach. J Laryngol Otol 2008; 1-3.

19. Jammal H, Barakat F, Hadi U. Maxillary sinus cavernous hemangioma: A rare entity. Acta Otolaryngol 2004; 124: 331-3.

20. Eviatar E, Vaiman M, Shlamkovitch N, Segal S, Kessler A, Katzenell U. Removal of Sinonasal Tumors by the Endonasal Endoscopic Approach. IMAJ 2004; 6: 346-9.

21. Pasquini E, Sciarretta V, Frank G, Cantaroni C, Modugno G, et al. Endoscopic treatment of benign tumors of the nose and paranasal sinuses. Otolaryngol Head Neck Surg 2004; 131: 180-6.
22. Semino L, Pagella F, Delú G, Todeschini A, Luinetti 0 , Zappol $F$ et aL. Endoscopic treatment of ethmoidal hemangioendothelioma: case report and review of the literature. Am J Otolaryngol 2006; 27(2): 287-90.

23. Goyal $N$, Jones $M$, Sandison A, Clarke P. Maxillary haemangioma. J Laryngol Otol 2006; 120: e14.

24. Guzmán P, Baeza A, Araya J, Roa J, Brevis L, TORRES P. Quiste óseo aneurismático del maxilar superior. Reporte de un caso. Rev Méd Chile 2005; 133: 1355-60.

25. Morales M, Sanjurjo J, Madrigal J. Hemangioma cavernoso del seno maxilar: reporte de un caso y revisión de la literatura. An Orl Mex 2005; 50(2): 26-9.

26. KIm HJ, KIm JH, KIm JH, Hwang EG. Bone erosion caused by sinonasal hemangioma: $\mathrm{CT}$ findings in two patients. Am J Neuroradiol 1995; 16(5): 1176-8.

27. Mussak E, Lin J, Prasad M. Hemangioma cavernous of maxillary sinus with bone erosion. ENT 2007; 86(9): 565-6.

28. Altug H, BüyüKsoy V, ОKcu K, Dogan N. Hemangiomas of the head and neck with phleboliths: Clinical features, diagnostic imaging and treatment of 3 cases. Oral Surg Oral Med Oral Pathol Oral Radiol Endod 2007; 103: e60-e64.

29. Perkins J, Sidhu M, Manning S, Ghioni V, Sze R. Three-dimensional CT angiography imaging of vascular tumors of the head and neck. Int J Pediatr Otolaryngol 2005; 69(3): 319-25.

Dirección: Dr. Alfredo Naser González

Santos Dumont 999. Recoleta. Santiago. Chile

E mail: aanaser@gmail.com 


\title{
Estenosis subglótica secundaria a granulomatosis de Wegener. Reporte de un caso y revisión de la literatura
}

\author{
Subglottic stenosis secondary to Wegener's granulomatosis. \\ A case report and literature review.
}

Christian Olavarría L1', Daniel Muñoz S².

\begin{abstract}
RESUMEN
La granulomatosis de Wegener es una enfermedad multisistémica de origen autoinmune con numerosas manifestaciones otorrinolaringológicas. Dentro de éstas destaca la estenosis subglótica que puede eventualmente comprometer la vida del paciente. Su diagnóstico requiere un alto grado de sospecha, pues se ha visto que su desarrollo es independiente de la actividad de la enfermedad sistémica y debe basarse principalmente en la visión endoscópica de la lesión. El tratamiento de la estenosis subglótica en pacientes con granulomatosis de Wegener es complejo, requiere a menudo de repetidas intervenciones debido a reestenosis. Actualmente, no existe consenso en la técnica quirúrgica más adecuada, por lo que la decisión final deberá basarse en la evaluación de cada caso en particular. Presentamos el caso de un paciente con estenosis subglótica y granulomatosis de Wegener atendido en nuestro servicio y revisamos la literatura con énfasis en las alternativas de tratamiento de esta enfermedad.
\end{abstract}

Palabras clave: Estenosis subglótica, granulomatosis de Wegener, vasculitis, tratamiento.

\begin{abstract}
Wegener's granulomatosis is a autoimmune systemic disease with numerous upper respiratory tract manifestations. Among these, subglottic stenosis represents a potentially lethal complication. Its diagnosis is complicated by the fact that it develops independently from the systemic disease, as it is mainly based on endoscopic examination. Treating subglottic stenosis in patients suffering from Wegener's granulomatosis is complex, it often requires repeated interventions due to restenosis. There is no current consensus on the most adequate surgical technique, and thus it must be evaluated and decided on a case-to-case basis. We present the case of a subglottic stenosis and Wegener's granulomatosis patient from our department. In addition, we reviewed the literature, emphasizing treatment alternatives.
\end{abstract}

Key words: Subglottic stenosis, Wegener's granulomatosis, vasculitis, treatment.

Médico, Servicio de Otorrinolaringología, Hospital Clínico Universidad de Chile.

Médico Cirujano, Universidad de Chile. 


\section{INTRODUCCIÓN}

La granulomatosis de Wegener (GW) es una enfermedad crónica sistémica de origen autoinmune. Fue descrita inicialmente por Klinger en $1932 \mathrm{y}$, en forma acabada, por Friedrich Wegener como una tríada de vasculitis granulomatosa de las vías respiratorias, vasculitis sistémica y gromeluronefritis focal necrotizante ${ }^{1,2}$. Actualmente es clasificada como una vasculitis de pequeño vaso asociada a anticuerpos citoplasmáticos antineutrófilos, especialmente subtipo c (c-ANCA), útiles para su diagnóstico precoz y seguimiento ${ }^{3}$.

Esta enfermedad tiene $82 \%$ de mortalidad a un año del inicio de los síntomas ${ }^{4}$. Se presenta a cualquier edad, pero es más frecuente entre la $5^{\mathrm{a}} \mathrm{y}$ $6^{a}$ década de vida, con predominio en el sexo masculino. En EE.UU., la prevalencia es de 3 casos en 100.000 habitantes, casi exclusivamente en caucásicos 5 .

La granulomatosis de Wegener presenta un amplio rango de manifestaciones otorrinolaringológicas, ya sea como complicación o como síntoma inicial. El compromiso en cabeza y cuello es la manifestación más frecuente seguida por el pulmonar, articular, ocular y renal ${ }^{6}$.

En las cavidades nasosinusales, puede manifestarse como sinusitis, epistaxis, perforación septal 0 deformidad nasal en silla de montar. Se ha descrito compromiso otológico en $25 \%-40 \%$ de los casos, dado principalmente por otitis media con efusión e hipoacusia sensorioneural secundaria a vasculitis coclear? ${ }^{7}$. En la Tabla 1 se resumen las manifestaciones de la GW de interés en otorrinolaringología.

En la laringe, la estenosis subglótica se ha reportado en el 9\%-23\% de los pacientes ${ }^{8}$ con GW, pudiendo coexistir más de una lesión en el árbol laringo-tráqueo-bronquial. Es más frecuente en mujeres y en aquellos pacientes con diagnóstico de GW a edad temprana9. Esta región es un área particularmente susceptible de estrechamiento debido a la presencia de un anillo cartilaginoso completo como es el cartílago cricoides $^{10}$. Se ha descrito también, que los pacientes con GW y estenosis subglótica, padecen mayor compromiso sinusal y menor compromiso renal y pulmonar ${ }^{11}$.

La presentación clínica puede ir desde casos asintomáticos hasta el compromiso vital por estrechamiento de la vía aérea. La disnea de esfuerzo es el síntoma más frecuente de la estenosis subglótica $(79 \%-82 \%)$ y puede acompañarse de cambios en la voz y disfonía, estridor 0 tos $^{12}$. La disfonía puede deberse a parálisis de cuerdas vocales, posiblemente debido a eventos vasculíticos sobre los nervios laríngeos ${ }^{13} 0$ a alteraciones de la articulación cricoaritenoidea.

Tabla 1. Manifestaciones otorrinolaringológicas de la granulomatosis de Wegener

Otológicas

Destrucción y deformidad de pabellón auricular

Disfunción tubaria

Otitis media con efusión

Otomastoiditis granulomatosa

Meningitis

Parálisis nervio facial

Hipoacusia

Vértigo

Nariz y senos paranasales

Rinosinusitis crónica

Epistaxis

Obstrucción nasal

Perforación septal

Rinorrea

Deformidad nasal (en silla de montar)

Costras nasales

Epífora
Cavidad oral y glándulas salivales

Estomatitis ulcerativa

Inflamación mucosa crónica

Fístula oro-antral

Necrosis de paladar

Nódulos mucosos

Hiperplasia gingival

Sialoadenitis

Parotidomegalia

Laringe

Estenosis subglótica

Estenosis supraglótica

Parálisis de cuerdas vocales 
La vía aérea requiere ser evaluada endoscópicamente (idealmente mediante traqueobroncoscopía) y la estenosis subglótica debe ser clasificada usando la escala de Cotton-Mayer, según porcentaje de obstrucción del diámetro de la vía aérea ${ }^{14}$ (Tabla 2).

El diagnóstico de la estenosis debe complementarse siempre con la medición de c-ANCA. Cabe señalar que inicialmente sólo un poco más de la mitad de los pacientes es positivo al momento del diagnóstico del compromiso subglótico, pudiendo el resto hacerse positivo con posterioridad $^{15}$. Asimismo, nos podemos apoyar en el estudio histológico a través de la presencia de vasculitis, granulomas necrotizantes y células gigantes². Las biopsias de lesiones subglóticas (realizadas en pacientes ANCA+ y con estenosis) son consistentes con una GW en el $5 \%-15 \%$ de los casos. Por el contrario, las biopsias nasales han mostrado $82 \%$ de sensibilidad para GW ${ }^{16}$.

Con respecto al diagnóstico por imágenes, la tomografía computada provee una buena aproximación para evaluar lesiones laringotraqueales. Además, tiene la ventaja de realizar reconstrucciones sagitales lo que confiere mayor precisión en definir los límites superior e inferior de la lesión y el compromiso de cuerdas vocales ${ }^{17}$.

El diagnóstico diferencial de la GW involucra una variedad de enfermedades granulomatosas y autoinmunes tales como la sarcoidosis, enfermedad de Churg-Strauss, poliarteritis nodosa, poliangeítis microscópica y policondritis recidivante ${ }^{2-5}$.
Tabla 2. Clasificación de la estenosis subglótica (Cotton - Myer) $^{14}$

\begin{tabular}{|lc|}
\hline Grado & Obstrucción (\%) \\
\hline I & $0-50$ \\
II & $51-70$ \\
III & $71-99$ \\
IV & 100 \\
\hline
\end{tabular}

\section{CASO CLÍNICO}

Paciente de sexo masculino de 42 años de edad, con antecedente de aspergilosis pulmonar resuelta con lobectomía izquierda, intubación endotraqueal y otitis media por efusión tratada. Refiere cuadro de 2 años de evolución con rinorrea serosa, obstrucción nasal, hipoacusia bilateral progresiva y disfonía de 1 año de evolución. Desde hace 6 meses se agrega tos irritativa y dificultad respiratoria progresiva. Destaca al examen físico la presencia de deformidad nasal en "silla de montar», estridor laríngeo bifásico leve y compromiso ocular a derecha tipo epiescleritis.

La nasofibroscopía muestra fosas nasales con abundantes costras, sinequias entre el tabique nasal y cornete medio. En la región glótica, se observan cuerdas vocales móviles con sinequia anterior que ocluye en al menos $50 \%$ el lumen y presencia de material costroso en laringe (Figura 1). La región

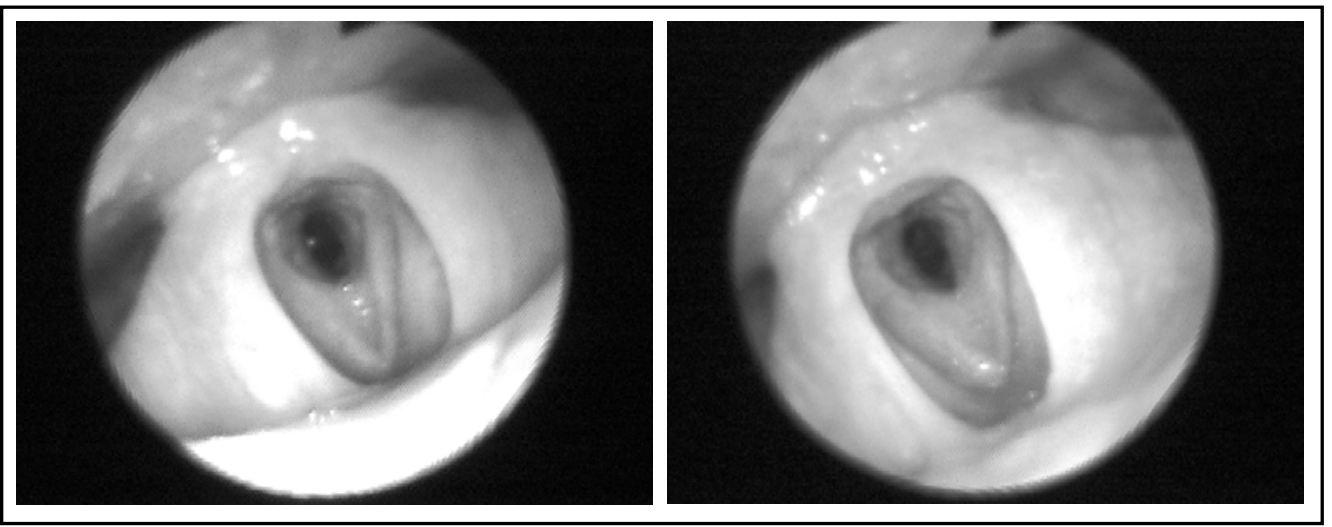

Figura 1. Imagen endoscópica de la estenosis subglótica del paciente en discusión. Destaca el estrechamiento de aproximadamente el $50 \%$ del lumen respiratorio. 
Revisión del tratamiento quirúrgico para estenosis subglótica en GW, publicado en la literatura durante los últimos 12 años

\begin{tabular}{|c|c|c|c|c|c|c|}
\hline Autor & Tratamiento & $\begin{array}{c}n^{\circ} \\
\text { pacientes }\end{array}$ & $\begin{array}{l}\text { Seguimiento } \\
(\overline{\mathrm{x}} \text { meses })\end{array}$ & $\begin{array}{l}\text { Procedimientos } \\
\qquad(\overline{\mathrm{x}})\end{array}$ & $\begin{array}{c}\text { ANCA + } \\
(\%)\end{array}$ & $\begin{array}{c}\text { Complicaciones } \\
(\%)\end{array}$ \\
\hline Lanford $^{19}(1996)$ & $\mathrm{DE}+\mathrm{Cl}$ & 20 & 35 & 3 & 100 & 0,08 \\
\hline Herridge $^{33}$ (1996) & RLT & 3 & 85,5 & 1 & 100 & 0 \\
\hline Sttapaerts $^{31}(2000)$ & $\mathrm{DE}+\mathrm{Cl}$ & 1 & 6 & 1 & 100 & 0 \\
\hline Utzig $^{32}(2002)$ & $\mathrm{DE}+\mathrm{Cl}+$ escisión quirúrgica & 7 & 30 & 1,2 & 80 & 14 \\
\hline Watters ${ }^{28}(2003)$ & Stent de Nitinol & 1 & 48 & 1 & 100 & 0 \\
\hline Gluth ${ }^{11}(2003)$ & DE + Láser C02 & 12 & 76,8 & 2,3 & 100 & - \\
\hline Hoffman $^{25}$ (2003) & $\mathrm{DE}+\mathrm{Cl}+$ escisión quirúrgica & 21 & 24 & 3,3 & - & 3 \\
\hline Shvero $^{26}(2007)$ & Láser C02 o ND:YAG & 5 & 21,6 & 7,8 & 100 & 0 \\
\hline Shoeckkenbroek ${ }^{24}(2008)$ & $\mathrm{DE}$ & 9 & 25,4 & 2,4 & 100 & 0 \\
\hline
\end{tabular}

DE =Dilatación endoscópica; $\mathrm{Cl}$ =corticoides intralesionales; RLT =Reconstrucción laringotraqueal.

subglótica presenta un estrechamiento de su lumen en aproximadamente $50 \%$. La tomografía computada de cavidades paranasales evidencia extensa ocupación del laberinto etmoidal izquierdo, engrosamiento de mucosa maxilar derecha con extensa ocupación maxilar izquierda y ocupación parcial del seno esfenoidal izquierdo (Figura 2).

Se toma biopsia de tejido laríngeo (bajo laringoscopía directa) y biopsia de cavidad nasal (cornete medio izquierdo). El resultado del estudio histológico sólo mostró, para ambas muestras obtenidas, un proceso inflamatorio crónico. Desde el punto de vista inmunológico, destaca la negatividad de anticuerpos como c-ANCA, p-ANCA y serología de VIH (-). Dado el compromiso respiratorio progresivo, se decide su manejo con terapia inmunosupresora (corticoesteroides), con buena respuesta sintomática a corto plazo.

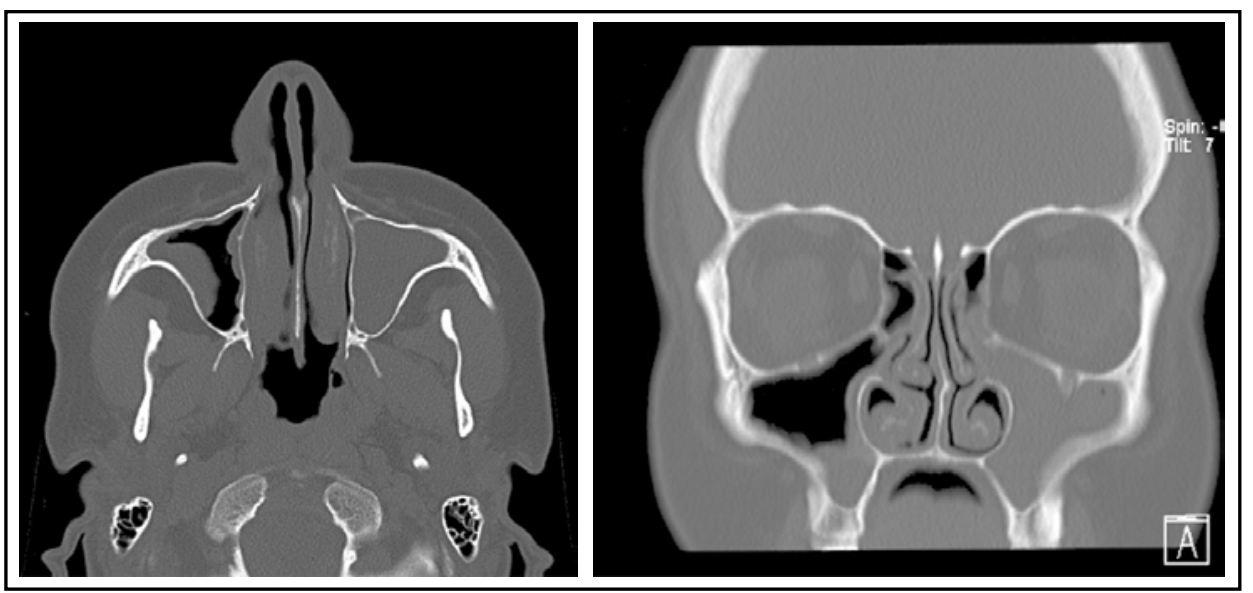

Figura 2. Tomografía computada de cavidades paranasales del paciente con granulomatosis de Wegener. Destaca el extenso compromiso, especialmente, del seno maxilar izquierdo. 


\section{DISCUSIÓN}

La estenosis subglótica ocurre en aproximadamente el $9 \%-23 \%$ de los pacientes con GW y representa la manifestación más frecuente en vía aérea ${ }^{8}$. Según Rottem y cols., es cinco veces más frecuente en pacientes cuyo diagnóstico de GW se hizo antes de los 19 años de edad'. El segmento estenótico puede estar limitado a la subglotis 0 extenderse hasta 3 ó $4 \mathrm{~cm}$ hacia la tráquea y eventualmente hacia la supraglotis ${ }^{18}$ y aproximadamente la mitad de los pacientes con compromiso laríngeo requerirán traqueostomía en algún momento de su evolución ${ }^{5}$.

La clínica de la estenosis subglótica es variable y puede ocurrir en ausencia de otras características de GW activa. Según Langford y cols., $79 \%$ de los casos presentan disnea, $61 \%$ disfonía y estridor y $22 \%$ tos $^{19}$. Resulta llamativo que algunos pacientes con GW con estenosis en estadios iniciales se han diagnosticado como asmáticos, pues los test de función pulmonar son anormales en cerca del $60 \%$ de los pacientes con estenosis subglótica, mostrando un patrón obstructivo que confunde al médico tratante ${ }^{34,35}$. Cabe señalar, que en nuestro caso existen otros antecedentes de factores predisponentes al desarrollo de estenosis subglótica, como la intubación endotraqueal, lo que sumado a GW claramente contribuye al proceso patológico.

Nuestro paciente no presentó alteraciones en su estudio serológico, como se hubiese esperado. Sin embargo, este hecho no excluye la enfermedad pues se ha reportado vasculitis de pequeño vaso ANCA negativo, estimándose que 1 de cada 5 pacientes con la enfermedad inicial pueden ser seronegativos ${ }^{20}$. Resulta de importancia entonces, el seguimiento de los títulos de ANCA, pues en algunos pacientes los títulos negativos pueden hacerse positivos con el tiempo. La decisión de iniciar tratamiento inmunosupresor en nuestro caso fue empírica, dada la progresión de la disnea y la consiguiente disminución de la capacidad funcional. La exclusión de otros diagnósticos diferenciales, se basó en la apreciación clínicosindromática de la granulomatosis de Wegener, que en este caso es la que más concordaba dentro del espectro de enfermedades granulomatosas.
El tratamiento de la estenosis subglótica en pacientes con GW es complejo y requiere a menudo de repetidas intervenciones, por una alta tasa de recurrencia de la estenosis ${ }^{21}$.

\section{Tratamiento médico}

Se basa en el uso de drogas inmunosupresoras como corticosteroides, ciclofosfamida, entre otras. Éstas, han sido útiles en la enfermedad sistémica, pero no así en estenosis subglótica, siendo posible incluso que ésta debute mientras el paciente está en tratamiento ${ }^{22}$. Su éxito en aliviar la obstrucción varía entre $22 \%$ y $26 \%{ }^{23}$.

\section{Tratamiento quirúrgico}

\section{- Traqueostomía}

La obstrucción severa de la vía aérea requiere traqueostomía, ya sea temporal o permanente, hasta en el $60 \%$ de los casos ${ }^{5}$. La decanulación del traqueostoma ha sido utilizada por algunos autores como un parámetro de éxito de otros tratamientos ${ }^{15}$.

- Tratamiento endoscópico

Los procedimientos endoscópicos han sido, en general, exitosos en el manejo de esta condición. La dilatación endoscópica es efectiva la mayoría de las veces para casos Cotton-Meyer grado I-II, con escasas complicaciones, pero son pocos los casos reportados ${ }^{24}$. Por otro lado, se ha usado la dilatación endoscópica, combinada con inyecciones de corticoides intralesionales. Hoffman y cols., reclutaron 21 pacientes que requirieron entre 2 ó 3 procedimientos al año para mantener la apertura de la vía aérea. Ninguno de ellos requirió una nueva traqueostomía y la tasa de complicaciones fue menor y sin secuelas a largo plazo ${ }^{25}$.

- Tratamiento láser

Para lesiones distales a las cuerdas vocales se ha usado láser Nd:YAG con $80 \%$ de éxito 0 decanulación durante el seguimiento. Sin embargo, todos los pacientes requirieron múltiples tratamientos ${ }^{26}$. Según otros autores, los procedimientos láser provocan fibrosis extensa y aquellos pacientes son más difíciles de manejar con posterioridad ${ }^{27}$. 
- Laringotraqueoplastía

Consiste en la reconstrucción laringotraqueal con injerto de cartílago costal. Gluth y cols, reportaron una serie de pacientes con excelentes resultados, pues la totalidad de ellos fueron decanulados y no hubo evidencia de falla del injerto ${ }^{11}$. Lebovics y cols realizaron laringotraqueoplastía en 5 pacientes que habían tenido múltiples procedimientos endoscópicos fallidos, logrando decanulación con adecuada calidad de voz en todos los casos ${ }^{16}$.

- Prótesis de vía aérea

Watters y cols., utilizaron un stent expandible de nitinol (aleación de níquel y titanio) en la vía aérea estenótica en un paciente que evolucionó sin complicaciones y sin tejido de granulación ${ }^{28}$. Sin embargo, su uso no está exento de complicaciones, por lo que no existe acuerdo en su recomendación ${ }^{29,30,34}$.

\section{CONCLUSIONES}

Resulta trascendental un alto grado de sospecha clínica en la GW dado que su pronóstico final depende, en gran medida, de un diagnóstico pre$\mathrm{coz}$.

El compromiso laringotraqueal, potencialmente mortal, debe evaluarse dirigidamente en todos estos pacientes, principalmente bajo visión endoscópica. Debemos recordar que, a pesar de la alta sensibilidad de c-ANCA, existe la posibilidad de enfermedad seronegativa. Así, como en nuestro caso, la decisión terapéutica no debiera retrasarse a la espera de un diagnóstico serológico pues ésta es una entidad que eventualmente puede comprometer la vida del paciente si no es tratada oportunamente.

La estrategia terapéutica debe ser evaluada caso a caso. El uso de traqueostomía, si hay compromiso respiratorio vital, es indiscutible. Por otro lado, de acuerdo a la evidencia, parece sensato el uso inicial de dilatación endoscópica idealmente con corticoides intralesionales. Si los procedimientos endoscópicos no son satisfactorios, debe evaluarse la reconstrucción laringotraqueal abierta. El uso de stents de vía aérea no está exento de complicaciones, por lo que su recomendación dependerá sólo de que el beneficio de usarlos sea superior al riesgo de complicarse.

\section{BIBLIOGRAFÍA}

1. Khan AM, Elahi F, Hashmi SR, Mahida KH, Ingrams DR. Wegener's granulomatosis: a rare, chronic and multisystem disease. Surgeon 2006; 4(1): 45-52.

2. ERICKSON VR, HWAng PH. Wegener's granulomatosis: current trends in diagnosis and management. Curr Opin Otolaryngol Head Neck Surg 2007; 15(3): 170-6.

3. Gaughan RK, De Santo LW, McDonald TJ. Use of anticytoplasmicautoantibodies in the diagnosis of Wegener's granulomatosis with subglotticstenosis. Laryngoscope 1990; 100(6): 561-3.

4. Thickett DR, Richter AG, Nathani N, Perkins GD, Harper L. Pulmonary manifestations of antineutrophilcytoplasmic antibody (ANCA)positive vasculitis. Rheumatology (Oxford) 2006; 45(3): 261-8.

5. Gottschlich S, Ambrosch P, Kramkowski D, Laudien M, Buchelt T, Gross WL, Hellmich B. Head and neck manifestations of Wegener's granulomatosis. Rhinology 2006; 44(4): 227-33.

6. Rasmussen N. Management of the ear, nose, and throat manifestations of Wegener granulomatosis: an otorhinolaryngologist's perspective. Curr Opin Rheumatol 2001; 13(1): 3-11.

7. Takagi D, Nakamaru $Y$, Maguchi $S$, Furuta $Y$, FUKUDA S. Otologic manifestations of Wegener's granulomatosis. Laryngoscope 2002; 112(9): 1684-90.

8. Seo P. Wegener's granulomatosis: managing more than inflammation. Curr Opin Rheumatol 2008; 20(1): 10-6.

9. Rottem M, Fauci as, Hallahan CW, Kerr GS, Lebovics R, Leavitt RY, Hoffman GS. Wegener granulomatosis in children and adolescents: clinical presentation and outcome. J Pediatr 1993; 122(1): 26-31.

10. LANGFORD CA. Wegener's granulomatosis: current and upcoming therapies. Arthritis Res Ther 2003; 5(4): 180-91. 
11. Gluth MB, Shinners PA, Kasperbauer JL. Subglotticstenosis associated with Wegener's granulomatosis. Laryngoscope 2003; 113(8): 1304-7.

12. Polychronopoulos VS, Prakash UB, Golbin JM, Edel ES, Specks U. Airway involvement in Wegener's granulomatosis. Rheum Dis Clin North Am 2007; 33(4): 755-75, vi.

13. Alahn $A$, Hogg RP, Drake lee $A$. Wegener's granulomatosis and subglotticstenosis: management of the airway. J Laryngol Otol 2004; 118(10): 786-90.

14. Blaivas AJ, Strauss W, Yudd M. Subglotticstenosis as a complication of Wegener's granulomatosis. Prim Care Respir J 2008; 17(2): 114-6.

15. Bandi V, Munnur U, Braman SS. Airway problems in patients with rheumatologic disorders. Crit Care Clin 2002; 18(4): 749-65.

16. Lebovics RS, Hoffman GS, Leavitt RY, Kerr GS, Travis WD, Kammerer W, Hallahan C, Rottem M, Faucl AS. The management of subglotticstenosis in patients with Wegener's granulomatosis. Laryngoscope 1992; $102(12$ Pt 1): 1341-5.

17. Allen SD, Harvey CJ. Imaging of Wegener's granulomatosis. $\mathrm{Br} J$ Radiol 2007; 80(957): 757-65.

18. Belloso A, Estrach C, Keith A0. Supraglotticstenosis in localized Wegener granulomatosis. Ear Nose Throat J 2008; 87(7): E11-4.

19. Langford CA, Sneller MC, Hallahan CW, Hoffman GS, Kammerer WA, Talar-Williams C, Fauci AS, LeBovics RS. Clinical features and therapeutic management of subglotticstenosis in patients with Wegener's granulomatosis. Arthritis Rheum 1996; 39(10): 1754-60.

20. Carrie $S$, Hughes KB, Watson MG. Negative ANCA in Wegener's granulomatosis. J Laryngol Otol 1994; 108(5): 420-2.

21. LORENZ RR. Adult laryngotrachealstenosis: etiology and surgical management. Curr Opin Otolaryngol Head Neck Surg 2003; 11(6): 467-72.

22. Thurnher D, Moukarbel RV, Novak CB, Gullane PJ. The glottis and subglottis: an otolaryngologist's perspective. Thorac Surg Clin 2007; 17(4): 549-60.
23. Loehrl TA, Smith TL. Inflammatory and granulomatous lesions of the larynx and pharynx. Am J Med 2001; 111 Suppl 8A: 113S-117S.

24. Schokkenbroek AA, Franssen CF, Dikkers FG. Dilatation tracheoscopy for laryngeal and tracheal stenosis in patients with Wegener's granulomatosis. Eur Arch Otorhinolaryngol 2008; 265(5): 549-55.

25. Hoffman GS, Thomas-Golbanow CK, Chan J, Akst LM, ELIACHAR I. Treatment of subglotticstenosis, due to Wegener's granulomatosis, with intralesional corticosteroids and dilation. $J$ Rheumatol 2003; 30(5): 1017-21.

26. Shvero J, Shitrit D, Koren R, Shalomi D, Kramer MR. Endoscopic laser surgery for subglotticstenosis in Wegener's granulomatosis. Yonsei Med J 2007; 48(5): 748-53.

27. Ahmad I, Lee WC, Nagendran V, Wilson F, SHORTRIDGE RT. Localised Wegener's granulomatosis in otolaryngology: a review of six cases. ORL J Otorhinolaryngol Relat Spec 2000; 62(3): 149-55.

28. Watters K, Russell J. Subglotticstenosis in Wegener's granulomatosis and the nitinolstent. Laryngoscope 2003; 113(12): 2222-4.

29. Eliachar I, Chan J, Aкst L. New approaches to the management of subglotticstenosis in Wegener's granulomatosis. Cleve Clin J Med 2002; 69 Suppl 2: SIl149-51.

30. Yumoto E, SaekI K, Kadota Y. Subglotticstenosis in Wegener's granulomatosis limited to the head and neck region. Ear Nose Throat J 1997; 76(8): 571-4.

31. Stappaerts I, Van Laer C, Deschepper K, Van de Heyning P, VermelRE P. Endoscopic management of severe subglotticstenosis in Wegener's granulomatosis. Clin Rheumatol 2000; 19(4): 315-7.

32. Utzig MJ, Warzelhan J, Wertzel H, Berwanger I, HASSE J. Role of thoracic surgery and interventional bronchoscopy in Wegener's granulomatosis. Ann Thorac Surg 2002; 74(6): 1948-52.

33. Herridge MS, Pearson FG, Downey GP. Subglotticstenosis complicating Wegener's granulomatosis: surgical repair as a viable treatment option. J Thorac Cardiovasc Surg 1996; 111(5): 961-6. 
34. Simon C, McCammon S, Quinn F. Subglottic Stenosis in Wegener Granulomatosis. Grand Rounds Presentation, UTMB, Dept. of Otolaryngology. 21 de mayo, 2001. <http:// www.utmb.edu/otoref/grnds/GrndsIndex.html> [Consulta, enero de 2009].
35. Solans-Laqué R, Bosch-Gil J, Canela $M$, Lorente J, Pallisa E, Vilardell-Tarrés M. Clinical features and therapeutic management of subglottic stenosis in patients with Wegener's granulomatosis. Lupus 2008; 17(9): 832-6. 


\title{
Absceso subperióstico y síndrome del vértice orbitario. Complicación posterior a la extracción del tercer molar mandibular
}

\author{
Subperiostial orbital abscess and apex syndrome as a complication \\ after a mandibular molar extraction
}

\author{
Lupe Salado R${ }^{1}$, Lupe Alvarez S², Beatriz Brunetto $\mathrm{M}^{3}$.
}

\begin{abstract}
RESUMEN
Introducción: La diseminación de las infecciones que se extienden de dientes mandibulares y estructuras adyacentes hacia la órbita y tejido periorbitario son infrecuentes, pero graves ya que tienen el potencial de causar la pérdida de la visión.

Objetivos: El propósito de este artículo es publicar un caso clínico muy interesante por lo infrecuente, y explicar a juicio de los autores las vías de diseminación de la infección, a su vez alertar a los diferentes especialistas involucrados sobre las severas consecuencias que pueden resultar tras la extracción de piezas dentales, como es la pérdida definitiva de la visión.

Reporte del caso: Se trata de un paciente masculino de 43 años, sin antecedentes mórbidos relevantes, que fue enviado al Servicio Médico Legal para examen clínico forense con pérdida total de la visión del ojo derecho por atrofia óptica como complicación de un síndrome del vértice orbitario, luego de la exodoncia del tercer molar mandibular derecho.

Conclusiones: Es fundamental el tratamiento oportuno y agresivo para detener la diseminación de una infección desde las estructuras adyacentes hacia la órbita. La comunicación efectiva interdisciplinaria entre los profesionales involucrados evita complicaciones de tipo médico-legales y secuelas definitivas al paciente.

Palabras clave: Absceso orbital, infección odontogénica, síndrome del vértice orbitario, atrofia óptica.
\end{abstract}

\section{ABSTRACT}

Introduction: Infection dissemination from mandibular teeth to the orbit and adjacent structures is infrequent, but nevertheless serious, as they may cause severe problems, including vision loss.

Aim: The purpose of this study is to present a rare and interesting case of such a dissemination, to discuss the possible routes of infection propagation, and to alert the different specialists involved on the possible complications after dental extractions, such as visual loss.

Report of the case: The case of a 43-year-old previously healthy male is presented. The patient was sent to the Medical Legal Service for clinical forensic examination after

\footnotetext{
Médico Oftalmóloga Forense, Servicio Médico Legal Santiago.

Cirujano Dentista, Universidad Nacional Andrés Bello.

Médico Otorrinolaringólogo Forense, Servicio Médico Legal.
} 
total vision loss of the right eye, caused by optic atrophy as a complication of orbital apex syndrome, after the extraction of the third right mandibular molar.

Conclusions: Opportune and aggressive treatment is crucial to stop infection spread from adjacent structures to the orbit. Effective communication among the professionals involved avoids medical - legal complications and precludes permanent sequels to the patient.

Key words: Orbital abscess, odontogenous infection, orbital apex syndrome, optical atrophy.

\section{INTRODUCCIÓN}

La arquitectura, la severidad de las secuelas, el potencial de morbilidad y hasta la mortalidad hacen crítica la detección temprana y el manejo agresivo de las infecciones orbitarias. Las afecciones dentales que se diseminan más allá del saco periodontal pueden iniciar la infección tanto de los músculos como del tejido conectivo adyacente y diseminarse a la órbita por varios caminos. Las infecciones odontogénicas tienen su origen en piezas dañadas por caries, o infecciones periodontales, y en casos aislados a través del alveolo desocupado luego de una exodoncia dental. La anatomía y topografía de las raíces dentarias, hace posible que los patógenos orales y mediadores inflamatorios infiltren rápidamente los sitios adyacentes como es el trígono submandibular 0 el seno maxilar; lo que trae como resultado licuefacción de tejido y formación de un absceso, que se puede expandir cranealmente a las cavidades y tejidos contiguos. Gracias a las terapias modernas antibióticas, secuelas tan serias como fasceítis necrotizante y abscesos intracraneales son poco frecuentes en la actualidad. Sin embargo, estas complicaciones requieren atención especial en su manejo, el diagnóstico precoz es esencial, y el tratamiento debe ser inmediato y especializado. Los abscesos y flegmones orbitarios demandan de un tratamiento enérgico para evitar complicaciones tales como pérdida de la visión, bacteremias, trombosis del seno cavernoso, meningitis, absceso cerebral y hasta la muerte ${ }^{1}$.

Un alto porcentaje de los casos con celulitis orbitaria, son secundarios a complicación por infección de los senos paranasales, siendo más frecuente el del seno etmoidal, esta es la fuente de infección más común de las patologías infecciosas orbitarias en niños ${ }^{2-3}$.

La diseminación del proceso infeccioso y severidad de las secuelas dependen de diversos factores incluyendo la virulencia del microorganismo, la resistencia del paciente y la anatomía del área infectada ${ }^{4}$.

La diseminación de la infección de igual forma, puede producirse por tres mecanismos ${ }^{5}$ :

1. Extensión directa por la vía de los espacios faciales.

2. Por vía hematógena (trombos) infectados a través del sistema venoso.

3. Por vía linfática.

En el presente trabajo nos ocuparemos de la extensión directa por la vía de los espacios faciales, hematógena y anatomía del área involucrada.

El recorrido de los gérmenes dentro de la órbita está dado por la poca adherencia del periostio dentro de la misma, el cual es fácilmente desplazado por la colección purulenta permitiendo su entrada desde las áreas adyacentes ${ }^{6}$. La relación de los ápices de las raíces dentarias con los músculos contiguos es lo que determina la dirección de la diseminación, que habitualmente sigue el camino de menor resistencia. La cortical ósea externa del hueso maxilar es muy delgada, es por esto que la mayoría de los abscesos penetra por esta vía.

La infección a través de las piezas anteriores maxilares, puede provocar celulitis orbitaria por diseminación retrógrada a través de las venas facial, angular u oftálmica, o por diseminación directa a través de los espacios faciales. La comunicación extensa entre las venas facial y oftálmica ocurre en el canto de la región medial sobre el ligamento palpebral medial, donde la vena angular se anastomosa con las venas supraorbitaria y 
supratroclear. El hecho que estas venas no presenten válvulas facilita una extensa comunicación bidireccional entre la órbita, cara, cavidades nasales, senos, plexo venoso pterigoideo, y en consecuencia la rápida diseminación del proceso infeccioso entre estas áreas ${ }^{1}$.

Las infecciones de dientes premolares y molares mandibulares pueden perforar la cortical ósea externa, sobre o bajo el origen de la inserción del músculo buccinador que a su vez se relaciona con la vena facial y vena angular en la región del canto medial del globo ocular, para luego anastomosarse con las venas supratroclear y supraorbitaria, alcanzando así la órbita. La otra vía es a través de la fosa pterigopalatomaxilar o fosa infratemporal que accede a la órbita vía plexo pterigoideo y luego vena oftálmica inferior. Si las piezas dentales son antrales (sus ápices se encuentran insertos en el seno maxilar), y la afección dental se disemina más allá del saco periodontal se puede iniciar la infección tanto de músculos como de tejido conectivo adyacente; según esta teoría la infección originaria en piezas maxilares puede diseminarse a la órbita vía seno maxilar, a través de las celdillas etmoidales alcanzan el seno maxilar y luego hacia la fisura orbitaria inferior. Finalmente pueden alcanzar la órbita porque están en relación anatómica vía fosa canina y reborde inferior de la órbita².

La celulitis preseptal es la infección del tejido subcutáneo anterior al septo orbitario, es de relativa frecuencia siendo su diagnóstico y resolución rápida. La celulitis orbitaria bacteriana es la infección de los tejidos blandos posteriores al septo, mayoritariamente es de carácter grave, y su diagnóstico no está exento de complejidad, ya que puede complicarse con trombosis del seno cavernoso, meningitis, absceso cerebral y hasta la muerte. Es de etiología polimicrobiana incluyendo a los gérmenes anaerobios, y de los aerobios los más frecuentes son neumococos, Estaphylococcus aureus y Estreptococos pyogenes; en los niños menores de cinco años el microorganismo aislado con más frecuencia ha sido el Haemophilus Influenzae ${ }^{7-8}$.

El cuadro clínico característico es de inicio rápido con compromiso del estado general, fiebre, los signos orbitarios incluyen gran edema palpebral, rubor, calor, dolor a la palpación e inmovilidad palpebral, proptosis asociada también a la tumefacción palpebral, movimientos oculares restringidos y dolorosos. Si el cuadro se prolonga aparecen complicaciones corneales asociadas, hay oftalmoplejía, se presentan signos de disfunción del nervio óptico, aumento de la presión intraocular y oclusión de la arteria o la vena central de la retina que finalmente si no son diagnosticadas y tratadas oportunamente conlleva a la pérdida de la visión.

Otra complicación descrita en la literatura es el absceso orbitario, que está asociado a la celulitis orbitaria relacionada con los senos paranasales 0 traumatismos penetrantes, y menos frecuente el absceso subperióstico, localizado a lo largo de la pared lateral de la órbita tal como se presentó en el caso clínico reportado 7 .

\section{CASO CLÍNICO}

Paciente examinado en el Servicio Médico Legal, masculino de 43 años sin antecedentes mórbidos, refiere que como consecuencia de una extracción dentaria mandibular presentó cuadro infeccioso que le provocó pérdida de la visión del ojo derecho y alteración en la movilidad de la cara, de la cual ya se está recuperando.

Antecedentes consignados en las fichas: consulta a odontólogo por dolor en pieza dental №17 (tercer molar mandibular derecho), quien realiza exodoncia de dicha pieza con curetaje, hemostasia más amoxicilina comprimidos por 7 días y describe que la pieza dental $N^{0} 18$ presenta múltiples obturaciones pero es asintomática.

Cuarenta y ocho horas después refiere cefalea, dolor intenso en región malar derecha, aumento de volumen, trismus+++ y disfagia+++. Es hospitalizado con diagnóstico de flegmón facial, y absceso submandibular de origen dentario, evaluado por dentista quien no encuentra pus, deja drenaje y administra penicilina 2 millones ev.

Evoluciona tórpidamente con dolor cervical, edema hemifacial derecho, aumento de volumen progresivo desde la región malar hasta la región periocular derecha, eritema bipalpebral y fluctuación dolorosa.

Se le realiza tomografía axial computada (TAC) de cuello que demuestra absceso cervical de ori- 
gen dentario con extensión probable supramandibular. Al $4^{\circ}$ día le realizan exploración quirúrgica: incisión cervical hasta espacio visceral cervical sin evidencia de colecciones, colgajo subplatismal anterior hasta celdilla submaxilar con glándula edematosa, salida secreción purulenta en cavidad dento alveolar pieza 17 (drenaje rígido) drenaje de absceso de piso de boca, exodoncia de pieza dentaria $\mathrm{N}^{0} 18$ que da salida a pus del lecho. Se deja tubo nasotraqueal. Procedimiento realizado por cirujano maxilofacial y odontólogo. Temperatura: $37,5^{\circ} \mathrm{C}$, pulso 88 por minuto, TA: 130/80. Se le administra gentamicina $160 \mathrm{mg}$ ev/día.

Quinto día: el paciente presenta evidente exoftalmos derecho con aumento de volumen hemifacial y oftalmoplejía. Bajo anestesia troncular exploran fosa cigomática drenando abundante colección purulenta casi sin olor, se deja drenaje submentoniano, posterior al drenaje se produce una evidente disminución del exoftalmos por lo que recomiendan interconsulta urgente a especialista en oftalmología. Al día siguiente el paciente se mantiene en condiciones similares, persiste exoftalmía, odontólogo le diagnostica: absceso de fosa temporal y realizan drenaje de líquido hemopurulento de olor muy fétido. El infectólogo recomienda tratamiento con clindamicina $600 \mathrm{mg}$ ev c/8 más ceftriaxona (2 gr/día ev).

Séptimo día, el paciente se mantiene con exoftalmos en ojo derecho, trismus (+), temp. $37,2^{\circ} \mathrm{C}$, oftalmoplejía, dolor y edema hemifacial, gran eritema bipalpebral, presenta secreción purulenta conjuntival y amaurosis del ojo derecho.

Escáner de cuello y CPN al $9^{\circ}$ día muestra:

1. Colección líquida alargada que recorre la región anterior del cuello de $4 \mathrm{~cm}$ de longitud $\times 1,7 \mathrm{~cm}$ diámetro anteroposterior, que nace en región submandibular derecha y se extiende hasta el espacio parafaríngeo.

2. Segunda colección en espacio masticador a derecha con gas en su espesor que mide $2 \mathrm{~cm}$. en su eje mayor, exoftalmos derecho con importante compromiso inflamatorio, y presencia de burbujas de gas a nivel de la grasa intra y extraconal.
3. Senos maxilares y frontales adecuadamente neumatizados, vasos del cuello de morfología y calibre normal.

Se decide intervención quirúrgica para drenaje de colección, se realiza vestibulotomía superior derecha sobre orificio de drenaje previo con debridación digital paramandibular y retrocigomática hasta llegar a fosa infratemporal y hendidura suborbitaria derecha, saliendo abundante pus. Se dejan dos drenajes: suborbitario derecho y submaxilar con comunicación a piso boca, durante la intervención deciden localizar a oftalmólogo para que colabore con el drenaje retroocular 0 trasladarlo de servicio para mejorar el tratamiento. Control del paciente al día siguiente y se sugiere agregar vancomicina (ev).

Finalmente es trasladado a los 10 días con los diagnósticos:

1. Absceso piso boca operado

2. Absceso cervical operado

3. Absceso temporal

4. Exoftalmos

Es intervenido quirúrgicamente en conjunto con oftalmólogo con diagnóstico preoperatorio:

1. Absceso retroocular ojo derecho.

2. Flegmón geniano orbitario derecho.

Se consigna en protocolo: abordaje intraoral derecho pared maxilar, se retira tubo de drenaje inactivo donde se encuentra gran hematoma geniano infectado. Se explora piso orbitario sin secreción, ni colección. Se realiza el abordaje por cola de ceja, con anestesia local, decolamiento mucoperióstico de pared externa de órbita derecha, incisión lineal $1 \mathrm{~cm}$ en periostio orbitario donde se drena abundante secreción purulenta, y se realiza otra incisión subpalpebral por conjuntiva con drenaje seropurulento. Se dejan drenajes. El cultivo intraoperatorio es negativo.

Primer día posoperatorio, temperatura $36,8^{\circ} \mathrm{C}$, mejores condiciones, ojo derecho sin proptosis, gran edema bipalpebral, con quemosis. Se mantiene el esquema antibiótico y se agrega, tobramicina (col) cada 3 horas, Ibuprofeno $400 \mathrm{mg}$ cada 12 horas. 
A 15 días del posoperatorio: Menos edema palpebral y eritema, quemosis leve, permanece la restricción de la motilidad ocular, al fondo de ojo derecho: papila pálida, atrofia óptica.

Un año después: Es enviado para examen físico y oftalmológico en el Servicio Médico Legal.

Examen externo: Cicatriz quirúrgica cervical de $12 \mathrm{~cm}$ aprox y otra de $8 \mathrm{~cm}$ aprox en zona fronto ciliar derecha, con moderada paresia facial derecha.

Agudeza visual OD: Amaurosis, OI: 1 (normal).

Biomicroscopio: OD. Cicatriz blanquecina en forma de banda en sector inferior corneal. Reflejo fotomotor abolido OD. Discreta ptosis palpebral.

Fondo ojo: OD papila con atrofia óptica total.

\section{DISCUSIÓN}

El presente caso es médico legal, es por ello que se trató de no modificar los hechos y se describieron los datos más relevantes tal y como se consignaron en las fichas clínicas.

Comenzó con una infección submandibular luego de la exodoncia de un molar inferior, sin estar afectado el seno maxilar, lo que hace que su presentación sea muy poco común dentro de los casos reportados en la literatura. Las infecciones orbitarias espontáneas son raras, los pacientes sin una sinusitis previa deben someterse a la búsqueda de otro foco de infección, realizándose el examen dental para descartar la presencia de un cuerpo extraño oculto. Se debe examinar el saco lagrimal intentando obtener reflujo de material purulento para descartar la dacriocistitis. De no encontrar foco de infección deben realizarse exámenes de mayor complejidad para descartar condición de inmunosupresión. En este paciente el escáner informó una colección líquida desde la región submandibular con extensión al espacio parafaríngeo, una en el espacio masticador con gas en su espesor y otra colección retroocular derecha con burbujas de gas a nivel de la grasa intra y extraconal, de esta manera deducimos la presencia de gérmenes anaerobios y la concordancia con la bibliografía en relación a la etiología polimicrobiana de las infecciones orbitarias ${ }^{8}$.
Analizando las posibles vías de diseminación de la infección en este caso en particular, vemos que el tercer molar mandibular derecho tiene una relación directa con la inserción fija del músculo buccinador, siendo ésta, la cresta alveolar de los molares inferiores y la línea oblicua externa de la mandíbula, el músculo se relaciona hacia atrás con el ligamento pretigomaxilar 0 aponeurosis buccinatofaríngea, esta aponeurosis se relaciona íntimamente con la aponeurosis cervical superficial, por medio de la celda submandibular que a su vez se continúa por detrás con la fasciaparotídea y por delante con la aponeurosis del músculo buccinador, es así entonces como a través de estos espacios la infección se pudo diseminar a través del espacio parafaríngeo.

Hacia la órbita se pudo diseminar a través de dos vías; una, por la relación entre el músculo buccinador con la vena facial y la vena angular que se comunican en la región del canto medial del globo ocular, y se anastomosan con las venas supratroclear y supraorbitaria.

La siguiente vía es a través de la fosa pterigopalatina, que se encuentra situada inmediatamente por debajo del vértice de la órbita y comunica varios espacios entre sí, pudiendo facilitar la extensión de procesos patológicos, se comunica superiormente con la órbita a través de la parte posterior de la hendidura esfenomaxilar, lateralmente con la fosa pretigomaxilar, medialmente el espacio se comunica con las fosas nasales y con la cavidad oral a través del surco palatino mayor, contiene el segmento pterigopalatino de la arteria y vena pterigomaxilar, esta última forma parte del plexo venoso pterigomaxilar, el cual está formado por las anastomosis de las venas pterigoideas, temporales profundas, meníngeas, maseterianas y dentarias inferiores, este plexo confluye en la vena oftálmica inferior, que alcanza la órbita mediante la hendidura esfenoidal 9 (véase Figura 1), este es el recorrido aceptado por los autores, como vía de diseminación en este caso.

El paciente tuvo un cuadro con aumento de volumen progresivo hemifacial desde la región submandibular y malar hasta la región orbitaria derecha, eritema y fluctuación dolorosa que se extendió hasta el cuello, trismus, disfagia compromiso del estado general sin fiebre alta, se le realizó 
escáner que demostró un absceso cervical con extensión supramaxilar no encontrándose compromiso del seno maxilar derecho.

Están indicados entonces la incisión y drenaje del absceso en el momento que es identificado, siendo el sitio de la extracción dentaria la primera ruta de drenaje indicada. Sin embargo la propia manipulación quirúrgica, si es realizada prematuramente puede diseminar una infección localizada hacia los espacios circundantes, y eventualmente hacia la órbita ${ }^{10}$. Deben ser monitoreados los signos vitales, realizar estudios de imagen y laboratorio con cultivos de sangre utilizando las técnicas anaerobias de toma de muestra apropiadas ${ }^{11}$.

El tratamiento interdisciplinario entre oftalmólogo, otorrino y/o cirujano maxilofacial es de vital importancia. La evaluación oftalmológica precoz puede evitar secuelas como en el caso descrito y tener en cuenta una conducta terapéutica agresiva, considerando los antibióticos de amplio espectro al igual que para los anaerobios 6 .

La patología dental como la fuente de partida del absceso subperióstico orbitario aquí presentada, a diferencia de la mayor parte de los abscesos, hace que la penetración antibiótica no haya sido óptima, ya que es un espacio relativamente avascular, en el que los microorganismos están secuestrados, por esta razón el absceso subperióstico orbitario en particular requiere de una acción quirúrgica agresiva antes que la observación a la respuesta antibiótica por varios días ${ }^{12}$.

Los mecanismos de pérdida visual debido al absceso subperióstico merecen una particular atención por sus implicaciones terapéuticas. Las causas pueden ser neuritis óptica séptica, lesiones embólicas o trombóticas en el suplemento vascular del nervio óptico, retina 0 coroides ${ }^{13-14}$. Sin embargo la elevación rápida y sostenida de la presión intraorbitaria es la que juega el rol de mayor relevancia y es potencialmente reversible si se trata precozmente. En estos casos la isquemia es producida por la disminución neta de la presión de perfusión, que acompaña a la elevación de la presión intraocular, es decir la presión de la arteria orbitaria cae y la presión venosa aumenta provocando finalmente la muerte del tejido $0^{15}$.

El curso natural de los abscesos orbitarios pueden oscurecer la interpretación de los hallazgos clínicos, a pesar de que la colección purulenta puede dirigirse hacia adelante y drenar espontáneamente a través de la piel del párpado hacia el ángulo medio cantal, también puede extenderse a la región posterior y provocar una trombosis del seno cavernoso, un absceso cerebral o hacia el espacio subperióstico; tal como sucedió en este caso en particular donde al mismo tiempo el cono retroocular completo se vio comprometido provocando el síndrome del vértice orbitario; con los signos que incluyeron exoftalmos, oftalmoplejía, blefaroptosis, midriasis, trastornos de la sensibilidad; y la disfunción del nervio óptico con la consecuente atrofia óptica ${ }^{16}$.

\section{CONCLUSIÓN}

En la práctica médica habitual, no es frecuente que ocurran casos como el descrito, tal como lo evidencia la literatura hay muy pocos pacientes reportados (tres casos en nuestra revisión) con la presencia de atrofia óptica tras la extracción de una pieza dental mandibular; pero anatómicamente estamos expuestos siempre a la posibilidad de una complicación como la presentada.

Podemos concluir que una vez más es fundamental el tratamiento interdisciplinario entre oftalmólogos, otorrinos y maxilofaciales para abordar este tipo de pacientes. El otorrino está familiarizado con el abordaje de la órbita en diversas patologías tanto infecciosas como tumorales que son comunes con los oftalmólogos.

Aunque nuestro propósito inicial fue presentar el caso por lo interesante y explicar las vías de diseminación específicas, pensamos que el tratamiento en estos casos debe ser con antibióticos de amplio espectro que cubran gérmenes gran positivos y anaerobios, proponemos ceftriaxona $y$ clindamicina endovenosa en altas dosis desde el inicio ya que éstos atraviesan la barrera hematoencefálica, también usamos la vancomicina aunque difunde poco al SNC. No es nuestra intención en este artículo explicar vías de abordaje quirúrgico, preferimos dejar que sea motivo de otra discusión.

El tratamiento oportuno y eficaz dentro de las primeras 72 horas podría haber evitado la disemi- 


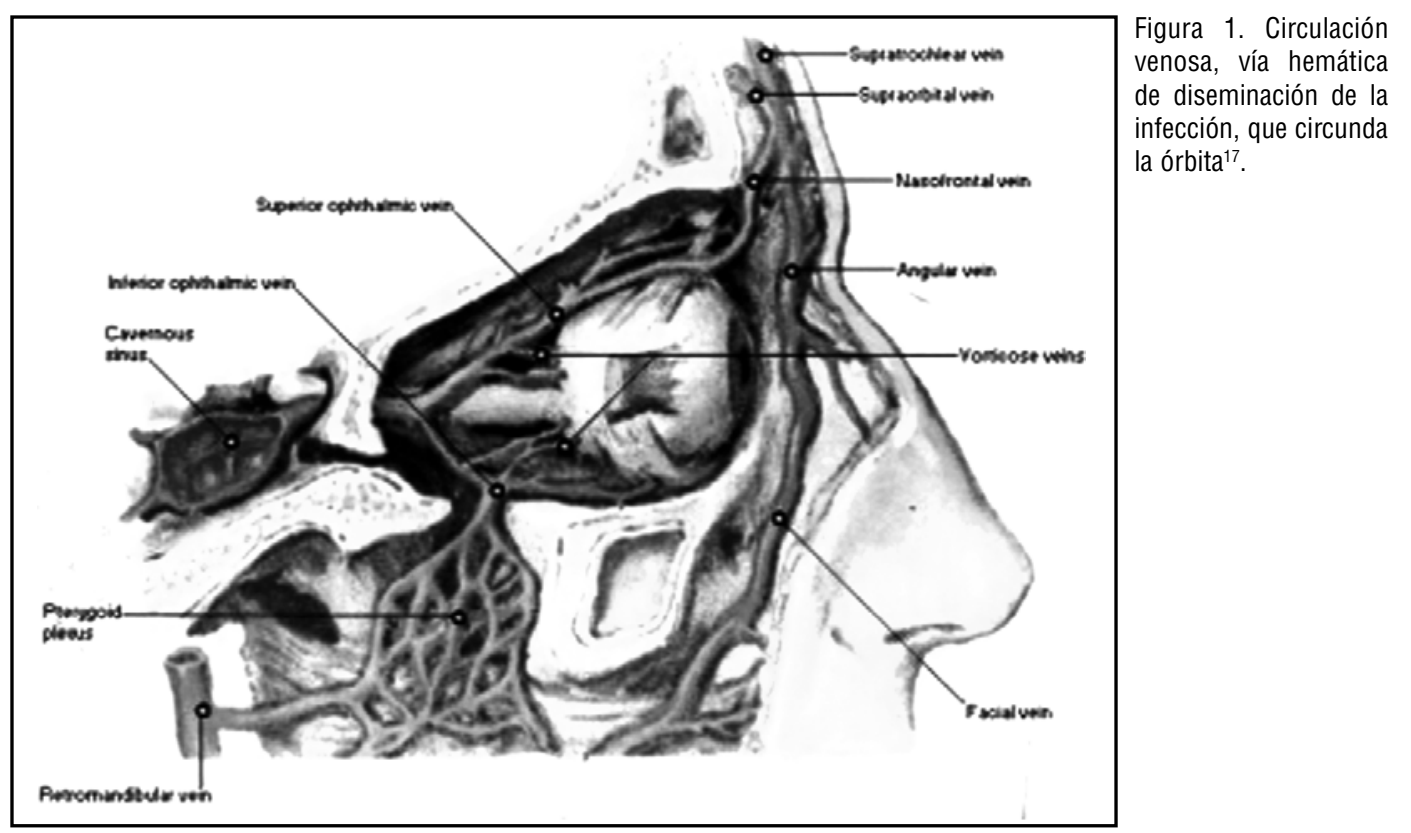

nación de la infección hacia la órbita con la consecuente pérdida definitiva de la visión. La comunicación efectiva interdisciplinaria entre los profesionales involucrados evita complicaciones de tipo médico-legales y finalmente secuelas irreversibles para el paciente.

\section{BIBLIOGRAFÍA}

1. Stubinger S, LeigGener C. "Intraorbital abscess, a rare complication alter maxillary molar extraction, Case Report". J of American Dental Association 2005; 136: 921-25.

2. Zachariades N, Vairaktaris E. "Orbital abscess: Visual loss following extraction of a tooth- Case Report". Oral Surg Oral Med Oral Pathol Oral Radial Endod 2005; 100: E70-3.

3. Allan BP, Egbert MA. "Orbital abscess of odontogenic origin. Case Report and review of the literature". J Oral Maxilofac Surge 1991; 20: 268-70.

4. GoLd RS, SILver L. "Parasinusitis, orbital cellulitis, and blindness as sequelae of delayed treatment of dental abscess". J Oral Surg 1974; 32: 40-3.

5. Miller EH, Kassebaum DK. "Managing periorbitalspace abscess secondary to dent alveolar abscess. A case report". JADA 1995; 126: 469-72.

6. O'Ryan F, Diloreto D. "Orbital infection: clinical and radiographic diagnosis and surgical treatment”. J Oral Maxilofac Surg 1988; 46: 991-7.

7. KanSKI JJ. Oftalmología Clínica. $4^{\text {a }}$ Edición Ed. Harcourt. 2000; 497-500.

8. Krohel GB, Krauss HR, Christensen Re. "Orbital Abscess". Arch Ophthalmol 1980; 98: 274-76.

9. Figún ME, Garino RR. Anatomía odontológica funcional y aplicada. $2^{\mathrm{a}}$ Edición Ed. El Ateneo. 2001; 63-75.

10. Janakarajah N, Sukumaran K. "Orbital cellulitis of dental origin: case report and review of the literature". Br J Oral Maxilofac Surg 1985; 23 : 140-5.

11. Henry CH, Hughes CV, Larned DC. "Odontogenic infection of the orbit". J Oral Maxilofac Surg 1992; 50: 172-8.

12. Morgan PR, Morrison WV. "Complications of frontal and ethmoid sinusitis". Laryngoscope 1980; 90: 661-6.

13. AmIEs DR. "Orbitalcellulitis". J Laryngol Otol 1974; 88: 559-64.

14. EL Shewr TM. "Acute infarction of the choroid and retina: A complication of orbital cellulitis". Br J Ophthalmol 1973; 57: 204-5. 
15. Gerald JH. "Subperiosteal abscess of the orbit". Arch Ophthalmol 1983; 101 (5): 75157.

16. Palomar FP. Neurooftalmología, exploración, pruebas y diagnóstico.2 Edición Ed. Elsevier Masson. 2008; 72-77.

17. NetTer FH. Atlas de Anatomía. $3^{\circ}$ Edición Ed. Masson. 2003.

Dirección: Dra. Lupe Salado Rumbaut

Avda. 11 de Septiembre 1881, Oficina 920

E mail: secretaria@sochiorl.cl 


\title{
Pilomatrixoma nasal
}

\author{
Nasal pilomatricoma

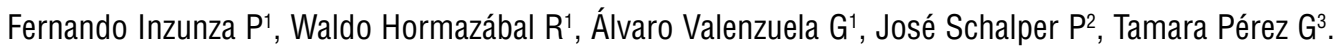

\section{RESUMEN}

Se expone el caso de un paciente de 1 año 3 meses, quien presenta un tumor subcutáneo nasal, el cual estaba rotulado como hemangioma cavernoso. Tras su extirpación completa se diagnostica un pilomatrixoma, derivado de la matriz pilosa. Se presenta el caso como diagnóstico diferencial de tumores subcutáneos nasales.

Palabras clave: Pilomatrixoma, pilomatrixoma nasal.

\begin{abstract}
The case of a 15 month-old patient that presented a nasal subcutaneous tumor, which was diagnosed as cavernous hemangioma is discussed. After its complete extirpation, a pilomatricoma was diagnosed, derived from the pilosa matrix. The case is presented as a differential diagnosis of nasal subcutaneous tumors.
\end{abstract}

Key words: Pilomatricoma, nasal pilomatricoma.

\section{INTRODUCCIÓN}

Los tumores cutáneos calcificados han sido descritos desde tiempos antiguos, Galeno en el 200 d.C., es el primero que lo menciona, Malherbe en 1905, I0 describe completamente dando su nombre al tumor ${ }^{1}$. Finalmente en 1961 Forbis y Helmig lo rotulan como pilomatrixoma ya que deriva de la matriz pilosa².

Estos tumores son infrecuentes de ver en nuestra especialidad, sin embargo están extensamente descritos en revistas dermatológicas, aunque por su ubicación $\left(90 \%\right.$ en cabeza y cuello) ${ }^{3}$ deberíamos tener más reportes.

\section{CASO CLÍNICO}

Paciente varón de 1 año 3 meses, sin antecedentes mórbidos de importancia, quien presenta una le- sión tumoral en el dorso nasal, de aproximadamente 10 meses de evolución, tamaño $3 \times 3 \mathrm{~cm}$., no sensible, coloración violácea, crecimiento exofítico y con sangrados frecuentes (Figura 1).

Fue evaluado previamente por dermatólogos, quienes lo habían interpretado como un hemangioma cavernoso, siendo la conducta expectante.

Dentro de los exámenes destaca una ecografía, descrita como un nódulo subcutáneo hiperecogénico heterogéneo, con zonas hiperecogénicas centrales, que no fueron interpretados como microcalcificaciones.

En la tomografía computada (TC) (Figura 2) se informa como una lesión exofítica altamente vascularizada dependiente de ambas arterias faciales, sin calcificaciones en su interior, de $28 \times 25 \mathrm{~mm}$.

Ambos exámenes concluían como impresión diagnóstica un hemangioma cavernoso.

Dado que el tumor seguía creciendo en forma rápida se decide su resección, la cual se logra

\footnotetext{
Médico Otorrinolaringólogo, Hospital Las Higueras, Talcahuano.

Médico Anatomopatólogo, Hospital Las Higueras, Talcahuano.

Médico Inmunólogo, Centro de Alergia e Inmunología.
} 
realizar en forma completa, cubriendo el defecto cutáneo con la piel sana de la base de implantación (Figura 3). No se realizó embolización previa ya que según la opinión del radiólogo intervencionista y del equipo quirúrgico el tumor era de fácil extracción y los riesgos de la embolización a ese nivel eran mayores que los potenciales beneficios.

El estudio histopatológico es compatible con un pilomatrixoma (Figuras 4 y 5 ).

La evolución del paciente ha sido satisfactoria, con un muy buen resultado estético y ausencia de recidiva (Figura 6).

\section{DISCUSIÓN}

El pilomatrixoma o epitelioma calcificado de Malherbe, en un tumor subcutáneo de origen ectodérmico, derivado del folículo piloso. Habitualmente benigno y de crecimiento lento, suelen ser únicos y pueden tener una consistencia firme 0 pétrea y una coloración rosada, azulada 0 violácea ${ }^{4,5}$.

Su incidencia es de 1/1.000 de todos los tumores cutáneos, puede aparecer a cualquier edad aunque tiene 2 picos de incidencia: en la infancia y adolescencia (5-15 años) y en el adulto (50 y 65 años) $)^{3}$.

La localización en $90 \%$ de los casos es en cara, cuello y extremidades superiores ${ }^{3}$, aunque se han descrito otras localizaciones como extremidades inferiores y paratesticulare ${ }^{6-8}$.

Estos tumores miden habitualmente entre $0,5 \mathrm{y}$ $5 \mathrm{~cm}$., aunque se han descrito mayores a $15 \mathrm{~cm}$. Se han descrito casos múltiples asociados a distintos síndromes: síndrome del nevo epidérmico, Turner, Gardner, enfermedad celíaca, distrofia miotónica, trisomía 9, carcinoma medular de tiroides, en todo caso su incidencia asociada a estos síndromes es inferior al 3,5\%9.

Las variedades descritas de este tumor son: exofítica, bulosa, linfangiectásica, anetodérmica y perforante ${ }^{10,11}$. También pueden tener una degeneración maligna aunque muy rara ${ }^{12}$.

El diagnóstico rara vez se hace por la clínica, aunque puede sospecharse, siendo el estudio histopatológico el que da el diagnóstico definitivo, aunque puede confundirse en biopsias parciales con carcinoma de células basales ${ }^{13}$.

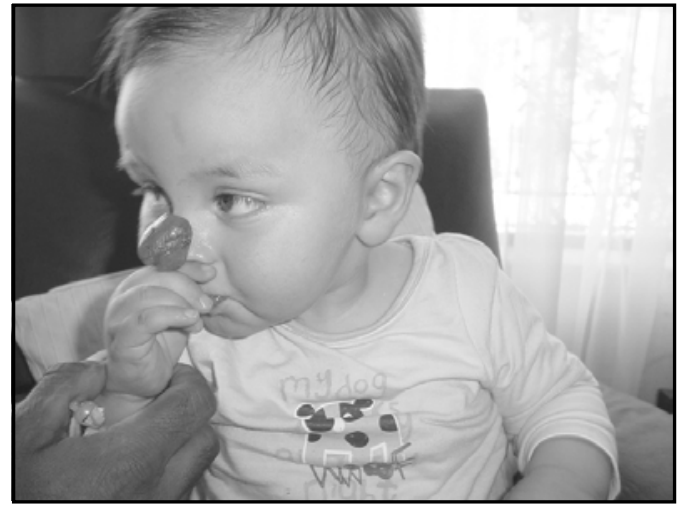

Figura 1.

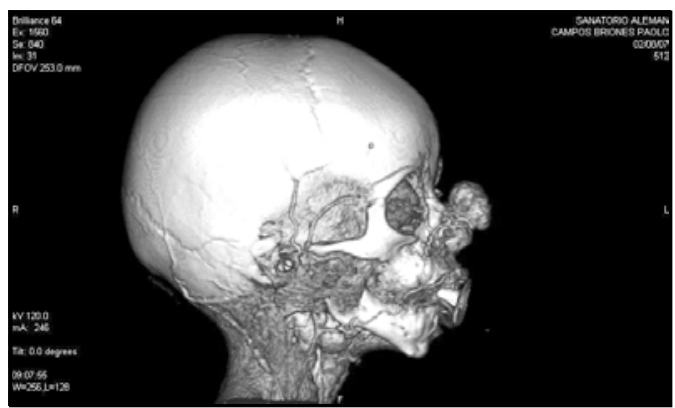

Figura 2.

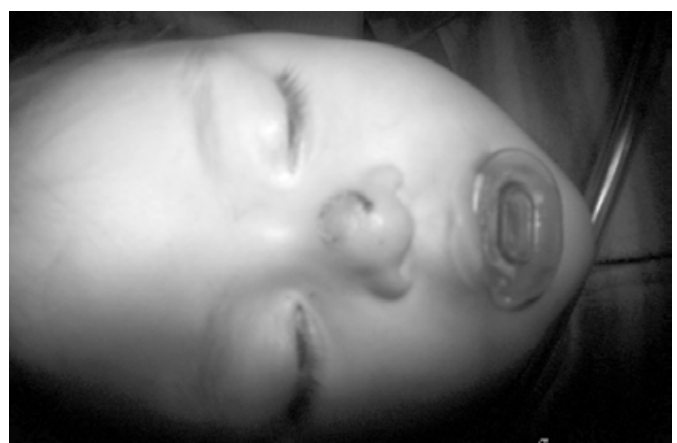

Figura 3.

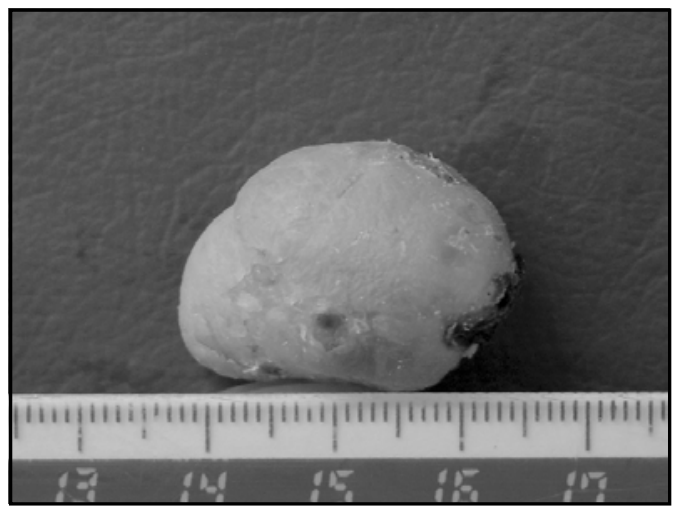

Figura 4. 


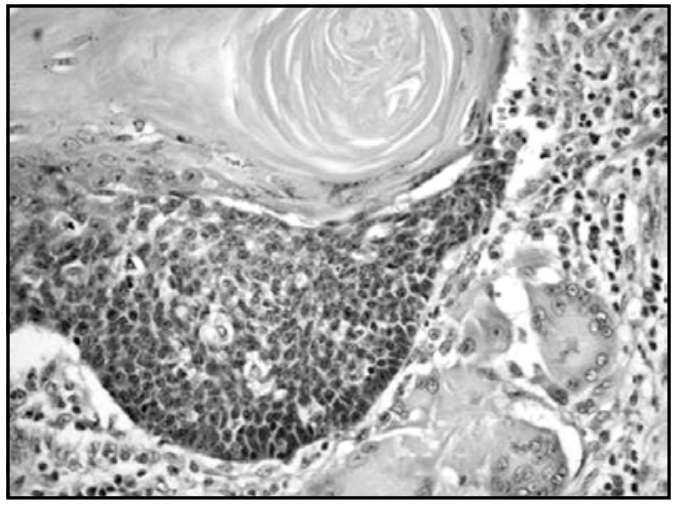

Figura 5.

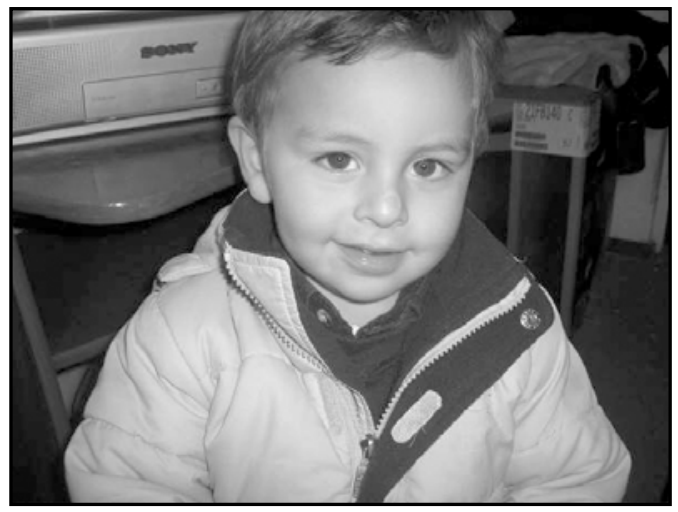

Figura 6.

Dentro de los diagnósticos diferenciales tenemos el quiste dermoide, hemangioma, granulomatosis, queratosis folicular, papiloma, lipomas calcificados, tricoepitelioma, nevus ${ }^{14}$.

La imagenología puede aportar al diagnóstico, mostrando en la ecografía de alta resolución o en la TC un nódulo bien definido con un halo parcialmente calcificado, con microcalcificaciones centrales $^{3}$.

En la resonancia magnética (RM) muestra un tumor con una buena definición de sus márgenes con alta intensidad en la secuencia T1.

La histopatología característica de estos tumores lo constituye una cápsula de tejido conectivo que rodea islotes de células basofílicas con nucleolos prominentes y acúmulos de queratina, también se ven células fantasmas esosinofílicas que carecen de núcleo. También están presentes células gigantes tipo cuerpo extraño y células escamosas nucleadas, aunque éstas son menos específicas $^{14,15}$.

Además se encuentran calcificaciones en $70 \%$ y osificación en $20 \%{ }^{16}$.

En la inmunohistoquímica estos tumores se marcan con la proteína S100, y el anticuerpo LEF-1 (un marcador para las células de la matriz pilosa) ${ }^{17}$.

Estudios recientes muestran que existen mutaciones en el gen CTNNB1, el cual está directamente implicado con la desregulación beta-catenina/LEF, sindicado como la principal causa de tumorogénesis de la matriz pilosa ${ }^{18}$.

El tratamiento de elección es la excisión quirúrgica completa incluso con un margen de seguridad de 1-2 cm. También se han reportado resecciones con láser de $\mathrm{CO} 2$ con buenos resultados ${ }^{19}$.

\section{BIBLIOGRAFÍA}

1. Julian C, Bowers PW. A Clinical review of 209 pilomatricomas. J Am Acad Dermatol 1998; 39: 191-5.

2. Camiña I, Lapetra C, Rueda JA y cols. Múltiples pilomatrixomas asociados a enfermedad celíaca. Anales de Pediatría 2004; 60: 381-3.

3. Whittle $C$, Martínez $W$, Baldassare $G$ y col. Pilomatrixoma: Diagnóstico por ultrasonido. Rev Méd Chile 2003; 131: 735-40.

4. Alper S, RehA Y, IpeK I et Al. Atypical presentation of pilomatrixoma: A case report. Dermatol Surg 2002; 28: 603-5.

5. Yong-Kwang T. Exophytic pilomatrixoma. Ped Dermatol 2003; 20: 373.

6. Sari A, Yavuzer R, ISIK I et Al. Atypical presentation of pilomatricoma: a case report. Dermatology Surg 2002; 37: E20.

7. Diomedi F, Francalanci $P$, Boldrini $R$ y cols. Paratesticular pilomatricoma: a new location. Ped Surg Int 2001; 17: 652-3.

8. Khammash M, Todd D, AbalKhall A. Concurrent pilomatrix carcinoma and giant pilomatrixoma. Aust J Dermatol 2001; 42: 120-3.

9. Rivera M et Al. Pilomatrixomas múltiples asociados a distrofia miotónica y a carcinoma medular de tiroides. Med Cut 1989; 17: 395-398.

10. Del Pozo J, Martínez W, Yebra Pimentel Mt et al. Lymphangiectatic variant of pilomatricoma. J Eur Acad Dermatol Venérelo 1999; 8: 88-90. 
11. Takamitsu 0, Yuko N, Shinchi W. Perforating pilomatricoma in process of total elimination. $J$ Am Acad Dermatol 2003; 49: 146-7.

12. Waxtein L, Vega E, Alvarez L et al. Malignant pilomatricoma: a case report. Int J Dermatol 1998; 37: 538-40.

13. Seitz B, Holbach LM, Naumann GO. Pilomatrixoma of the eyelids. Clinical differential diagnosis and follow-up. Report of 17 patients. Ophthalmologe 1993; 90(6): 746-9.

14. Vogelbruch M, Rutten A, Bocking A, Kapp A, Kiehl P. Differentiation between malignant and benign follicular adnexal tumors of the skin by DNA image cytometri. Br J Dermatol 2002; 146: 238-43.

15. Wang J, Cobb CJ, Martin SE et al. Pilomatrixoma: clinicopathologic study of 51 cases with emphasis on cytologic features. Diagn Cytopathol 2002; 27: 167-72.
16. Viero R, Tani E, Skoog L. Fine needle aspiration (FNA) cytology of pilomatrixoma: report of 14 cases and review of the literature. Cytopathol 1999; 10: 263-9.

17. Kurokawa I, Kusumoto K, Bessho K et al. Immunohistochemical expression of bone morphogenetic protein-2 in pilomatricoma. Brit J Dermatol 2000; 143: 754.

18. Hasannein A, Glanz S, Kessler H et al. BetaCatenin is expressed aberrantly in tumors expressing shadow cells. Pilomatricoma, craniopharyngioma, and calcifying odontogenic cyst. Am J Clin Pathol 2003; 120: 732-6.

19. Pirouzmanesh A, Reinisch JF, González-Gómez I, Smith EM, Meara JG. Pilomatrixoma: a review of 346 cases. Plast Reconstr Surg 2003; 112(7): 1784-1789. 


\title{
Intolerancia a la aspirina en pacientes con poliposis nasal y asma bronquial
}

\author{
Aspirin intolerante in patients with nasal polyps and asthma
}

Pilar Gajardo 01, Ximena Fonseca $A^{2}$.

\begin{abstract}
RESUMEN
La tríada de la aspirina, caracterizada por intolerancia a la aspirina, asma bronquial y poliposis nasal, fue descrita inicialmente por Widal en 1922. La prevalencia de intolerancia a la aspirina en la población general es de aproximadamente $6 \%$, pero estudios han revelado que hasta $78 \%$ de los pacientes con poliposis nasal padecen la triada. La presentación clínica consiste en un patrón característico evolutivo de la aparición de los síntomas, presentándose en primer lugar rinitis, luego poliposis nasal, asma bronquial y finalmente IA. Si bien es sabido que esta patología corresponde a una pseudoalergia, donde ocurre una degranulación inespecífica de los mastocitos, los mecanismos fisiopatológicos que gatillan esta degranulación no están totalmente dilucidados, siendo la hipótesis más aceptada actualmente aquella que guarda relación con las modificaciones en el metabolismo del ácido araquidónico causadas por la aspirina. Actualmente no existen exámenes de laboratorio para la confirmación diagnóstica de intolerancia a la aspirina, por lo que frente a la sospecha clínica de esta patología debe someterse al paciente a pruebas de provocación para hacer el diagnóstico certero de esta enfermedad, siendo la más utilizada la prueba de provocación con aspirina oral.
\end{abstract}

Palabras clave: Intolerancia a la aspirina, poliposis nasal, triada de la aspirina.

\begin{abstract}
The aspirin triad, characterized by aspirin intolerance, bronchial asthma and nasal polyposis was first described by Widal in 1922. Prevalence of aspirin intolerance in the general population is near $6 \%$, but studies have shown that $78 \%$ of the patients with nasal polyps suffer from the triad. Clinical presentation consists of a characteristic evolutive pattern, with rhinitis appearing first, then nasal polyps, bronchial asthma and finally aspirin intolerance. Even though it is well known that this pathology corresponds to pseudoallergy, where unspecific mast cell degranulation occurs, the physiopathologic mechanisms that trigger this degranulation are not completely understood. The most accepted hypothesis involves aspirin-induced modifications in the metabolism of arachidonic acid. Currently there are no in vitro tests available for aspirin intolerance
\end{abstract}

Médico, Tesista de magíster en Ciencias Médicas, Mención Inmunología, Universidad de Chile.

2 Médico Otorrinolaringólogo, Departamento de Otorrinolaringología, Hospital Clínico de la Pontificia Universidad Católica de Chile. 
diagnosis, so if this pathology is suspected, a provocation test with aspirin is necessary to confirm the diagnosis, oral provocation test being the most frequently used in clinical practice.

Key words: Aspirin intolerance, nasal polyposis, aspirin triad.

\section{INTRODUCCIÓN}

Desde su introducción en 1897 el ácido acetil salicílico (AAS), conocido comercialmente como aspirina se ha transformado en uno de los medicamentos más utilizados en el mundo, debido a sus conocidos efectos analgésicos, antiinflamatorios e inhibitorios de la agregación plaquetaria, transformándose en la primera opción para la profilaxis de eventos cardiovasculares. En general la aspirina es bien tolerada por la mayoría de los pacientes, pero se han descrito una gama de efectos adversos relacionados con el uso de este medicamento, que van desde molestias gastrointestinales hasta la poco conocida, pero potencialmente severa intolerancia a la aspirina $(I A)^{1}$.

\section{DEFINICIONES}

Las reacciones adversas a drogas pueden ser dependientes 0 independientes de la dosis administrada. Las primeras son generalmente causadas por las propiedades farmacológicas del medicamento, son predecibles y tienen una baja mortalidad. Por el contrario, las reacciones independientes de la dosis del medicamento, son poco comunes, no se relacionan con las propiedades farmacológicas de la droga, son impredecibles y tienen una alta mortalidad ${ }^{2}$. Dentro de este último tipo de reacciones se encuentran las reacciones alérgicas, mediadas por anticuerpos tipo IgE específicos, las cuales se producen generalmente frente a la segunda exposición al fármaco, y las reacciones pseudoalérgicas, las cuales pueden ocurrir con la primera ingesta del medicamento. Estas últimas se caracterizan por una degranulación del mastocito no mediada por $\mathrm{lgE}$, sino por estímulos inespecíficos que favorecen la liberación de histamina y otros mediadores. Dentro de las reacciones pseudoalérgicas se encuentra la IA, que puede presentarse con síntomas respiratorios (rinitis, obstrucción bronquial) o cutáneos (urticaria y angioedema), siendo estos últimos la forma más frecuente de presentación ${ }^{3}$.

Se ha descrito un tipo de asma caracterizado por episodios de hiperreactividad bronquial severos secundarios a la ingesta de aspirina y otros antiinflamatorios no esteroidales (AINES), que se ha llamado asma inducido por aspirina (AIA $)^{4}$. En la literatura también existe la nomenclatura de enfermedad respiratoria exacerbada por aspirina (EREA), que engloba a los síntomas nasales y bronquiales empeorados por el consumo de éste y otros AINES.

En 1922 Widal y colaboradores fueron los primeros en describir la asociación entre poliposis nasal (PN), asma bronquial e IA. Posteriormente en 1967 Samter y Beers definieron la «tríada de la aspirina» caracterizada por intolerancia a la aspirina, asma bronquial y poliposis nasal ${ }^{5}$. Este conjunto de síntomas es también conocido como «enfermedad de la aspirina» 0 «tríada de Samter».

\section{EPIDEMIOLOGÍA}

Se ha descrito una prevalencia de IA en la población general de $0,6 \%$ a 2,5\% ${ }^{4}$. Un estudio finlandés estudió la prevalencia de IA en cuatro mil trescientos adultos utilizando un cuestionario específico. En este estudio se describe una prevalencia general de $5,7 \%$, mientras que la prevalencia de IA que se presenta con síntomas respiratorios fue de $1,2 \%{ }^{6}$. La prevalencia de AIA en la población general es de aproximadamente $0,2 \%$, pero en los pacientes con IA aumenta a $16,4 \%{ }^{3}$. Este subgrupo de pacientes representa entre el $8 \%$ y el $20 \%$ de pacientes asmáticos adultos ${ }^{7}$. Tanto la IA como el AIA son más frecuentes en mujeres, con una relación de 2,5:1. 
Entre $1 \%$ y $4 \%$ de la población general presenta PN, la prevalencia aumenta a $16,5 \%$ en el subgrupo de pacientes con $a s m a^{6}$ y a $60 \%$ en los pacientes con $I A^{8}$.

Finalmente, la prevalencia de la tríada de la aspirina en la población general es de aproximadamente $2 \%^{3}$. De los pacientes con IA $78 \%$ tiene la tríada ${ }^{1}$. Entre $48 \%$ y $95 \%$ de los pacientes con AIA presentan $\mathrm{PN}^{9}$ y de los pacientes con PN hasta el $70,8 \%$ tiene IA y asma bronquial ${ }^{10}$.

\section{PRESENTACIÓN CLÍNICA}

La tríada de la aspirina se presenta clínicamente como una enfermedad evolutiva, con un patrón característico en la aparición de los síntomas. El cuadro clínico se inicia típicamente entre los treinta y cuarenta años de edad, con síntomas de rinitis persistente, los cuales aparecen generalmente luego de una infección viral. Alrededor de dos años después de iniciada la rinitis aparece la PN, el asma puede desarrollarse dentro de tres meses a cinco años de iniciada la rinitis y finalmente los síntomas respiratorios inducidos por aspirina pueden aparecer a lo largo de todo el curso de la enfermedad ${ }^{11}$. Este cuadro clínico no sólo es más frecuente en mujeres, sino que en ellas se presenta más precozmente y evoluciona con mayor agresividad.

Una típica reacción nasal inducida por aspirina ocurre dentro de treinta minutos a dos horas de ingerido el medicamento. Sus síntomas clásicos son rinorrea serosa y congestión nasal. Al contrario de la rinitis alérgica, edema y estornudos no son predominantes ${ }^{5}$.

Con respecto al AIA se ha descrito que $50 \%$ de los pacientes sufre de un asma severa, y requieren de corticoides sistémicos para el control de su enfermedad $^{12}$. Esta severidad puede estar asociada a la mayor prevalencia de PN que presentan estos pacientes, ya que esta enfermedad produce una mayor obstrucción de la vía aérea, o a factores solubles que afectan tanto la mucosa nasal como la mucosa bronquial.

La influencia de atopía en el desarrollo de la enfermedad se estudió en un trabajo multicéntrico realizado en Europa el cual reveló que un tercio de Ios pacientes con AIA presentan atopía. Este subgrupo de pacientes atópicos presenta síntomas de rinitis y asma bronquial más precozmente que los pacientes no atópicos, no obstante, el diagnóstico de IA y PN fue a edades similares que los pacientes no atópicos ${ }^{7}$.

Histológicamente la vía aérea de pacientes con AIA muestra signos de inflamación persistente similares a los presentes en todos los pacientes asmáticos, sin embargo, en biopsias bronquiales de pacientes con AIA los eosinófilos son cuatro veces más numerosos que en pacientes con asma tolerante a la aspirina, y quince veces más numerosos que en biopsias de mucosa normal ${ }^{13}$.

Los pacientes portadores de la tríada representan el $7 \%$ de los casos de rinosinusitis crónica ${ }^{14}$. La PN en los pacientes con IA se caracteriza por tener un comportamiento agresivo, ocupando casi la totalidad de las fosas nasales ${ }^{5}$. La extensión de la rinosinusitis es mayor en los pacientes con IA en comparación con aquellos tolerantes a la aspirina que presentan un cuadro clínico de igual severidad $^{10}$.

El aspecto macroscópico de los pólipos en los pacientes con la tríada es similar al de otros tipos de $\mathrm{PN}^{5}$. A nivel microscópico, los cilios de la mucosa nasal son normales desde un punto de vista estructural y funcional. No se ha observado ningún efecto de la aspirina en la función de los cilios de los pacientes con la tríada de la aspirina ${ }^{15}$.

Con respecto a sujetos normales, pacientes con rinitis sensible a la aspirina tienen un mayor número de eosinófilos totales y activados, mayor número de mastocitos, linfocitos $\mathrm{T}$ activados y macrófagos. Adicionalmente, en estos pacientes se ha visto un mayor número de células que expresan ARN mensajero de interleuquina 5 (IL-5), una citoquina importante en la quimiotaxis de eosinófilos ${ }^{16,17}$.

\section{FISIOPATOLOGÍA}

Los mecanismos fisiopatológicos de la IA y los síntomas respiratorios asociados a ella no están totalmente dilucidados. La hipótesis más aceptada actualmente tiene relación con las modificaciones en el metabolismo del ácido araquidónico (AA) causadas por la aspirina y otros AINES. 
El $A A$ es un ácido graso esencial que se encuentra esterificado en los fosfolípidos de la membrana plasmática celular de eosinófilos y mastocitos. Existen dos vías de metabolización del AA, la vía de la cicloxigenasa (COX) y la vía de la lipoxigenasa (LOX), las cuales dan origen a distintos eicosanoides (Figura 1). La enzima COX existe en dos isoformas, COX-1 que se expresa de manera constitutiva, y COX-2 la cual es inducible en condiciones inflamatorias. Bajo condiciones fisiológicas los metabolitos producidos por la vía de COX son prostaglandina E2 (PGE2), la cual cumple un importante rol en la inhibición de la liberación de cisteinil leucotrienos (cys-L) e inhibe la broncoconstricción, prostaglandina 12 (prostaciclina) y tromboxanos. En condiciones inflamatorias también se produce prostaglandina F2 y prostaglandina D2 (PGD2), la cual produce vasodilatación, broncoconstricción y es un potente atrayente para eosinófilos ${ }^{1}$.

Mediante la vía de la LOX el AA se convierte en leucotrieno A4 (LTA4), el cual puede ser hidrolizado, dando origen al leucotrieno B4 (LTB4), el cual atrae y activa a neutrófilos. El LTA4 puede también ser convertido en cys-L (LTC4, LTD4 y LTE4) mediante la enzima LTC4 sintasa (LTC4S). Los cys-L aumentan la permeabilidad vascular, favorecen la exudación del plasma y formación de edema, atraen eosinófilos, estimulan la hiperproducción de mucus por células bronquiales y estimulan la broncoconstricción.

Una de las teorías con respecto a la alteración del metabolismo del AA en pacientes con la tríada de la aspirina plantea que la aspirina y otros AINES inhibirían a la enzima COX-1, inclinando el metabolismo del AA hacia la vía de LOX, con el consiguiente aumento de los niveles de cys- $L$ y por ende sus acciones perjudiciales a nivel nasal y bronquial'. Con respecto a esta teoría existe un estudio que muestra que los pacientes asmáticos tolerantes e intolerantes a la aspirina presentan niveles basales elevados de cys-L, en comparación con sujetos sanos, y que luego de un estímulo bronquial con aspirina, los pacientes intolerantes a la aspirina muestran un aumento aún mayor de los niveles de cys-L. Este mismo estudio muestra que los pacien-

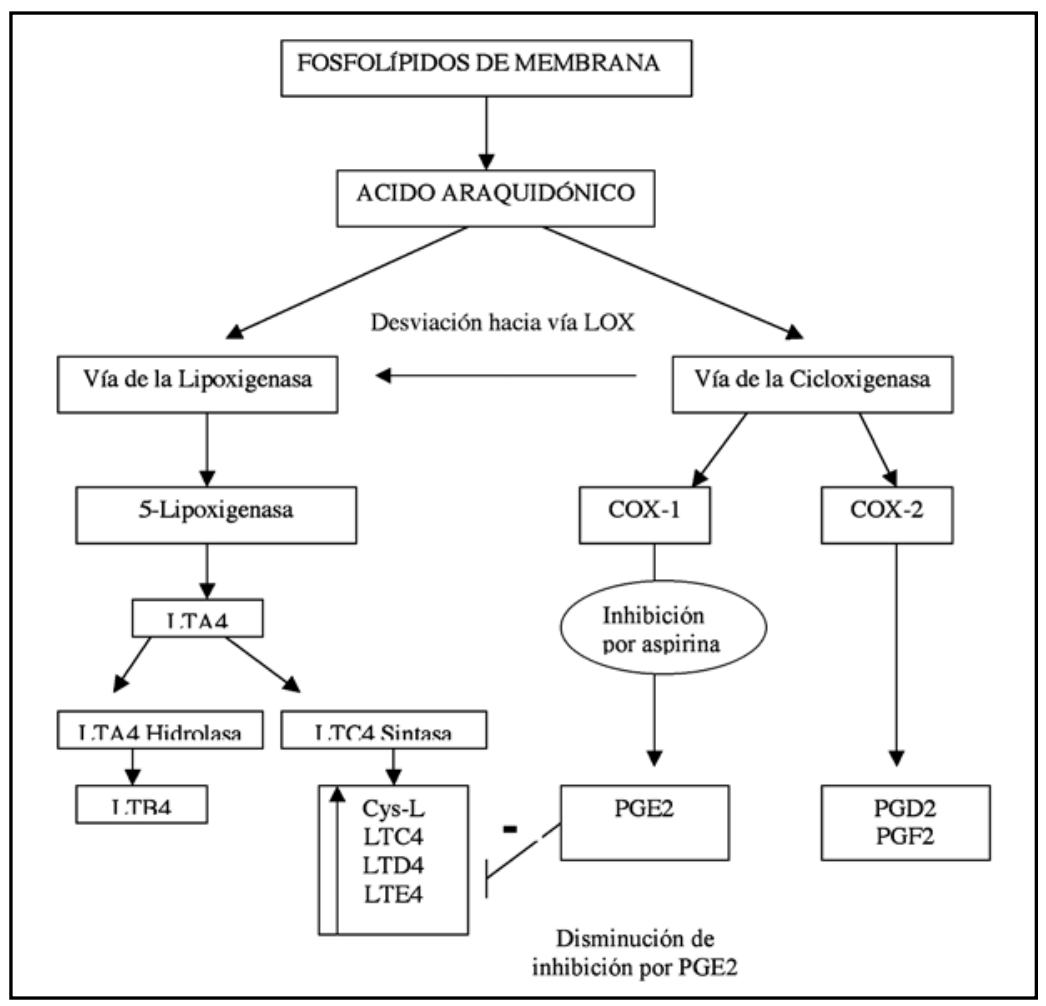

Figura 1. Metabolismo del ácido araquidónico y modificaciones causadas por la aspirina. 
tes con AIA tienen niveles basales disminuidos de PGE2 ${ }^{18}$.

Los pacientes con AIA presentan niveles elevados de cys- $L$ en orina, los cuales se asocian con la presencia de PN y rinosinusitis crónica, y disminuyen luego de cirugía sinusal, sugiriendo que sería la mucosa nasosinusal la fuente principal de cys-L en estos pacientes ${ }^{19}$.

Se ha observado que los pacientes con AIA presentan un aumento en el número de células que expresan la enzima LTC4S en biopsias bronquiales. La expresión de esta enzima en pacientes con AlA es cinco veces mayor que en pacientes con asma tolerante a la aspirina y dieciocho veces mayor en comparación con sujetos normales ${ }^{20}$. Estudios recientes también muestran un aumento de expresión de LTC4S en eosinófilos presentes en la mucosa de pólipos nasales de pacientes con AIA ${ }^{21}$.

Finalmente un estudio realizado en Inglaterra mostró que en los pacientes con rinosinusitis crónica e IA las células inflamatorias de la submucosa nasal tienen una mayor expresión selectiva del receptor de cys-L tipo 1(RCysLT1), la cual disminuye con el tratamiento de desensibilización con aspirina. Los autores proponen que junto con el aumento de cys-L, la mayor expresión de este receptor jugaría un rol importante en la fisiopatología de la enfermedad $^{22}$.

Con respecto a la búsqueda de marcadores genéticos de esta enfermedad, se ha descrito una asociación entre el alelo HLA-DPB1 0301 y el fenotipo de AIA en individuos coreanos y pola$\cos ^{1}$. También se han descrito polimorfismos de un único nucleótido en genes que codifican para enzimas y receptores relacionados con el metabolismo del AA en pacientes con AIA, como es el caso de la enzima $\mathrm{LTC}_{\mathrm{S}} \mathrm{S}^{23}$ y el receptor de cys-L tipo 2.

\section{DIAGNÓSTICO}

Actualmente no existen exámenes de laboratorio para la confirmación diagnóstica de IA, por lo que frente a la sospecha clínica de esta patología debe someterse al paciente a pruebas de provocación con aspirina para hacer el diagnóstico certero de esta enfermedad ${ }^{11}$, las cuales consisten en administrar dosis crecientes de aspirina y evaluar la presencia de síntomas en relación a la ingesta del medicamento. Existen cuatro vías de provocación con aspirina: oral, bronquial, nasal y endovenosa, esta última no es usada regularmente. Los médicos encargados de llevar a cabo esta prueba diagnóstica deben estar preparados para tratar agresivamente las reacciones adversas a la aspirina, ya que los pacientes pueden presentar broncoespasmos severos e incluso efectos vasculares, con el potencial riesgo de shock ${ }^{24}$.

Para poder someterse al test de provocación, el paciente debe tener un $\mathrm{VEF}_{1}$ igual o mayor a $70 \%{ }^{25}$. Las contraindicaciones para la realización del test de provocación con aspirina se describen en la Tabla 1. Es importante señalar que los pacientes deben continuar el tratamiento con corticoides (orales y/o tópicos) al momento del diagnóstico, ya que suspender estos medicamentos puede empeorar la patología de base del paciente con la subsiguiente declinación de su función pulmonar, lo cual puede ser un impedimento para llevar a cabo la prueba diagnóstica. Sin embargo, hay algunos medicamentos que deben suspenderse ${ }^{25}$ :

- Suspender ocho horas antes: cromolina, broncodilatadores de corta acción y bromuro de ipatropio.

- Suspender cuarenta y ocho horas antes: broncodilatadores de larga acción, teofilina y bromuto de tiotropio.

- Suspender tres días antes: antihistamínicos de corta acción.

Tabla 1. Contraindicaciones para la realización del test de provocación oral y bronquial con aspirina ${ }^{25}$
1. Historia de anafilaxis severa causada por aspirina u otros AINES (considerar provocación nasal).
2. Enfermedad severa cardiaca, digestiva, hepática y/o renal.
3. Infección del tracto respiratorio cuatro semanas previo a la realización del test.
4. Embarazo.
5. Tratamiento actual con betabloqueadores. 
- Suspender una semana antes: modificadores de la acción de leucotrienos.

El test de provocación oral (TPO) es considerado gold standard para el diagnóstico de reacciones respiratorias y cutáneas causadas por la aspirina'. Se han descrito distintos protocolos de este tipo de prueba diagnóstica, los cuales difieren en la dosis de aspirina administrada, los intervalos entre cada dosis y los criterios de positividad del test ${ }^{26}$. El más utilizado es un protocolo de tres días en el cual durante el primer día se realiza una espirometría y se fija el valor basal de $\mathrm{VEF}_{1}$, posteriormente se administran tres dosis de placebo, con un intervalo de dos horas entre ellas. Se realiza una espirometría cada treinta minutos, para evaluar la estabilidad de la vía aérea, ya que si el VEF, varía más del $15 \%$ el paciente no puede llevar a cabo el TPO. En el segundo día se comienza con la administración de dosis crecientes de aspirina, con intervalos de dos horas, hasta alcanzar una dosis acumulativa de 500 mg de aspirina ( $10 \mathrm{mg}, 27 \mathrm{mg}, 44 \mathrm{mg}, 117 \mathrm{mg}, 312$ $\mathrm{mg}, 500 \mathrm{mg}$ ). Antes de cada dosis se realiza una espirometría, la cual se repite cada treinta minutos durante el estudio. Además se evalúa la aparición de síntomas respiratorios como broncoespasmo, rinorrea, congestión nasal y síntomas extrarrespiratorios como inyección ocular, eritema y náuseas. Los criterios de positividad son ${ }^{25}$.

- Disminución del VEF Vayor $_{1}$ igual al 20\%.

- Aparición de síntomas extrabronquiales severos, como rinorrea profusa, aunque el $\mathrm{VEF}_{1}$ no sea menor al $20 \%$.

Otro método utilizado para la confirmación de IA es la prueba de provocación bronquial 0 inhalatoria (TPB) con acetilsalicilato de lisina (alis), que es una sal soluble derivada del ácido acetilsalicílico (AAS) que se puede emplear por vía oral y parenteral, quedando libre en el organismo posteriormente el AAS. $1.000 \mathrm{mg}$ de a-lis equivalen a $500 \mathrm{mg}$ de AAS.

Nizankowska ${ }^{26}$ y cols compararon la eficacia diagnóstica de la provocación oral versus provocación bronquial y observaron que ambos test tienen especificidades similares, pero el TPO mostró una sensibilidad mayor, aunque esta diferencia no fue estadísticamente significativa. La mayor ventaja del TPB fue el menor tiempo requerido para realizarlo. La inclusión de síntomas extrabronquiales aumentó el valor diagnóstico de ambas pruebas.

El test de provocación nasal (TPN) con a-lis ha demostrado ser un test simple, seguro y rápido en el diagnóstico de AIA e IA caracterizada principalmente por síntomas nasales ${ }^{27}$; no obstante, el TPN ha demostrado tener algunas limitaciones, ya que en aquellos pacientes con una función nasal alterada 0 aquellos que presentan una hiperreactividad nasal inespecífica, la respuesta no sería valorable ${ }^{28}$. Recientemente se ha implementado un TPN utilizando una solución de ketorolaco diluido ${ }^{29}$, siendo una alternativa al TPN con a-lis en Estados Unidos, debido a que esta última no ha sido aprobada para su uso en humanos en ese país.

Micheletto y $\operatorname{cols}^{30}$ relacionaron la respuesta nasal y los niveles de leucotrienos en orina luego de TPN con a-lis en pacientes asmáticos tolerantes e intolerantes a la aspirina, observando que sólo los pacientes con AIA presentaron respuestas nasales positivas (medidas mediante rinometría acústica) y aumento de leucotrienos urinarios.

EI TPN puede utilizarse como estudio inicial en el diagnóstico de IA. Pacientes con alta sospecha de IA con un resultado negativo en el TPN deberían someterse a TPB o TPO con aspirina para confirmar su diagnóstico. En la Tabla 2 se encuentra una

Tabla 2. Comparación del rendimiento de las distintas pruebas diagnósticas para la intolerancia a la aspirina ${ }^{25}$

\begin{tabular}{|lcc|}
\hline Test & Sensibilidad & Especificidad \\
\hline TP0 aspirina & $89 \%$ & $93 \%$ \\
TPB aspirina & $77 \%$ & $93 \%$ \\
TPB a-lis & $90 \%$ & $90 \%$ \\
TPN a-lis & $80 \%-86,7 \%$ & $92,5 \%-95,7 \%$ \\
\hline
\end{tabular}


comparación de sensibilidad y especificidad de los distintos tipos de test de provocación con aspirina.

Es importante señalar que todas las pruebas de provocación deben ser precedidas por una provocación con placebo, para excluir la variabilidad de la respuesta naso-bronquial ${ }^{13}$.

\section{TRATAMIENTO}

\section{Tratamiento de la(s) patología(s) de base}

Como se dijo anteriormente, los pacientes con la tríada de la aspirina sufren de un asma severa, por lo cual el tratamiento eficaz de su patología debe incluir el tratamiento adecuado del asma bronquial, lo cual en la mayoría de los casos incluye el uso de corticoides sistémicos. Un estudio que incluyó trescientos pacientes con EREA observó que el $77 \%$ de ellos era usuario de corticoides sistémicos, $22 \%$ lo hacía de manera diaria, con una dosis promedio de prednisona de $7,5 \mathrm{mg}$ al día ${ }^{31}$. Con respecto al uso de modificadores de la acción de leucotrienos, existen publicaciones que muestran el beneficio de estas drogas en el tratamiento del AIA. Un estudio mostró que al agregar el inhibidor de la enzima 5-lipoxigenasa, zileuton, en una dosis de $600 \mathrm{mg}$ cuatro veces al día, al tratamiento de pacientes con AIA, existe una mejoría clínica de estos pacientes. El uso de este medicamento también disminuyó los niveles de leucotrienos urinarios en pacientes con $\mathrm{AlA}^{32}$. Un estudio de los mismos autores, evaluó los beneficios de agregar un antagonista de leucotrienos, montelukast, al tratamiento de pacientes con AIA. El grupo que recibió montelukast mostró una mejoría en los síntomas asmáticos, en la función pulmonar y en la calidad de vida en comparación con los pacientes que recibieron placebo ${ }^{33}$. Con respecto a los beneficios que ofrece el tratamiento con montelukast a los pacientes con PN e IA, diversos estudios han demostrado que el uso de este medicamento se asocia con una menor recurrencia de PN poscirugía ${ }^{34}$ y con una mejoría en la calidad de vida de los pacientes ${ }^{35}$, en comparación con el uso de placebo. Estos resultados sugieren que el agregar modificadores de la acción de los leucotrienos mejoraría el tratamiento en los pacientes con la tríada de la aspirina y serían una alternativa terapéutica que permitiría disminuir las dosis de corticoides sistémicos utilizados en estos pacientes, disminuyendo así los potenciales efectos adversos de los glucocorticoides.

\section{Prevención y seguridad en el consumo de otros AINES}

Una vez hecho el diagnóstico de tríada de la aspirina el paciente debe ser educado acerca de las posibles reacciones cruzadas entre aspirina y otros AINES, siendo de gran utilidad la entrega de una lista con los nombres de medicamentos que el paciente no puede consumir. Se ha descrito una reactividad cruzada del $100 \%$ entre aspirina y los AINES que inhiben COX-1, por lo cual estos últimos están contraindicados en pacientes con la tríada ${ }^{11}$. Con respecto al uso del paracetamol, inhibidor parcial de COX-1, está descrito que la mayoría de los pacientes tolera adecuadamente $500 \mathrm{mg}$ de esta droga, hasta $28 \%$ tiene reacciones respiratorias leves con $1 \mathrm{gr}$ y $6 \%$ adicional reaccionó a $1,5 \mathrm{gr}$ de paracetamol ${ }^{11}$. Actualmente están disponibles en el mercado AINES que inhiben selectivamente a la enzima COX-2, Ios cuales inicialmente se consideraban de uso seguro en pacientes con IA. Estudios recientes ${ }^{36}$ han demostrado que $7 \%$ y $3 \%$ de pacientes con IA presentan síntomas respiratorios frente a la ingesta de dosis habituales de nimesulide y meloxicam, respectivamente, por lo cual estos medicamentos ya no son de uso aconsejable en pacientes con IA. Los AINES más seguros son celecoxib y refecoxib ${ }^{37,38}$. Sin embargo, antes de permitir el uso de AINES en un paciente con IA se recomienda realizar un TPO para el medicamento particular, certificando de esta manera su uso seguro para el paciente.

Los pacientes con la tríada de la aspirina pueden someterse a cirugía para la resolución quirúrgica de los PN. Es importante recalcar la importancia de la evaluación por el anestesista, previo a la cirugía, debido a que éstos pueden presentar crisis asmáticas severas durante el período posoperatorio debido a su disfunción pulmonar. Otra tarea del anestesista es planear, en conjunto con el paciente, el uso adecuado de analgésicos poscirugía ${ }^{39}$.

Con respecto a la mejoría posquirúrgica de los síntomas en pacientes con PN e IA existen resultados contradictorios. Algunos autores han encon- 
trado que los pacientes con la tríada de la aspirina obtienen menores beneficios posquirúrgicos en comparación con pacientes tolerantes a la aspiri$\mathrm{na}^{40}$, sin embargo, estudios posteriores relatan igual mejoría sintomática y en la calidad de vida en ambos subgrupos luego de cirugía endoscópica ${ }^{41}$. Se ha visto que la cirugía endoscópica destinada a corregir los pólipos nasales, mejora también el componente asmático de los pacientes con la tríada. Esta mejoría en los síntomas asmáticos es mayor al año poscirugía y se mantiene hasta un período de diez años ${ }^{42}$.

\section{Desensibilización}

Existen pacientes con la tríada de la aspirina que cumplen los criterios para someterse a una terapia de desensibilización (Tabla 3). Estos criterios son bastante estrictos ya que este tratamiento consiste en exponer al paciente a dosis crecientes del fármaco con el fin de inducir tolerancia inmunológica, lo cual tiene algunos efectos adversos como, por ejemplo, sangramiento gastrointestinal. Los mecanismos fisiopatológicos de la desensibilización no están totalmente establecidos, pero se sabe que este tratamiento disminuye la expresión de RCysLT1, disminuye la producción de tromboxano B2 y LTB4 en monocitos, inhibe la liberación de histamina y PGD2 por mastocitos ${ }^{43}$, y posiblemente influye en los mecanismos de señalización intracelular de la vía de los cys-L ${ }^{14}$. Desde un punto de vista clínico los pacientes sometidos a desensibilización muestran no sólo una mejoría sintomática, sino que también logran disminuir la dosis de corticoides necesarias para un adecuado control de la enfermedad ${ }^{44}$. A pesar del éxito reportado, esta terapia permanece subutilizada en el enfrentamiento de estos pacientes.

Hasta la fecha se han descrito distintos protocolos de desensibilización, que varían en la vía de administración y dosis de aspirina.

La desensibilización oral fue la primera descrita y es actualmente la más utilizada. Puede llevarse a cabo bajo un protocolo extrahospitalario de dos a tres días si el paciente y el centro de atención cumplen con los requisitos necesarios, los cuales se describen en la Tabla 4, y que tienen relación con el monitoreo constante del paciente, ya que el principal riesgo de esta terapia es la aparición de síntomas respiratorios graves e incluso shock.

Este protocolo se inicia con una evaluación que tiene como objetivo constatar que el paciente se encuentra estable de su patología de base, con el fin de disminuir los efectos adversos de esta

Tabla 3. Criterios de inclusión para desensibilización con aspirina ${ }^{50}$

1. Enfermedad vascular con indicación de antiagregación plaquetaria con inhibidores de COX-1 a permanencia.

2. Asma bronquial o rinosinusitis con respuesta clínica subóptima a tratamiento con corticoides sistémicos y modificadores de la acción de leucotrienos.

3. Poliposis nasal recurrente, que ha requerido múltiples polipectomías.

Tabla 4. Criterios de terapia intrahospitalaria y ambulatoria para desensibilización oral con aspirina ${ }^{50}$

\begin{tabular}{|ll|}
\hline Terapia Intrahospitalaria & Terapia Ambulatoria \\
\hline Uso betabloqueadores & Médico disponible siempre para evaluar al paciente y manejar eventua- \\
& les complicaciones \\
Infarto agudo al miocardio reciente & $\begin{array}{l}\text { Personal de salud experimentado para evaluación y atención al pacien- } \\
\text { te y eventuales complicaciones }\end{array}$ \\
Asma severa & $\begin{array}{l}\text { Un miembro del equipo médico con dedicación exclusiva al paciente } \\
\text { durante toda la desensibilización }\end{array}$ \\
Antecedente shock anafiláctico por & $\begin{array}{l}\text { Equipo de monitorización cardiopulmonar disponible durante toda la } \\
\text { aspirina u otros AINES }\end{array}$ \\
\hline
\end{tabular}


terapia. En la Tabla 5 se enumeran los pasos de esta evaluación inicial, la cual debe realizarse entre uno a siete días antes del tratamiento de desensibilización con aspirina.

Si el paciente se encuentra estable se programa el inicio de la desensibilización. El protocolo se inicia con la administración de $30 \mathrm{mg}$ de aspirina, y luego cada tres horas se administran consecutivamente dosis crecientes del fármaco $(30 \mathrm{mg}, 45$ $\mathrm{mg}, 60 \mathrm{mg}, 100 \mathrm{mg}, 150 \mathrm{mg}, 325 \mathrm{mg}$ y $650 \mathrm{mg}$ ). La menor dosis de aspirina a la cual el paciente presenta síntomas se denomina dosis de provocación (habitualmente entre $30 \mathrm{mg}$ y $100 \mathrm{mg}$ ). Debe realizarse una evaluación clínica y medición de $V_{E F}{ }_{1}$ cada una hora, teniendo presente de tratar adecuadamente los síntomas del paciente, acorde con la naturaleza de éstos, y luego de que el paciente esté asintomático proseguir con la dosis siguiente. Si ocurren síntomas nasales, oculares 0 gastrointestinales durante el primer día, debe tratarse al paciente con antihistamínicos a lo largo de todo el protocolo. Luego de establecer la dosis de provocación ésta debe repetirse, lo cual puede llevarse a cabo el primer día, o si no se cuenta con el tiempo necesario, se inicia el segundo día y posteriormente se continúa con dosis crecientes del fármaco hasta lograr que el paciente permanezca asintomático con $650 \mathrm{mg}$ de aspirina, con lo cual se considera desensibilizado. Posteriormente el paciente debe continuar con una dosis de mantención, ya que si el paciente desensibilizado no consume aspirina por un plazo igual o mayor a cuarenta y ocho horas, se considera nuevamente susceptible a la aspirina. Un estudio reciente recomienda iniciar una dosis de mantención de $650 \mathrm{mg}$ dos veces al día y si el paciente permanece estable por un mes se puede disminuir la dosis de mantención progresivamente, hasta la mínima dosis efectiva (generalmente $325 \mathrm{mg}$ una vez al día) ${ }^{45}$.
Buchimiller y cols ${ }^{50}$ han desarrollado un nuevo protocolo de desensibilización para pacientes con PN e IA refractaria a tratamiento, en el cual dosis crecientes de aspirina son administradas con intervalos de una hora, con el fin de acortar la duración del protocolo, teniendo hasta la fecha un éxito del $47 \%$ en lograr la desensibilización en un solo día, y $100 \%$ en dos días (versus tres días del protocolo habitual).

En los pacientes IA con enfermedad cardiovascular que necesitan la implantación urgente de un stent coronario y mantención de tratamiento antiplaquetario, se ha establecido un protocolo de desensibilización rápida de aproximadamente tres horas de duración. Este protocolo se inicia con 1 mg de aspirina, doblando la dosis cada treinta minutos hasta alcanzar $100 \mathrm{mg}$ del fármaco, logrando excelentes resultados. La dosis de mantención de estos pacientes es menor, generalmente entre 75 y $100 \mathrm{mg}$, lo que se ajusta a su tratamiento profiláctico $0^{46}$. Un estudio realizado en Italia relata que de mil catorce pacientes ingresados para cateterización coronaria, veintiséis $(2,6 \%)$ tenían historia de IA, y de éstos diez presentaban AIA. De los diez pacientes con AIA todos fueron sometidos a un esquema de desensibilización rápida, que consistió en la administración de dosis crecientes de aspirina (1 mg, $5 \mathrm{mg}, 10 \mathrm{mg}, 20 \mathrm{mg}, 40 \mathrm{mg} \mathrm{y}$ $100 \mathrm{mg}$ ), las cuales fueron ingeridas con un intervalo de treinta a ciento veinte minutos, teniendo el protocolo de desensibilización una duración total de cinco horas y media. De los diez pacientes, nueve tuvieron una desensibilización exitosa $(90 \%)$, y de éstos solamente un paciente había suspendido el uso de aspirina al año de seguimiento, debido a una úlcera péptica ${ }^{47}$.

Se ha descrito un protocolo de desensibilización por vía endonasal, el cual está indicado en pacientes cuyos síntomas son preferentemente

\section{Tabla 5. Determinación de la estabilidad de la vía aérea previo al inicio de la desensibilización con aspirina ${ }^{50}$}

1. $\mathrm{VEF}_{1}>70 \%$ del valor esperado (valor absoluto $>1,5 \mathrm{~L}$ ).

2. Medición de $\mathrm{VEF}_{1}$ cada tres horas: menos de $10 \%$ de variabilidad.

3. Iniciar o continuar montelukast, $10 \mathrm{mg} /$ día.

4. Iniciar o continuar corticoides inhalatorios/broncodilatadores de acción prolongada.

5. Dar pulso de corticoides sistémicos en caso de bajo $\mathrm{VEF}_{1} 0$ inestabilidad bronquial.

6. Descontinuar antihistamínicos cuarenta y ocho horas antes del tratamiento con aspirina. 
nasales. Se lleva a cabo administrando dosis de alis equivalentes a 20, 200 y 2.000 microgramos de aspirina, existiendo resultados contradictorios con respecto a su utilidad, ya que si bien se ha mostrado beneficios en el tratamiento de la PN en pacientes con $I A^{43}$, un estudio reciente no mostró beneficios clínicos de esta vía de desensibilización, pero evidenció que las células inflamatorias de la submucosa nasal de pacientes sometidos a desensibilización nasal disminuyeron la expresión del RCysLT1. Este cambio a nivel microscópico sugiere que este tipo de desensibilización tiene efectos moleculares, y que el hecho de no encontrar beneficio clínico podría deberse a que el tamaño del grupo de estudio fue muy pequeño (once pacientes).

Un grupo estadounidense ha descrito un protocolo mixto de provocación y desensibilización que consiste en la administración de cinco dosis crecientes de ketorolaco por vía endonasal, con un intervalo de treinta minutos entre cada dosis. Posterior a la desensibilización intranasal los pacientes reciben una dosis de $60 \mathrm{mg}$ de aspirina, la cual es repetida a los noventa minutos. A la mañana siguiente se administra una dosis de aspirina de $150 \mathrm{mg}$ y tres horas después una última dosis de $325 \mathrm{mg}$ de aspirina. De diez pacientes sometidos a este protocolo nueve fueron desensibilizados satisfactoriamente, lo cual demuestra la eficacia, seguridad y eficiencia de este nuevo enfoque diagnóstico-terapéutico49.

\section{CONCLUSIONES}

La tríada de la aspirina es una patología poco frecuente, pero el otorrinolaringólogo en su práctica clínica puede verse enfrentado con una frecuencia mayor de lo sospechada a pacientes en los cuales la intolerancia a la aspirina esté jugando un rol importante en la sintomatología y gravedad de la patología nasal y respiratoria. Actualmente el diagnóstico de esta enfermedad se basa en las pruebas de provocación. Una vez hecho el diagnóstico debe tenerse en cuenta las variaciones clínicas de esta enfermedad e instruir al paciente acerca de los AINES que puede consumir y si la clínica del paciente lo requiere puede someterse a terapia de desensibilización con aspirina, la cual ha demostrado tener excelentes resultados en disminuir los síntomas de estos pacientes.

\section{BIBLIOGRAFÍA}

1. Jenneck $C$, Juergens $U$, Buecheler $M$, and Novak N. Pathogenesis, diagnosis, and treatment of aspirin intolerance. Ann Allergy Asthma Immunol 2007; 99: 13-21.

2. Edwards IR AND ARonson JK. Adverse drug reactions: definitions, diagnosis, and management. Lancet 2000; 356: 1255-9.

3. Schiavino D, Nucera E, Milani A, et al. The aspirin disease. Thorax 2000; 55 Suppl 2: S66-9.

4. Slepian IK, Mathews KP, and McLean JA. Aspirinsensitive asthma. Chest 1985; 87: 386-91.

5. PICAdo C. Aspirin intolerance and nasal polyposis. Curr Allergy Asthma Rep 2002; 2: 488-93.

6. Hedman J, Kaprio J, Poussa T, and Nieminen MM. Prevalence of asthma, aspirin intolerance, nasal polyposis and chronic obstructive pulmonary disease in a population-based study. Int J Epidemiol 1999; 28: 717-22.

7. Szczeklik A, Nizankowska E, and Duplaga M. Natural history of aspirin-induced asthma. AIANE Investigators. European Network on AspirinInduced Asthma. Eur Respir J 2000; 16: 432-6.

8. Pawankar R. Nasal polyposis: an update: editorial review. Curr Opin Allergy Clin Immunol 2003; 3: 1-6.

9. Ceylan E, Gencer M, and San I. Nasal polyps and the severity of asthma. Respirology 2007; 12 : 272-6.

10. KowALSKI ML. Rhinosinusitis and nasal polyposis in aspirin sensitive and aspirin tolerant patients: are they different? Thorax 2000; 55 Suppl 2: S84-6.

11. Stevenson DD and Szczeklik A. Clinical and pathologic perspectives on aspirin sensitivity and asthma. J Allergy Clin Immunol 2006; 118: 773-86; quiz 787-8.

12. PfaAr 0 and Klimek L. Eicosanoids, aspirinintolerance and the upper airways-current standards and recent improvements of the desensitization therapy. J Physiol Pharmacol 2006; 57 Suppl 12: 5-13.

13. Szczeklik A and Stevenson DD. Aspirin-induced asthma: advances in pathogenesis, diagnosis, 
and management. J Allergy Clin Immunol 2003; 111: 913-21; quiz 922.

14. Hosemann W. Surgical treatment of nasal polyposis in patients with aspirin intolerance. Thorax 2000; 55 Suppl 2: S87-90.

15. Lewis FH, Beals TF, Carey TE, Baker SR, and Mathews KP. Ultrastructural and functional studies of cilia from patients with asthma, aspirin intolerance, and nasal polyps. Chest 1983; 83: 487-90.

16. Varga eM, Jacobson MR, Masuyama K, et al. Inflammatory cell populations and cytokine mRNA expression in the nasal mucosa in aspirin-sensitive rhinitis. Eur Respir J 1999; 14: 610-5.

17. Park HS, Nahm DH, Park K, Suh KS, and Yim HE. Immunohistochemical characterization of cellular infiltrate in nasal polyp from aspirinsensitive asthmatic patients. Ann Allergy Asthma Immunol 1998; 81: 219-24.

18. Schafer D, Schmid M, Gode UC, and Baenkler HW. Dynamics of eicosanoids in peripheral blood cells during bronchial provocation in aspirinintolerant asthmatics. Eur Respir J 1999; 13: 638-46.

19. Higashi N, Taniguchi M, Mita H, et al. Clinical features of asthmatic patients with increased urinary leukotriene E4 excretion (hyperleukotrienuria): Involvement of chronic hyperplastic rhinosinusitis with nasal polyposis. J Allergy Clin Immunol 2004; 113: 277-83.

20. Cowburn AS, Sladek K, Soja J, et al. Overexpression of leukotriene C4 synthase in bronchial biopsies from patients with aspirinintolerant asthma. J Clin Invest 1998; 101: 834-46.

21. Adamjee J, Suh YJ, Park HS, et al. Expression of 5-lipoxygenase and cyclooxygenase pathway enzymes in nasal polyps of patients with aspirin-intolerant asthma. J Pathol 2006; 209: 392-9.

22. Sousa AR, Parikh A, Scadding G, Corrigan CJ, and LEE TH. Leukotriene-receptor expression on nasal mucosal inflammatory cells in aspirinsensitive rhinosinusitis. N Engl J Med 2002; 347: 1493-9.

23. Sanak M, Pierzchalska M, Bazan-Socha S, and Szczexlik A. Enhanced expression of the leukotriene $C(4)$ synthase due to overactive transcription of an allelic variant associated with aspirin-intolerant asthma. Am J Respir Cell Mol Biol 2000; 23: 290-6.

24. Namazy JA and Simon RA. Sensitivity to nonsteroidal anti-inflammatory drugs. Ann Allergy Asthma Immunol 2002; 89: 542-50; quiz 550, 605.

25. Nizankowska-Mogilnicka E, Bochenek $G$, Mastalerz L, ET AL. EAACI/GA2LEN guideline: aspirin provocation tests for diagnosis of aspirin hypersensitivity. Allergy 2007; 62: 1111-8.

26. Nizankowska E, Bestynska-Krypel $A$, Cmiel $A$, and SzCZEKLIK A. Oral and bronchial provocation tests with aspirin for diagnosis of aspirininduced asthma. Eur Respir J 2000; 15: 863-9.

27. Milewski M, Mastalerz L, Nizankowska E, and SzCZEKLIK A. Nasal provocation test with lysineaspirin for diagnosis of aspirin-sensitive asthma. J Allergy Clin Immunol 1998; 101: 581-6.

28. Alonso A, and Vives R. Test de provocación bronquial y nasal con acetil salicilato de lisina en el diagnóstico de intolerancia a AINES. Alergol Imunol Clin 2002; 17: 168-174.

29. White A, Bigby T, and Stevenson D. Intranasal ketorolac challenge for the diagnosis of aspirinexacerbated respiratory disease. Ann Allergy Asthma Immunol 2006; 97: 190-5.

30. Micheletto C, Tognella S, Visconti M, Trevisan F, and DaL Negro RW. Changes in urinary LTE4 and nasal functions following nasal provocation test with ASA in ASA-tolerant and -intolerant asthmatics. Respir Med 2006; 100: 2144-50.

31. Berges-Gimeno MP, Simon RA, and Stevenson DD. The natural history and clinical characteristics of aspirin-exacerbated respiratory disease. Ann Allergy Asthma Immunol 2002; 89: 474-8.

32. Dahlen B, Nizankowska E, Szczeklik A, et al. Benefits from adding the 5-lipoxygenase inhibitor zileuton to conventional therapy in aspirin-intolerant asthmatics. Am J Respir Crit Care Med 1998; 157: 1187-94.

33. Dahlen Se, Malmstrom K, Nizankowska e, et al. Improvement of aspirin-intolerant asthma by montelukast, a leukotriene antagonist: a randomized, double-blind, placebo-controlled trial. Am J Respir Crit Care Med 2002; 165: 9-14.

34. Grundmann T and Topfner M. [Treatment of ASSAssociated Polyposis (ASSAP) with a cysteinyl 
leukotriene receptor antagonist - a prospective drug study on its antiinflammatory effects]. Laryngorhinootologie 2001; 80: 576-82.

35. Pauli C, Fintelmann R, Klemens C, et al. [Polyposis nasi-improvement in quality of life by the influence of leukotrien receptor antagonists]. Laryngorhinootologie 2007; 86: 282-6.

36. Bavbek S, Celik G, Ozer F, Mungan D, and MISIRLIGIL Z. Safety of selective COX-2 inhibitors in aspirin/nonsteroidal anti-inflammatory drugintolerant patients: comparison of nimesulide, meloxicam, and rofecoxib. J Asthma 2004; 41: 67-75.

37. Knowles SR, Drucker AM, Weber EA, and Shear $\mathrm{NH}$. Management options for patients with aspirin and nonsteroidal antiinflammatory drug sensitivity. Ann Pharmacother 2007; 41: 1191200.

38. Martin-García C, Hinojosa M, Berges P, et al. Safety of a cyclooxygenase-2 inhibitor in patients with aspirin-sensitive asthma. Chest 2002; 121: 1812-7.

39. Celiker V and Basgul E. Anaesthesia in aspirininduced asthma. Allergol Immunopathol (Madr) 2003; 31: 338-41.

40. Batra PS, Kern RC, Tripathi A, et al. Outcome analysis of endoscopic sinus surgery in patients with nasal polyps and asthma. Laryngoscope 2003; 113: 1703-6.

41. Robinson JL, Griest S, James KE, and Smith TL. Impact of aspirin intolerance on outcomes of sinus surgery. Laryngoscope 2007; 117: 82530.

42. Loehrl ta, Ferre RM, Toohill RJ, and Smith TL. Long-term asthma outcomes after endoscopic sinus surgery in aspirin triad patients. $A m \mathrm{~J}$ Otolaryngol 2006; 27: 154-60.

43. Pfaar 0 and Klimek L. Aspirin desensitization in aspirin intolerance: update on current standards and recent improvements. Curr Opin Allergy Clin Immunol 2006; 6: 161-6.

44. Stevenson DD and Simon RA. Selection of patients for aspirin desensitization treatment. $J$ Allergy Clin Immunol 2006; 118: 801-4.

45. Lee JY, Simon RA, and Stevenson DD. Selection of aspirin dosages for aspirin desensitization treatment in patients with aspirin-exacerbated respiratory disease. J Allergy Clin Immunol 2007; 119: 157-64.

46. Silberman S, Neukirch-Stoop C, and Steg PG. Rapid desensitization procedure for patients with aspirin hypersensitivity undergoing coronary stenting. Am J Cardiol 2005; 95: 50910.

47. Rossini R, Angiolillo DJ, Musumeci G, et al. Aspirin desensitization in patients undergoing percutaneous coronary interventions with stent implantation. Am J Cardiol 2008; 101: 786-9.

48. PariKh AA and Scadding GK. Intranasal lysineaspirin in aspirin-sensitive nasal polyposis: a controlled trial. Laryngoscope 2005; 115: 1385-90.

49. Lee RU, Simon RA, and Stevenson DD. Intranasal Ketorolac for Desensitization in Patients with Aspirin Exacerbated Respiratory Disease. J Allergy Clin Immunol 2008; 121: 1.

50. Macy E, Bernstein Ja, Castells MC, et al. Aspirin challenge and desensitization for aspirinexacerbated respiratory disease: a practice paper. Ann Allergy Asthma Immunol 2007; 98: $172-4$ 


\title{
Tratamiento médico de la rinosinusitis crónica
}

\author{
Medical treatment of chronic rhinosinusitis. Literature review
}

David Jofré $\mathrm{P}^{1}$, Javiera Pardo J², Andrés Finkelstein $\mathrm{K}^{1}$.

\begin{abstract}
RESUMEN
La rinosinusitis crónica (RSC) es actualmente una de las patologías crónicas de mayor prevalencia en nuestra sociedad. Se distinguen dos formas clínicas: la RSC con pólipos (RSCCP) y la RSC sin pólipos (RSCSP). Es considerada, en términos generales, como una inflamación de la cavidad nasal y senos paranasales de una duración superior a 12 semanas.

En la actualidad, los posibles mecanismos fisiopatológicos involucrados ubican al componente inflamatorio como entidad central en su etiología. La relación entre inflamación y poliposis nasal es aún objeto de gran debate.

Existen distintos tratamientos médicos con evidencia científica de diferentes niveles de calidad, dentro de los cuales se encuentran antibióticos, corticoides, lavados nasales $y$ antileucotrienos.

El uso de macrólidos en bajas dosis y por períodos prolongados de tiempo surge como una eficaz alternativa tanto en el control de síntomas como de parámetros objetivos, principalmente en pacientes con RSCSP.

Este artículo efectúa una exposición respecto al tratamiento médico actualmente disponible, su eficacia y evidencia científica, tanto para la RSCP como para la RSCSP.

Palabras clave: Rinosinusitis crónica, poliposis nasal, antibióticos, corticoides, antileucotrienos, lavados nasales.
\end{abstract}

\begin{abstract}
Chronic rhinosinusitis (CRS) is currently one of the most prevalent chronic pathologies in Chile. Two forms are distinguishable: Polyp CRS and non-polyp CRS. CRS is condidered, generally speaking, an inflammation of the nasal cavities and paranasal sinuses lasting longer than 12 weeks. Current possible physiopathological mechanisms involved establish inflammation as a central entity in CRS etiology. The relationship between inflammation and nasal polyposis is still a matter of great debate. Several treatment options are available, supported by heterogeneous scientific evidence; among these are antibiotics, corticoids, nasal rinses and antileucotriens.

Prolonged treatment with low-dose macrolides treatment has become a good alternative, effectively controlling both symptoms and objective parameters, mainly in non-polyp CRS.

This article reviews the CRS medical treatment currently available, its efficacy and the scientific evidence supporting it, both for the polyp and non-polyp types.

Key words: Chronic rhinosinusitis, nasal polyposis, antibiotics, corticoids, antileukotrienes, nasal wash.
\end{abstract}

Médico Departamento de Otorrinolaringología, Hospital Clínico Pontificia Universidad Católica de Chile.

2 Médico Cirujano, Hospital Clínico Pontificia Universidad Católica de Chile. 


\section{INTRODUCCIÓN}

La rinosinusitis crónica (RSC) es reconocida como una de las patologías crónicas con mayor prevalencia en la actualidad. Se estima que $15,5 \%$ de la población en U.S.A. padece de RSC, la que es definida como inflamación sinusal de duración superior a 3 meses. Sin embargo, la prevalencia estimada disminuye a $2 \%$ cuando el diagnóstico es realizado por un médico ${ }^{1}$. De acuerdo a estas cifras existe una gran cantidad de pacientes involucrados, lo que genera una importante demanda de servicios y altos costos asociados. Esto refleja -en parte- la magnitud del problema.

En su evaluación y manejo participan diferentes niveles de atención y especialistas, dentro de los que destacan: médicos generales, pediatras, broncopulmonares, alergólogos e inmunólogos. Sin embargo, existe disparidad en los criterios diagnósticos a utilizar y respecto a los tratamientos que han demostrado ser de utilidad en estos pacientes. Es así como el médico otorrinolaringólogo debe recibir, con frecuencia, casos refractarios a tratamiento.

Según la Academia Americana de Otorrinolaringología y Cirugía de Cabeza y Cuello, se define como rinosinusitis a la inflamación de la cavidad nasal y senos paranasales. Ésta se caracteriza por la presencia de 20 más síntomas, entre los que necesariamente debe estar bloqueo/obstrucción/ congestión nasal, o la secreción nasal anterior/ posterior; acompañado de dolor/presión facial y/o pérdida del olfato. Además de la evaluación clínica, el diagnóstico puede ser realizado mediante endoscopía nasal, la que proporciona hallazgos sugerentes de rinosinusitis, como presencia de pólipos, descarga mucopurulenta desde el meato medio, y edema/obstrucción primaria de la mucosa de éste. Por otro lado, al evaluar mediante tomografía computarizada (TC) es posible encontrar alteraciones que también se incluyen en el diagnóstico, tales como cambios en la mucosa del complejo osteomeatal y/o senos paranasales ${ }^{1}$.

Es preciso señalar que ha sido descontinuado el uso de criterios mayores y menores debido a la mala correlación hallada en estudios prospecti$\operatorname{vos}^{2,3}$.

Se define la RSC como la persistencia de síntomas durante más de 12 semanas. Se considera la presencia de pólipos en el seno o meato medio como un subgrupo de esta entidad, excluyéndose de esta clasificación la enfermedad polipoídea de la cavidad nasal. Es así como se pueden establecer dos subgrupos: RSC con pólipos (RSCCP) y RSC sin pólipos (RSCSP).

No existe claridad respecto el por qué sólo algunos pacientes con RSC desarrollan pólipos. Sin embargo, estos pacientes se comportan de manera distinta y en su evolución tienen una alta tendencia a recurrir poscirugía.

El objetivo de este trabajo es realizar una revisión bibliográfica del tratamiento médico disponible tanto para RSCCP como para RRCSP y definir el tratamiento médico máximo para determinar con mayor claridad cuáles pacientes son candidatos a tratamiento quirúrgico. Los distintos niveles de evidencia de los estudios revisados se detallan en la Tabla 1.

Tabla 1. Niveles de evidencia científica

\begin{tabular}{|cl|}
\hline $\begin{array}{c}\text { Niveles de evidencia } \\
\text { científica }\end{array}$ & Graduación de los diseños de estudios* \\
\hline II-1 & $\begin{array}{l}\text { Evidencia a partir de ensayos clínicos aleatorios. } \\
\text { Evidencia a partir de ensayos clínicos no aleatorios. }\end{array}$ \\
II-2 & $\begin{array}{l}\text { Evidencia a partir de estudios de cohorte, casos y controles preferiblemente realizados } \\
\text { por más de un centro o grupo de investigación. } \\
\text { Evidencia a partir de comparaciones en el tiempo o entre sitios, con y sin la intervención, } \\
\text { podrían incluirse resultados espectaculares provenientes de estudios no aleatorios. } \\
\text { Opinión de expertos, basado en la experiencia clínica; estudios descriptivos o informes } \\
\text { de comités de expertos. }\end{array}$ \\
&
\end{tabular}

${ }^{*}$ Calidad de diseño y rigor científico de mayor (I) a menor (III). De: U.S. Preventive Task Force. Guide to clinical preventive services: An assessment of the effectiveness of 169 interventions. Baltimore: Williams and Wilkins, 1989. 


\section{ETIOPATOGENIA}

La etiología de la RSC aún no está clara. Clásicamente se creía que existía un fenómeno infeccioso subyacente que determinaba, entre otros mecanismos, obstrucción del ostium de drenaje y persistencia de agentes infecciosos. Sin embargo, en los últimos años se le ha reconocido al componente inflamatorio un rol importante, generado por varios factores en forma simultánea 0 independiente ${ }^{4}$.

Además, dentro de su etiología han sido estudiados otros elementos, como biofilms, hongos, rol del hueso (osteítis) y la presencia del súperantígeno estafilocócico.

Mecanismos inflamatorios, histopatológicos, celulares y moleculares diferencian a la RSCSP de la RSCCP. Muchos factores contribuyen a la activación de estos mecanismos, como disfunción del sistema mucociliar, infecciones virales, bacterianas o micóticas, alergias, edema de la mucosa, obstrucción causada por variaciones anatómicas de la cavidad nasal o senos paranasales y factores ambientales, entre otros.

Pese a la superposición de hallazgos encontrados entre RSCSP y RSCCP, existen diferencias importantes entre ambas. Las principales características histopatológicas de RSCSP son hiperplasia de células calciformes, engrosamiento de la membrana basal, hiperplasia de glándulas submucosas en el estroma e infiltrado crónico de células inflamatorias, con predominio de linfocitos y neutrófilos. Es así como el proceso inflamatorio crónico de la RSCSP muestra un predominio linfoplasmocítico, caracterizado por incremento de células secretoras (Tabla 2) ${ }^{5-12}$.

Por otra parte, la principal característica en la RSCCP es la presencia de eosinofilia con edema del estroma (Tabla 3) ${ }^{13-18}$.

En relación con el perfil de citoquinas y mediadores inflamatorios en RSCSP, éste es de tipo Th1 con aumento de mediadores relacionados con neutrófilos, linfocitos y células plasmáticas, como

Tabla 2. Células inflamatorias implicadas en rinosinusitis crónica sin pólipos

\begin{tabular}{|lll|}
\hline Autor & Células & Conclusión \\
\hline Bernardes $(2004)^{5}$ & Eosinófilos & Aumento de activación \\
Claeys $(2004)^{6}$ & Macrófagos & Mayor expresión de MMR y RNAm en RSCSP que RSCCP y controles \\
Kramer $(2004)^{7}$ & Mastocitos & MC participan en RSC \\
Rudack $(2004)^{8}$ & Neutrófilos & Dominan inflamación RSC \\
Polzehl $(2005)^{9}$ & Eosinófilos, MC & Infiltración diferenciada macrófagos, LC, LB RSCP y RSSP \\
Seiberling $(2005)^{10}$ & Eosinófilos & RSCCP nivel más alto que en RSCSP \\
Hafidh $(2006)^{11}$ & Eosinófilos & Aumento en RSC con hongos \\
Van Zele $(2006)^{12}$ & Eosinófilos & Mayor cantidad en RSCCP que en RSCSP \\
\hline
\end{tabular}

MMR: receptor de manosa de macrófagos. ARNm: ARN mensajero. MC: mastocitos. LC: leucotrienos. LB: linfocitos B.

Tabla 3. Células inflamatorias en rinosinusitis crónica con pólipos

\begin{tabular}{|lll|}
\hline Autor & Células & Conclusión \\
\hline Jankowski (1996) & Eosinófilos & $10 \%$ más de eosinófilos \\
Loessel $(2001)^{14}$ & Mastocitos & Sin diferencias v/s sin pólipos \\
Sobol $(2002)^{15}$ & Neutrófilos (en FQ) & Activación masiva \\
Shin $(2003)^{16}$ & Células epiteliales & Eosinófilos activados por citoquinas del epitelio nasal \\
Conley $(2006)^{17}$ & Receptores de LT & Interacción en 35\% para SAgs \\
Hao $(2006)^{18}$ & Linfocitos T & Relación inversa Cd4/Cd8 en pólipos v/s mucosa nasal \\
\hline
\end{tabular}

FQ: fibrosis quística. LT: leucotrienos. SAgs: superantígeno de Staphylococcus aureus. 
interferón (INF), TGF- $\beta$, IL-8 y mieloperoxidasa (MPO). Por el contrario, en la RSCCP predomina un perfil Th2, cuyos principales mediadores están relacionados con presencia de eosinófilos, como la proteína catiónica de eosinófilos (ECP), IL-5 e $\lg \mathrm{E}^{19}$.

La activación de mecanismos inflamatorios es mantenido por factores como infecciones, agentes irritantes y contaminantes (agentes físicos o químicos), que determinan cambios estructurales (histopatológicos) y funcionales (mediadores inflamatorios y citoquinas), los cuales requieren de una predisposición genética.

Estudios recientes han demostrado que en la patogénesis de la RSC juega un importante rol el reconocimiento de patógenos realizada por la inmunidad innata mediante células de la mucosa nasosinusal. La expresión de la proteína TLR9 (toll like receptor 9) está presente tanto en células epiteliales normales como en la RSC. Sin embargo, su nivel de expresión está reducido en RSCCP. Lo anterior sugiere que la respuesta inmune a patógenos vía TLR9 en la mucosa nasosinusal es inapropiada, pudiendo esto ser clave en el mecanismo inflamatorio de la RSC ${ }^{19}$.

La importancia de un enfoque orientado específicamente en la inflamación permite un manejo más racional de la patología, definir más claramente el 'tratamiento médico máximo' y evitar fracasos quirúrgicos.

\section{TRATAMIENTO MÉDICO EN RINOSINUSITIS CRÓNICA}

Existen distintos tipos de tratamientos para el manejo tanto de la RSCCP como de la RSCSP, por lo que un buen análisis de la evidencia actual permite definir aquellos pacientes candidatos a cirugía. Los distintos tratamientos evaluados se resumen en la Tabla 4.

\section{Tratamiento antibiótico}

El rol de las bacterias en RSC es muy debatido, teniendo mayor respaldo en rinosinusitis aguda y exacerbaciones en RSC; sin embargo, algunos consideran que la inflamación crónica es -en parte- causada por persistencia de bacterias. Existen en la literatura pocos estudios clínicos controlados y revisiones sistemáticas al respecto ${ }^{20}$.

Legent y cols (1994) ${ }^{21}$ estudiaron 251 pacientes con diagnóstico de RSC, comparándose el uso de amoxicilina/ácido clavulánico respecto a ciprofloxacino durante 9 días, no encontrando diferencias significativas entre ambos grupos, tanto en la mejoría clínica como en la erradicación bacteriológica. El ciprofloxacino mostró poseer una tasa de curación significativamente mayor que amoxicilina/ácido clavulánico.

Mc Nally y cols (1997) ${ }^{2}$ analizaron 200 casos de pacientes con diagnóstico de RSC, tratados durante 4 semanas con antibióticos orales, corticoides inhalados, lavados nasales y descongestionantes tópicos, evidenciando mejoría de signos y síntomas con el tratamiento médico.

Subramanian y cols $(2002)^{23}$ evaluaron mediante un estudio retrospectivo a 40 pacientes con diagnóstico de RSC, quienes fueron tratados durante un mes con betalactámicos, corticoides orales por un breve período, y terapia adyuvante (corticoides inhalados y lavados nasales). Los autores observaron mejoría significativa tanto en síntomas como en TC. Encontraron, además, que pacientes con antecedentes de poliposis nasal e

Tabla 4. Tratamiento médico en rinosinusitis crónica

\begin{tabular}{|l}
\hline Antibióticos: particularmente, los macrólidos \\
$:$ Corticoides: sistémicos e inhalados \\
$:$ Antihistamínicos \\
$:$ Descifungicos \\
$:$ Lavados nasales salinos \\
$:$ Inhibidores de bomba de protones \\
\hline
\end{tabular}


historia de cirugía de senos paranasales se asociaban a mayores tasas de recaída precoz sintomática. Sin embargo, se hace necesario realizar un estudio prospectivo comparado con un grupo placebo para avalar estos resultados.

Otro estudio comparó la efectividad y seguridad del uso de amoxicilina/ácido clavulánico con cefuroximo en el tratamiento de RSC y exacerbaciones agudas de RSC. Namyslowski y cols (2002) ${ }^{24}$ evaluaron la respuesta clínica y erradicación bacteriana, luego de 14 días de tratamiento antibiótico, no encontrando diferencias significativas entre ambos grupos. Sin embargo, la recurrencia clínica fue significativamente mayor en el grupo con cefuroximo.

De esta forma, es posible evidenciar mejoría clínica en algunos estudios; sin embargo, éstos carecen de grupos controles con placebo y poseen gran variabilidad en el tiempo de administración del antibiótico (entre 9 y 30 días), por lo que se hace necesario contar con estudios con mejor diseño para ratificar los resultados. La evidencia disponible se resume en la Tabla $5^{21-24}$.

Por otra parte, existe una buena concordancia entre la bacteriología hallada en muestras de meato medio e intrasinusal, de relevancia clínica ${ }^{25-29}$. Por consiguiente, el uso de cultivo de meato medio se considera de gran utilidad al momento de diagnosticar una reagudización en pacientes con RSC e indicar tratamiento antibiótico por corto plazo.

Dentro de lo novedoso del tratamiento antibiótico se ha postulado que el uso de macrólidos por períodos prolongados pudiese tener utilidad en el tratamiento de la RSCSP. Desde hace un tiempo se conoce que los macrólidos poseen efectos más allá de su acción antimicrobiana. En pacientes con panbronquiolitis difusa, una patología inflamatoria crónica de alta mortalidad, se observó que el uso de bajas dosis de eritromicina por períodos prolongados, aumentaba significativamente la sobrevida de estos pacientes ${ }^{30}$. Por otra parte, se sabe que Ios macrólidos no poseen acción bactericida sobre Pseudomona aeruginosa; sin embargo, son capaces de mejorar la función pulmonar, disminuir el uso de antibióticos y la necesidad de hospitalización en pacientes portadores de fibrosis quística, habitualmente colonizados por esta bacteria ${ }^{31}$. De esta forma Hirakata ${ }^{32}$ demostró que la eritromicina es capaz de inhibir la producción de exotoxina $A$, proteasa, elastasa y fosfolipasa $C$ producidas por Pseudomona aeruginosa, sugiriendo un potencial efecto inmunomodulador.

Los macrólidos tienen un efecto antiinflamatorio independiente de su acción antimicrobiana. Poseen la capacidad de acumularse en el intracelular de las células inflamatorias y desde ahí ejercer su efecto a distintos niveles. Modulan la producción de citoquinas, alteran la estructura y función de biofilms, reducen la expresión de moléculas de adhesión de leucocitos, aceleran la apoptosis de neutrófilos e inducen estrés oxidativo, mejoran el aclaramiento mucociliar y disminuyen las secreciones $^{33}$.

Tabla 5. Tratamiento antibiótico durante corto tiempo

\begin{tabular}{|c|c|c|c|c|c|}
\hline Estudio & Tipo AB & $\mathrm{N}^{0}$ & Tiempo & Efecto & $\begin{array}{l}\text { Nivel de } \\
\text { evidencia }\end{array}$ \\
\hline Namysloski $(2002)^{24}$ & AC.v/s cefuroximo & $206^{*}$ & 14 días & $\begin{array}{l}\text { Mejoría clínica, erradicación } \\
\text { bacteriológica recaída clínica }\end{array}$ & $n 0^{* *}$ \\
\hline Subramanian $(2002)^{23}$ & Betalactámicos & 40 & $4-6 \mathrm{sm}$ & Mejoría clínica y TC & $\| I^{* * *}$ \\
\hline Mac Nally $(1997)^{22}$ & Betalactámicos & 200 & $4 \mathrm{sm}$ & Respuesta clínica & $\| I^{\star \star \star *}$ \\
\hline Legent $(1994)^{21}$ & Ciprofloxacino v/s AC & 251 & 9 días & $\begin{array}{l}\text { Disminuye descarga nasal, respuesta } \\
\text { clínica y erradicación bacteriológica }\end{array}$ & $n 0^{\star *}$ \\
\hline
\end{tabular}

De: LUND VJ. Maximal medical therapy for chronic rhinosinusitis Otolaryngol Clin North Am 2005; 38: 1301-10.

AB: antibióticos. sm: semanas. AC: amoxicilina-ácido clavulánico. TC: tomografía computarizada.

* Incluye pacientes con exacerbaciones agudas y pacientes con rinosinusitis crónica.

** No existen pruebas que no muestren diferencias significativas entre los fármacos probados.

*** Nivel de evidencia III: pruebas de estudios descriptivos no experimentales como estudios comparativos, estudios de correlación y estudios de casos y controles. 
Su uso en RSCSP es conocido. Ya en 1996, Hashiba y $\operatorname{cols}^{34}$ demostraron respuesta de parámetros inflamatorios en adultos con RSCSP, después de 12 semanas de uso. Posteriormente, Cervin y cols (2000) $)^{33}$ encontraron que la respuesta a una terapia de 3 meses de duración se mantiene al año de observación.

Por otra parte, Walwork y cols $(2006)^{35}$ realizaron el primer estudio clínico controlado, demostrando ventajas significativas en parámetros subjetivos (puntaje clínico) y objetivos (test de sacarina, IL8 en lavado nasal, puntaje endoscópico) posterior a 12 semanas de uso con roxitromicina, principalmente en pacientes sin componente alérgico, demostrado por bajos niveles de IgE y de eosinófilos en secreción y mucosa nasal.

Es así como se han desarrollado criterios de selección de pacientes para uso de macrólidos (Tabla 6). Se recomienda, previo al inicio del tratamiento, solicitar Ig E plasmática (para descartar atopia), enzimas hepáticas y recuento de glóbulos blancos. Se debe monitorizar una posible resistencia bacteriana mediante cultivo nasal cada 3 meses y chequear efectos adversos repitiendo pruebas hepáticas y recuento de glóbulos blancos.

Desde el punto de vista práctico, se recomienda su empleo en el período de invierno y descansar durante los meses en que las infecciones son menos probables.

La claritromicina es el macrólido más estudiado en RSC, recomendándose su uso en dosis de $250 \mathrm{mg} / \mathrm{día} 0$ de roxitromicina $150 \mathrm{mg} / \mathrm{día}^{33}$.
Ragab y cols (2004) ${ }^{37}$ compararon la eficacia del tratamiento médico (lavado nasal, corticoides inhalados y macrólidos por 12 semanas) con cirugía endocópica nasal, en pacientes con RSCSP y RSCCP. Un total de 90 pacientes fueron sometidos a evaluaciones mediante escalas de síntomas, mediciones de óxido nítrico, rinomanometría acústica, tiempo de clearance de sacarina y endoscopía nasal. Estos fueron evaluados antes del inicio de tratamiento, a los 6 meses y al año de seguimiento. Los resultados obtenidos demuestran que tanto el tratamiento médico como el quirúrgico lograron mejoría significativa en los parámetros objetivos y subjetivos, sin diferencias significativas entre ambos grupos, con excepción del volumen nasal total en el grupo de RSCSP donde se observaron mayores cambios al ser tratados con cirugía. Los autores concluyeron que la terapia de la RSC, con y sin pólipos, debe iniciarse con el tratamiento médico máximo disponible, el que incluye uso de macrólidos durante 3 meses, lavados nasales y corticoides inhalados. La cirugía debe reservarse sólo en los casos de rebeldía al tratamiento médico. Por otra parte, la presencia de pólipos nasales no es un factor de mal pronóstico al evaluar eficacia, tanto del tratamiento médico como quirúrgico. Los estudios realizados se resumen en la Tabla $7^{34-37}$.

\section{Corticoides}

Los corticoides sistémicos e inhalados son ampliamente usados en todo el mundo en RSCSP y RSCCP. Su acción se debe a la activación de

Tabla 6. Selección de pacientes para uso de macrólidos

\begin{tabular}{|ll|}
\hline A favor & En contra \\
\hline IgE sérica normal & IgE elevada \\
No alérgico & Alérgico \\
Cultivo negativo & Cultivo positivo $\left(1^{\circ}\right.$ tto específico $)$ \\
Corticoide nasal no efectivo & Corticoide nasal efectivo \\
SP: descarga posterior, dolor facial, cefalea & SP: rinorrea serosa, estornudos \\
& Disquinesia ciliar primaria \\
& Sinusitis alérgica fúngica \\
\hline
\end{tabular}

De: Cervin A, Wallwork $B$. Anti-inflammatory effects of macrolide antibiotics in the treatment of chronic rhinosinusitis. Otolaryngol Clin North Am 2005; 38: 1339-50.

IgE: inmunoglobulina E. SP: síntomas principales. tto: tratamiento. 
Tabla 7. Tratamiento antibiótico durante tiempo prolongado

\begin{tabular}{|llclc|}
\hline Estudio & Tipo AB & Tiempo & Efecto & Nivel de evidencia \\
\hline Nishi (1995) & Claritromicina & $3 \mathrm{~m}$ & decrece exacerbación & III \\
Hashiba (1996) & Claritromicina & $3 \mathrm{~m}$ & mejoría clínica 70\% & III \\
Ragab (2004) $)^{37}$ & Eritromicina & $3 \mathrm{~m}$ & mejoran puntajes clínicos, Ib y CEF & Ib \\
Wallwork (2006) & Eritromicina & $3 \mathrm{~m}$ & mejoría global & Ib \\
\hline
\end{tabular}

AB: antibiótico. m: meses. Ib: laboratorio. CEF: cirugía endoscópica funcional.

receptores intracelulares de glucocorticoides. Los principales efectos en la mucosa nasal y en pólipos son por reducción de la infiltración eosinofílica y la secreción de citoquinas quimiotácticas ${ }^{1,20}$.

\section{A. Corticoides sistémicos}

Para evaluar los efectos de los corticoides sistémicos en pacientes con poliposis nasal, Van Camp y cols $(1994)^{38}$ diseñaron un estudio en el que incluyeron 25 pacientes con diagnóstico de poliposis nasal, a quienes trataron durante 4 días con prednisolona $60 \mathrm{mg}$ en dosis decrecientes y evaluaron cambios en la sintomatología, la rinoscopía anterior y la TC de cavidades paranasales. Encontraron que el $72 \%$ de los pacientes mostraba disminución subjetiva de síntomas, pero sólo $52 \%$ evidenciaba una mejoría clara en la TC. Por otra parte, la eficacia terapéutica fue mayor en el grupo de pacientes con intolerancia a la aspirina y menor en el grupo de alérgicos. Por lo anterior plantearon que los corticoides sistémicos eran útiles como terapia preoperatoria para facilitar la cirugía de pólipos. Concluyeron recomendando reservar su uso para estos casos.

Damm y cols (1999) ${ }^{39}$ evaluaron la eficacia de la terapia esteroidal combinada (budesonida intranasal y fluocortolone) durante 20 días en 20 pacientes con RSCCP severa, mediante cuestionarios de síntomas y resonancia nuclear magnética
(RNM). Observaron una reducción significativa (mayor al 30\%) en el 50\% de los hallazgos en la RNM y disminución de síntomas en el $80 \%$ de los pacientes, reafirmando que su mayor indicación es como tratamiento preoperatorio, facilitando la cirugía endoscópica del seno.

Benítez y cols $(2006)^{40}$ realizaron un estudio en 84 pacientes con poliposis nasal severa, evaluando el efecto de prednisona oral administrada durante 2 semanas, seguido de budesonida intranasal por 12 semanas, en comparación con placebo. Observaron que los corticoides orales producían una mejoría significativa de los síntomas, tamaño de los pólipos, flujo nasal y resultados en la TC comparado con el grupo no tratado, y que estos efectos eran mantenidos por budesonida intranasal.

Hissaria y cols (2006) ${ }^{41}$ administraron 50 mg/día de prednisona oral durante 14 días en 20 pacientes con RSCCP y lo compararon con placebo, encontrando diferencias significativas en disminución de síntomas, reducción del tamaño de los pólipos -evaluado por endoscopía nasal y RNM- comparado con el grupo control, concluyendo que es un tratamiento seguro y efectivo en la poliposis nasal sintomática.

De estos estudios se puede concluir que los corticoides orales son de utilidad en el tratamiento de pacientes con RSCCP. Los hallazgos obtenidos se resumen en Tabla $8^{38-41}$.

Tabla 8. Corticoides sistémicos en rinosinusitis crónica con pólipos

\begin{tabular}{|llccc|}
\hline Estudio & Droga/Dosis & Tiempo & Efectos & Nivel de evidencia \\
\hline Van Camp (1994) & Prednisona $(60 \mathrm{mg})$ & $2 \mathrm{sm}$ & sí & III \\
Damm $(1999)^{31}$ & Budesonida + fluocortolone & $?$ & sí & III \\
Benitez $(2006)^{32}$ & Prednisona + budesonida & $2 \mathrm{sm}$ & sí & Ib \\
Izaría $(2006)^{33}$ & Prednisolona $(50 \mathrm{mg})$ & $2 \mathrm{sm}$ & sí & Ib \\
\hline
\end{tabular}

sm: semanas. Ib: laboratorio. 
En contraste con lo anterior, no existen estudios clínicos controlados que demuestren la eficacia de corticoides orales en RSCSP20,42.

\section{B. Corticoides inhalados}

Los corticoides inhalados poseen múltiples efectos antiinflamatorios, entre ellos el reducir la producción de citoquinas proinflamatorias, y disminuir la llegada de células inflamatorias, mejorando así la obstrucción nasal. Son sus propiedades antiinflamatorias las que generan el alivio de síntomas asociados a la inflamación: congestión nasal, dolor facial y obstrucción nasal.

La administración de corticoides inhalados por largo tiempo es segura, ya que no produce atrofia de la mucosa u otro cambio histológico y mantiene la función ciliar o clearance mucociliar. Su uso no se ha asociado a efectos adversos sistémicos, como supresión del eje hipotálamo-hipófisisadrenal, impedimento del crecimiento en niños 0 alteración del metabolismo óseo, pudiendo exacerbar la osteoporosis. Sin embargo, su empleo ha sido relacionado con efectos adversos locales: epistaxis, irritación de nariz o garganta, sequedad local, cefalea, faringitis y costras nasales ${ }^{42}$.

2.B.1. Corticoides inhalados en rinosinusitis crónica con pólipos

Keith y cols $(2000)^{43}$ evaluaron, mediante un estudio clínico controlado multicéntrico, la efectividad de la fluticasona (400 $\mu \mathrm{gr}$ ) aplicada durante 12 semanas, comparada con placebo, en pacientes con RSCCP. Encontraron una mejoría significativa en la reducción del tamaño de pólipos, disminución de obstrucción nasal y mejoría del flujo inspiratorio máximo nasal en el grupo con fluticasona. Señalan que la epistaxis fue la complicación más frecuente en este grupo.
Pentilla y cols $(2000)^{44}$ realizaron un estudio para evaluar la efectividad y tolerabilidad de fluticasona (400 $\mu \mathrm{gr})$ al ser administrada durante 12 semanas, una o dos veces al día, en comparación con placebo, encontrando que el uso de una doble dosis diaria produce mejoría significativa del tamaño de los pólipos, síntomas de rinitis, flujo inspiratorio máximo nasal. Concluyen que una doble dosis de fluticasona es significativamente más efectiva que la dosis única y el placebo. Small y cols $(2005)^{45}$ realizaron un estudio multinacional, en el que incluyeron 354 pacientes y evaluaron la eficacia y seguridad de fluorato de mometasona (200 $\mu \mathrm{gr}$ ) en dosis única o doble al día, mostrando mejoría significativa en reducción del tamaño de pólipos, recuperación en la pérdida olfatoria, rinorrea anterior, descarga posterior y congestión/obstrucción nasal al compararlo con placebo, disminuyendo 0 retardando la necesidad de cirugía.

Stjärne y cols $(2006)^{46}$ diseñaron un estudio multicéntrico para evaluar en 310 pacientes la efectividad de mometasona (200 $\mu \mathrm{gr})$ en dosis diaria única o doble comparado con placebo. Luego de 4 meses de uso demostraron una mejoría estadísticamente significativa en reducir el tamaño de los pólipos, congestión y obstrucción nasal.

Con estos resultados se puede concluir que el uso de corticoides inhalados es una terapia segura y efectiva en el tratamiento de la RSCCP (Tabla 9) ${ }^{43-46}$.

2.B.2. Corticoides inhalados en rinosinusitis crónica sin pólipos.

Cuenant y cols (1986) ${ }^{47}$ estudiaron la efectividad de la irrigación con tixocortol más

Tabla 9. Corticoides inhalados en rinosinusitis crónica con pólipos

\begin{tabular}{|llclcc|}
\hline Estudio & Droga & Tiempo & Clínica & Nivel de evidencia \\
\hline Keith $(2000)^{35}$ & Fluticasona & $12 \mathrm{sm}$ & Mejoría subjetiva y objetiva & NS & lb \\
Pentilla $(2000)^{36}$ & Fluticasona & $12 \mathrm{sm}$ & Mejorías nasales y olfato & sí & lb \\
Small $(2005)^{37}$ & Mometasona & $16 \mathrm{sm}$ & Mejoría de obstrucción y olfato & sí & lb \\
Stjarne $(2006)^{38}$ & Mometasona & $16 \mathrm{sm}$ & Mejora objetiva & sí & Ib \\
\hline
\end{tabular}

sm: semanas. lb: laboratorio. 
neomicina en comparación con uso exclusivo de neomicina en el tratamiento de RSCSP en 60 pacientes, obteniendo mejoría significativa de la obstrucción nasal en el grupo de tixocortol más neomicina tras 11 días de tratamiento.

Ese mismo año, Sykes y cols $^{48}$ realizaron un estudio clínico controlado en 50 pacientes con diagnóstico de RSC mucopurulenta, para evaluar efectividad del tratamiento con dexametasona, tramazolina y neomicina comparado con igual terapia sin antibiótico. Encontraron una reducción de la respuesta inflamatoria y congestión nasal sin necesidad de tratamiento antibiótico, postulando que probablemente el efecto se debería a mecanismos que permiten recuperar el clearance mucociliar.

Para evaluar el uso de propionato de fluticasona en spray, Parikh y cols (2001) ${ }^{49}$ realizaron un estudio clínico durante 4 meses en pacientes con diagnóstico de RSC, evaluaron puntajes de síntomas, puntajes endoscópicos, rinomanometría acústica entre otros. Encontraron que no existían diferencias al compararlo con placebo. Estos autores hallaron que el uso de fluticasona en spray no aumenta el riesgo de infección y provoca dow-regulation en la expresión de citoquinas inflamatorias.

Lavigne y cols (2002) ${ }^{50}$ evaluaron la eficacia de budesonida (256 $\mu \mathrm{gr}$ ) en 26 pacientes con diagnóstico de RSCSP quienes tras ser operados persistieron con síntomas, tales como rinorrea o presión/dolor facial. El corticoide fue administrado mediante un dispositivo de intubación (tubo de sinusotomía antromaxilar) durante 3 semanas, encontrando mejoría en escala de síntomas, por lo que sería un tratamiento útil en el control de la RSCSP poscirugía.

Lund y cols (2004) $)^{51}$ investigaron la eficacia de budesonida (128 $\mu \mathrm{gr}$ ) en spray nasal en el tratamiento de la RSCSP durante 20 semanas. Encontraron mejoría en escala de síntomas, descarga y congestión nasal, anosmia y aumento del flujo inspiratorio máximo nasal en pacientes que usaron budesonida comparado con placebo, concluyendo que es un tratamiento efectivo y bien tolerado para el manejo de estos pacientes. Posteriormente este mismo autor (2008) ${ }^{34}$ realizó una revisión sistemática para evaluar la eficacia del tratamiento sintomático con corticoides intranasales en pacientes adultos y pediátricos con rinosinusitis aguda, recurrente 0 crónica. Todos los artículos incluidos eran estudios clínicos controlados que comparaban el uso de corticoides inhalados con placebo, ya sea monoterapia 0 terapia adyuvante. Su conclusión fue que los corticoides inhalados disminuyen el bloqueo nasal, descarga purulenta, dolor facial y cefalea, reduciendo la inflamación local y mejorando el drenaje (Tabla 10) ${ }^{47-51}$.

Los corticoides inhalados son seguros, efectivos, y no aumentan el riesgo de infección bacteriana 0 recurrencia. Como terapia adyuvante a los antibióticos en pacientes con rinosinusitis aguda, recurrente 0 exacerbación de RSC muestran mayor mejoría sintomática que el tratamiento antibiótico aislado ${ }^{42}$.

De este modo los procesos inflamatorios son objetivos terapéuticos clínicamente importantes en

Tabla 10. Corticoides inhalados en rinosinusitis crónica sin pólipos

\begin{tabular}{|llclc|}
\hline Estudio & Droga & Tiempo & Efecto en síntomas & Nivel de evidencia \\
\hline Cuenant $(1986)^{39}$ & Tixocortol (irrigación) & 11 días & Mejoría significativa & Ib \\
Sykes $(1986)^{40}$ & Dexametasona más tramazoline & $4 \mathrm{sm}$ & Mejoría síntomas & Il \\
Parikh $(2001)^{41}$ & Fluticasona & $16 \mathrm{sm}$ & No significativo & Ib \\
Lavigne $(2002)^{42}$ & Budesonida intrasinusal & $3 \mathrm{sm}$ & Mejoría síntomas & Ib \\
Lund $(2004)^{43}$ & Budesonida & $20 \mathrm{sm}$ & Mejoría síntomas & Ib \\
\hline
\end{tabular}

sm: semanas. Ib: laboratorio. 
RSC. Los corticoides inhalados son capaces de abordar la respuesta inflamatoria subyacente a la congestión nasal, obstrucción y dolor facial (entre los síntomas más angustiantes de la rinosinusitis) y promueven el drenaje. Los corticoides inhalados se han recomendado como tratamiento de primera línea, debido a su capacidad de mejorar los síntomas y resultados clínicos si se administran concomitantemente con antibióticos ${ }^{42}$.

\section{Antihistamínicos}

Los antihistamínicos son medicamentos de amplio uso en la práctica clínica, particularmente en RSCCP52. Sin embargo, no existe evidencia para sostener algún rol de los antihistamínicos en esta patología. Es así como un estudio realizado a 45 pacientes con diagnóstico de poliposis nasal residual o recurrente posetmoidectomía comparó el tratamiento con cetirizina (20 mg 2 veces al día) con placebo durante 3 meses. Los autores observaron que el número y tamaño de los pólipos se mantuvo sin cambios durante el periodo de estudio. Se encontró, además, que la cetirizina reducía eficazmente estornudos y rinorrea. También logró un efecto beneficioso sobre la obstrucción nasal. Los efectos secundarios con $20 \mathrm{mg}$ de cetirizina, el doble de la dosis diaria recomendada para adultos, fueron pocos y comparables con placebo ${ }^{53}$.

Se puede concluir que el uso de antihistamínicos en pacientes con diagnóstico de RSCCP sólo es efectivo en manejar los síntomas derivados de la alergia, sin mostrar efectos en los pólipos, recomendándose su uso sólo en casos en los que la poliposis se asocie a sintomatología alérgica.

\section{Antifúngicos}

El rol del material fúngico inhalado en el desarrollo de procesos inflamatorios de la vía aérea superior fue un tema muy debatido durante la década de los '90. Como extensión de esta teoría, se adjudicó a las hifas fúngicas responsabilidad en la RSC, por lo que se usó terapia antifúngica oral y tópica para manejo de estos pacientes.

Diversos estudios han tratado de demostrar la utilidad del uso de anfotericina $B$ en el tratamiento de la rinosinusitis crónica. Ponikau y cols ${ }^{54}$ demostraron una mejoría del $75 \%$ en parámetros clínicos y endoscópicos en pacientes con RSCSP sometidos a tratamiento con lavados nasales con anfotricina B. Sin embargo este mismo autor, años más tarde, desarrolló un estudio clínico controlado, en el que se incluyeron 30 pacientes con RSCSP, no observando grandes diferencias entre el grupo tratado con anfotericina y el grupo placebo luego de 6 meses ${ }^{55}$.

Hallazgos similares fueron encontrados por Weschta y $\operatorname{cols}^{56}$ quienes diseñaron un estudio clínico controlado en el que participaron 60 pacientes con RSCCP, donde tampoco encontraron beneficio significativo con el uso de anfotericina $B$, por un período de 8 semanas.

Intentando aclarar el rol de los antifúngicos intranasales en el tratamiento de la RSC, Ebbens y cols $^{57}$ evaluaron la efectividad del uso de lavados nasales con anfotericina al compararlo con lavados nasales con placebo, en pacientes con RSCCP y RSCSP. Seleccionaron al azar un total de 166 pacientes con RSC para infusión de $25 \mathrm{ml}$ de anfotericina $B(100 \mathrm{mg} / \mathrm{ml})$ o placebo (en cada fosa nasal dos veces al día durante 3 meses). Los resultados, después de 13 semanas de tratamiento, no evidenciaron diferencias estadísticamente significativas entre ambos grupos respecto a reducción del puntaje de la escala visual análoga y de endoscopía nasal, como resultados principales, ni en flujo inspiratorio máximo nasal, características de pólipos, calidad de vida ni escala visual análoga individual. Concluyeron que los lavados nasales con anfotericina B no reducen los signos ni síntomas clínicos en pacientes con RSC, por lo que no recomiendan su uso tanto en RSCCP como en RSCSP.

Esto fue reafirmado en reciente estudio clínico controlado en el que se demostró que el uso de irrigación con anfotericina $B$ en pacientes con RSCSP no produce mejoría significativa de síntomas ni hallazgos endoscópicos en comparación con suero salino $0^{58}$.

Por otra parte, también se ha evaluado el efecto de la terapia antifúngica oral. Kennedy y cols ${ }^{59}$ realizaron estudio clínico controlado, en el que se trataron 53 pacientes con terbinafina oral en altas dosis durante 6 semanas, no mostrándose mejoría en puntaje de síntomas ni de TC.

Por lo tanto, según la evidencia actual no parece haber un rol de los lavados con antifúngicos 
en el tratamiento de la RSCCP y RSCSP. La evidencia disponible se resume en la Tabla 11 15-57,59.

\section{Descongestionantes}

En teoría, tanto los descongestionantes tópicos como los sistémicos tienen un efecto antiinflamatorio al disminuir los niveles de óxido nítrico sintetiza y por acción antioxidante, que podría ser beneficiosa; sin embargo, no existen estudios clínicos controlados en RSC.

En estudio efectuado a una población pediátrica con diagnóstico de RSC maxilar en tratamiento médico, el uso de descongestionantes no mostró un efecto superior al uso de solución salina al evaluar el drenaje del $s e n 0^{60}$. En la actualidad no se recomienda el uso rutinario de descongestionantes en RSC.

\section{Lavado intranasal}

El lavado intranasal es de uso frecuente en pacientes con RSC por su bajo costo, alta accesibilidad y escasos efectos adversos asociados. Sin embargo, no existen estudios bien diseñados que analicen métodos de instilación, cantidad, frecuencia y concentración. Existen algunos que han demostrado mejoría en síntomas, calidad de vida, parámetros endoscópicos y de imágenes ${ }^{61-64}$.

En general, se prefiere usar solución hipertónica, porque tiene aparentemente buen efecto sobre el clearance mucociliar ${ }^{65,66}$.

En una revisión sistemática realizada por la base de datos Cochrane (2007) ${ }^{67}$ se evaluó el efecto del uso de irrigación salina nasal en la sintomatología de RSC. Fueron seleccionados 8 trabajos que cumplían criterios de inclusión. Tres estudios compararon solución salina con ausencia de tratamiento $0^{68,69,70}$, uno con placebo (reflexología) $)^{71}$, uno como terapia adyuvante ${ }^{72}$, y otro en comparación a corticoides inhalados ${ }^{73}$. Dos estudios ponderaron diferentes soluciones hipertónicas con solución salina isotónica ${ }^{74,75}$. Esta revisión concluyó señalando que existe evidencia respecto a que la solución salina es beneficiosa en el tratamiento de los síntomas de RSC cuando se utiliza ya sea en modalidad única de tratamiento o como terapia adyuvante, mejorando puntajes de síntomas y calidad de vida. No obstante, la solución salina no fue tan efectiva como los corticoides inhalados, demostrado al medir puntajes de calidad de vida.

Algunas evidencias sugieren que la solución salina hipertónica mejora parámetros objetivos (puntaje radiológico), pero su efecto sobre los síntomas es menos claro.

Es posible concluir que las soluciones salinas son bien toleradas, aunque los efectos secundarios menores son comunes; sin embargo, su acción beneficiosa parece superar los inconvenientes en la mayoría de los pacientes. Por consiguiente, el uso de solución salina tópica puede incluirse como tratamiento adyuvante de los síntomas de RSC.

\section{Antileucotrienos}

Los leucotrienos son mediadores inflamatorios que han sido involucrados en múltiples enfermedades del tracto respiratorio, como rinitis alérgica, asma y poliposis nasal. A raíz de lo anterior se ha estudiado el rol de sus antagonistas en el tratamiento de la RSCCP, el cual se basa, entre otros efectos, en la reducción del recuento de eosinófilos ${ }^{76,77}$.

Es así como en un estudio se observó que el uso de montelukast generaba una mejoría en síntomas subjetivos y recuentos de eosinófilos en pacientes con RSCCP y rinitis alérgica con tratamiento esferoidal tópico $0^{78}$.

Tabla 11. Antifúngicos en rinosinusitis crónica

\begin{tabular}{|lllc|}
\hline Estudio & Droga & Efectos & Nivel de evidencia \\
\hline Weschta $(2004)^{48}$ & Anfotericina B spray & Sin diferencias en TC y NFC & $\mathrm{lb}$ \\
Ponikau $(2005)^{47}$ & Anfotericina B lavado & Sin diferencia sintomáticas & $\mathrm{lb}$ \\
Kennedy $(2005)^{51}$ & Terbinafina oral/placebo & Sin diferencias & $\mathrm{lb}$ \\
Ebens $(2006)^{49}$ & Anfotericina B lavado & Sin diferencias & $\mathrm{lb}$ \\
\hline
\end{tabular}

TC: tomografía computarizada. NFC: nasofibroscopía. Ib: laboratorio. 
Por otra parte, Stewart y cols ${ }^{79}$ compararon el uso de montelukast con placebo, en el tratamiento de pacientes con RSCCP, quienes ya se encontraban en tratamiento esteroidal tópico crónico. Dicho estudio mostró un beneficio significativo con el uso de montelukast en comparación con placebo en síntomas como cefalea, dolor facial y estornudos, mejoría que perdura mientras se utiliza este fármaco.

Dhalen y cols $^{80}$ evaluaron individuos con poliposis nasal quienes, además, tenían intolerancia a la aspirina y asma bronquial, encontrando beneficio significativo en el uso de inhibidores de la 5-lipooxigenasa, en cuanto a la medición de flujo nasal y síntomas como anosmia, rinorrea y congestión nasal.

Por consiguiente, el uso de antagonistas de los leucotrienos parecería ser una alternativa útil en pacientes con RSCCP, particularmente en quienes, además, existe asma bronquial asociada. Sin embargo, esto debe ser respaldado por estudios clínicos controlados de mayor número a los existentes actualmente.

\section{Inhibidores de la bomba de protones}

El reflujo gastroesofágico (RGE) ha sido sugerido como causa de RSC en población pediátrica; sin embargo, su contribución a la patogenia de la RSC en adultos no ha sido estudiada de manera sistemática. No existen estudios clínicos controlados que muestren beneficio en el uso de inhibidores de la bomba de protones.

En un ensayo clínico realizado por Ulualp y cols ${ }^{81}$ se evaluó la contribución del RGE a la patogenia de la RSC en un grupo de pacientes no estudiados sistemáticamente comparándose con un grupo control sano. Mediante técnica de monitoreo de $\mathrm{pH}$ esófago-faríngeo ambulatoria se evaluaron episodios de reflujo, observándose que la prevalencia de reflujo faríngeo fue significativamente mayor en el grupo de pacientes con RSC que no responden a tratamiento convencional comparado con el grupo control. Estos hallazgos sugieren que el RGE podría contribuir a la patogénesis de la RSC en algunos pacientes adultos.

En cambio, en pacientes con RSCCP no poseería ningún rol demostrado.

\section{TRATAMIENTO MÉDICO MÁXIMO}

La RSC es una patología frecuente, de curso prolongado y que altera en forma importante la calidad de vida de quienes la padecen.

La gran mayoría de los pacientes logra responder sintomáticamente al tratamiento médico y sólo un porcentaje de ellos es candidato a manejo quirúrgico, principalmente por persistencia de síntomas, pese a contar con la terapia médica máxima disponible.

Tradicionalmente se ha usado el concepto de tratamiento médico máximo para definir el manejo óptimo preoperatorio, el cual debe construirse en base a la mejor evidencia disponible. Sin embargo, aún no existe consenso sobre el mejor tratamiento médico a utilizar. En relación a esto, existen distintos tratamientos que han demostrado cierta utilidad. En primer lugar, está el uso de los corticoides inhalados como herramienta terapéutica de primera línea en el manejo crónico, tanto de pacientes con rinosinusitis crónica con pólipos como aquellos sin pólipos. Estos, mediante su poderoso efecto antiinflamatorio logran disminuir el dolor facial, la congestión y obstrucción nasal.

Para aquellos pacientes con rinosinusitis crónica sin evidencia de alergia, ya sea clínica 0 de laboratorio, surge como alternativa novedosa y eficaz el uso de terapias antibióticas por tiempos prolongados. Particularmente el uso de macrólidos, los cuales utilizados en bajas dosis y por un tiempo de 3 meses, tienen la capacidad de acumularse en el interior de las células inflamatorias y desde ahí ejercer su efecto antiinflamatorio a distintos niveles. De este modo, tal efecto se prolonga en el tiempo.

No existe referencia en la literatura para el uso de antibióticos por cortos períodos de tiempo en el tratamiento de la RSC. Aparentemente su mayor utilidad está dada en el manejo de las exacerbaciones agudas en estos pacientes.

Por otra parte, se ha recomendado como complemento a lo anterior, el uso de lavados nasales, ya que son de bajo costo y se asocian a pocos y leves efectos adversos. Aún no está del todo claro si el suero hipertónico favorece la evolución de estos pacientes.

Sabemos que no es posible dar "recetas de cocina", debido a que cada caso debe analizarse en 
Tabla 12. Tratamiento médico máximo

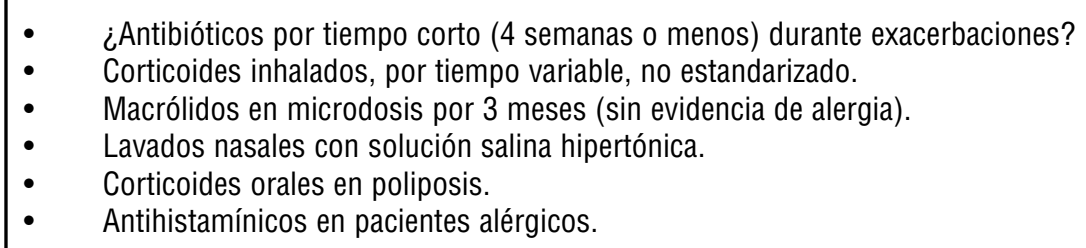

forma individual. Sin embargo existe consenso en terapias demostradas, las que se resumen en la Tabla 12.

Es así, que el diagnóstico adecuado es fundamental, y debe basarse en una minuciosa historia clínica, complementada con una evaluación endoscópica nasal y TC de cavidad nasal y senos paranasales. Debe incluirse además, estudio de inmunidad en todos los casos.

De este modo el conocimiento y uso racional del tratamiento médico nos permitirá elegir mejor a los candidatos quirúrgicos y así ofrecer a nuestros pacientes el mejor tratamiento disponible en cada caso.

\section{BIBLIOGRAFÍA}

1. Fokkens WJ, Lund VJ, Mullol J. et al. European Position Paper on Nasal Polyps 2007. Rhinology 45; 20 (suppl): 1-139.

2. Pearlman an, Conley DB. Review of current guidelines related to the diagnosis and treatment of rhinosinusitis.Curr Opin Otolaryngol Head Neck Surg. 2008; 16: 226-30.

3. Rosenfeld RM, Singer M, Jones S. Systematic review of antimicrobial therapy in patients with acute rhinosinusitis. Otolaryngol Head Neck Surg 2007; 137 (suppl): S32-45.

4. Meltzer eO, Hamilos DL, Hadley Ja. et al. Rhinosinusitis: Establishing definitions for clinical research and patient care. Otolaryngol Head Neck Surg. 2004; 131 (Suppl): S1-S62.

5. Bernardes JF, Shan J, Tewfik M, Hamid Q, Frenkiel S, EIdelman DH. Protein nitration in chronic sinusitis and nasal polyposis: Role of eosinophils. Otolaryngol Head Neck Surg 2004; 131: 696-703.
6. Claeys S, Be Belder T, Holtappels G, et al. Macrophage mannose receptor in chronic sinus disease. Allergy 2004; 59(6): 606-12.

7. Kramer MF, Burow G, Pfrogner E, Rasp G. In vitro diagnosis of chronic nasal inflammation. Clin Exp Allergy 2004; 34(7): 1086-92.

8. Rudack C, Sachse F, Alberty J. Chronic rhinosinusitis: Need for further classification? Inflamm Res 2004; 53(3): 111-7.

9. Polzehl D, Weschta M, Podielski A, Riechelmann H, RIMEK $D$. Fungus culture and PCR in nasal lavage samples of patients with chronic rhinosinusitis. $J$ Med Microbiol 2005; 54(1): 31-7.

10. Seiberling KA, Grammer L, Kern RC. Chronic rhinosinusitis and superantigens. Otolaryngol Clin North Am. 2005; 38: 1215-36.

11. Hafidh M, Harney M, Kane R, Donnelly M, Landers $R$, Sмутн $D$. The role of fungi in the etiology of chronic rhinosinusitis: A prospective study. Auris Nasus Larynx 2006; 26.

12. Van Zele $T$, Claeys $S$, Gevaert $P$, et al. Differentiation of chronic sinus diseases by measurement of inflammatory mediators. Allergy 2006; 61: 1280-9.

13. JankowskI R. Eosinophils in the pathophysiology of nasal polyposis. Acta Otolaryngol 1996; 116: 160-3.

14. LOESEL LS. Immunopathologic study of chronic sinusitis: a proposal for atopic and non-atopic lgE-activated mast cell allergic inflammation. Ann Otol Rhinol Laryngol 2001; 110(5 Pt 1): 447-52.

15. Sobol SE, Christodoulopoulos P, Manoukian JJ, et AL. Cytokine profile of chronic sinusitis in patients with cystic fibrosis. Arch Otolaryngol Head Neck Surg 2002; 128: 1295-8.

16. Shin SH, Lee SH, Jeong HS, Kita H. The effect of nasal polyp epithelial cells on eosinophil 
activation. Laryngoscope 2003; 113(8): 1374-7.

17. Conley DB, Tripathi A, Selberling KA, et al. Superantigens and chronic rhinosinusitis II: analysis of T-cell receptor $\mathrm{V}$ beta domains in nasal polyps. Am J Rhinol 2006; 20(4): 451-5.

18. HaO J, Pang YT, Wang DY. Diffuse mucosal inflammation in nasal polyps and adjacent middle turbinate. Otolaryngol Head Neck Surg 2006; 134(2): 267-75.

19. Brazilian Guidelines on Rhinosinusitis. Rev Bras Otorrinolaringol [online] 2008; 2 (suppl): 6-59.

20. Lund VJ. Maximal medical therapy for chronic rhinosinusitis. Otolaryngol Clin North $\mathrm{Am}$ 2005; 38(6): 1301-10.

21. Legent F, Bordure P, Beauvillain C, et al. A double-blind comparison of ciprofloxacin and amoxycillin/clavulanic acid in the treatment of chronic sinusitis. Chemotherapy 1994; 40(suppl 1): 8-15.

22. McNally PA, White MV, Kaliner MA. Sinusitis in an allergist's office: Analysis of 200 consecutive cases. Allergy Asthma Proc 1997; 18(3): 169-75.

23. Subramanian HN, Schechtman KB, Hamilos DL. A retrospective analysis of treatment outcomes and time to relapse after intensive medical treatment for chronic sinusitis. Am J Rhinol 2002; 16(6): 303-12.

24. Namyslowski G, Misiolek M, Czecior E, et al. Comparison of the efficacy and tolerability of amoxycillin/clavulanic acid $875 \mathrm{mg}$ b.i.d. with cefuroxime $500 \mathrm{mg}$ b.i.d. in the treatment of chronic and acute exacerbation of chronic sinusitis in adults. J Chemother 2002; 14(5): 50817.

25. Gold SM, TAMI TA. Role of middle meatus aspiration culture in the diagnosis of chronic sinusitis. Laryngoscope 1997; 107(12 Pt 1): 1586-9.

26. Klossek JM, Dubreuil L, Richet H, Richet B, BeUtTer P. Bacteriology of chronic purulent secretions in chronic rhinosinusitis. $J$ Laryngol Otol 1998; 112(12): 1162-6.

27. Vogan JC, Bolger WE, Keyes AS. Endoscopically guided sinonasal cultures: A direct comparison with maxillary sinus aspirate cultures. Otolaryngol Head Neck Surg 2000; 122: 370-3.

28. Talbot GH, Kennedy DW, Scheld WM, Granito K. Rigid nasal endoscopy versus sinus puncture and aspiration for microbiologic documentation of acute bacterial maxillary sinusitis. Clin Infect Dis 2001; 33(10): 1668-75.

29. Joniau S, Vlaminck $S$, Van Landuyt H, Kuhweide R, Dıck C. Microbiology of sinus puncture versus middle meatal aspiration in acute bacterial maxillary sinusitis.Am $J$ Rhinol 2005; 19(2): 135-40.

30. Kudoh S, Azuma A, Yamamoto M, Izumi T, Ando M. Improvement of survival in patients with diffuse panbronchiolitis treated with low-dose erythromycin. Am J Respir Crit Care Med 1998; 157(6 Pt 1): 1829-32.

31. SaIman L. The use of macrolide antibiotics in patients with cystic fibrosis. Curr Opin Pulm Med 2004; 10 (6): 515-23.

32. Hirakata Y, Kaku M, Mizukane R, et al. Potential effects of erythromycin on host defense systems and virulence of Pseudomonas aeruginosa. Antimicrob Agents Chemother 1992; 36(9): 1922-7.

33. Cervin A, Wallwork B. Anti-inflammatory effects of macrolide antibiotics in the treatment of chronic rhinosinusitis. Otolaryngol Clin North Am 2005; 38: 1339-50.

34. HASHIBA M, BaBA S. Efficacy of long-term administration of clarithromycin in the treatment of intractable chronic sinusitis. Acta Otolaryngol 1996; 525 (suppl): 73-8.

35. Wallwork B, Coman W, Mackay-Sim A, Greiff L, Cervin A. A double-blind, randomized, placebocontrolled trial of macrolide in the treatment of chronic rhinosinusitis. Laryngoscope 2006; 116(2): 189-93.

36. Nishi K, Mizuguch M, Tachibana H, et al. Effect of clarithromycin on symptoms and mucociliary transport in patients with sino-bronchial syndrome. Nihon Kyobu Shikkan Gakkai Zasshi 1995; 33 (12): 1392-400.

37. Ragab S, Lund V, Sccading G. Evaluation of the medical and surgical treatment of chronic rhinosinusitis: a prospective, randomized, controlled trial. Laryngoscope 2004; 114(5): 923-30.

38. Van Camp C. Results of oral steroid treatment in nasal polyposis. Rhinology. 1994; 32(1): 5-9.

39. Damm M. Effects of systemic steroid treatment in chronic polypoid rhinosinusitis evaluated with magnetic resonance imaging. Otolaryngol Head Neck Surg 1999; 120(4): 517-23. 
40. Benítez P. A short course of oral prednisone followed by intranasal budesonide is an effective treatment of severe nasal polyps. Laryngoscope 2006; 116(5): 770-5.

41. Hissaria P. Short course of systemic corticosteroids in sinonasal polyposis: a double-blind, randomized, placebo-controlled trial with evaluation of outcome measures. $J$ Allergy Clin Immunol 2006; 118(1): 128-33.

42. Lund V. Therapeutic targets in rhinosinusitis: Infection or inflammation? Medscape J Med 2008; 10(4): 105.

43. KEITH P. Efficacy and tolerability of fluticasone propionate nasal drops 400 microgram once daily compared with placebo for the treatment of bilateral polyposis in adults. Clin Exp Allergy 2000; 30 (10): 1460-8.

44. PentTilä M. Dose-related efficacy and tolerability of fluticasone propionate nasal drops 400 microg once daily and twice daily in the treatment of bilateral nasal polyposis: A placebo-controlled randomized study in adult patients. Clin Exp Allergy 2000; 30(1): 94-102.

45. SMALL CB. Efficacy and safety of mometasone furoate nasal spray in nasal polyposis. J Allergy Clin Immunol 2005; 116(6): 1275-81. Epub 2005 Sep 26.

46. StJÄRNE P. A randomized controlled trial of mometasone furoate nasal spray for the treatment of nasal polyposis. Arch Otolaryngol Head Neck Surg 2006; 132(2): 179-85.

47. Cuenant G. Efficacy of endonasal neomycintixocortol pivalate irrigation in the treatment of chronic allergic and bacterial sinusitis. ORL $J$ Otorhinolaryngol Relat Spec 1986; 48(4): 226-32.

48. SYKES DA. Relative importance of antibiotic and improved clearance in topical treatment of chronic mucopurulent rhinosinusitis. A controlled study. Lancet 1986; 16; 2(8503): 359-60.

49. PARIKH A. Topical corticosteroids in chronic rhinosinusitis: A randomized, double-blind, placebo-controlled trial using fluticasone propionate aqueous nasal spray. Rhinology 2001; 39(2): 75-9.

50. LAVIGNE F. Intrasinus administration of topical budesonide to allergic patients with chronic rhinosinusitis following surgery. Laryngoscope 2002; 112: 858-64.
51. Lund VJ. Efficacy and tolerability of budesonide aqueous nasal spray in chronic rhinosinusitis patients. Rhinology 2004; 42: 57-62.

52. Bhattacharyy NL. The economic burden and symptom manifestations of chronic rhinosinusitis. Am J Rhinol 2003; 17: 27-32.

53. Haye R, Aanesen JP, Burtin B, Donnelly F, Duby C.The effect of cetirizine on symptoms and signs of nasal polyposis. J Laryngol Otol 1998; 112(11): 1042-6.

54. Ponikau JU, Sherris DA, Kita H, Kern eB. Intranasal antifungal treatment in 51 patients with chronic rhinosinusitis. J Allergy Clin Immunol 2002; 110: 862-6.

55. Ponikau JU, Sherris da, Weaver A, Kita $H$. Treatment of chronic rhinosinusitis with intranasal amphotericin B: A randomized, placebo-controlled, double-blind pilot trial. $J$ Allergy Clin Immunol 2005; 115: 125-31.

56. Weschta M, Rimek D, Formanek M, Polzehl D, Podbielski A, Riechelmann $H$. Topical antifungal treatment of chronic rhinosinusitis with nasal polyps: A randomized, double-blind clinical trial. J Allergy Clin Immunol 2004; 113: 1122-8.

57. EBBENS F. Amphotericin B nasal lavages: Not a solution for patients with chronic rhinosinusitis. J Allergy Clin Immunol 2006; 118: 1149-56.

58. Kal-LI LIANG, M.D. Amphotericin B irrigation for the treatment of chronic rhinosinusitis without nasal polyps: A randomized, placebocontrolled, double-blind study. Am J Rhinol 2008; 22: 52-58.

59. Kennedy DW, Kuhn FA, Hamilos DL, et al. Treatment of chronic rhinosinusitis with high-dose oral terbinafine: A double blind, placebo-controlled study. Laryngoscope 2005; 115: 1793-9.

60. OtTEN FW. Conservative treatment of chronic maxillary sinusitis in children. Long-term follow-up. Acta Otorhinolaryngol Belg 1997; 51(3): 173-5.

61. Bachmann G, Hommel G, Michel OL. Effect of irrigation of the nose with isotonic salt solution on adult patients with chronic paranasal sinus disease. Eur Arch Otorhinolaryngol 2000; 257(10): 537-41.

62. Taccariello M, Parikh A, Darby Y, et al. Nasal douching as a valuable adjunct in the management of chronic rhinosinusitis. Rhinology 1999; 37(1): 29-32. 
63. Rabago D, Zgierska A, Mundt M, et al. Efficacy of daily hypertonic saline nasal irrigation among patients with sinusitis: a randomized controlled trial. J Fam Pract 2002; 51(12): 1049-55.

64. Shoseyov D, Bibi H, Shal P, et AL. Treatment with hypertonic saline versus normal saline nasal wash of pediatric chronic sinusitis. J Allergy Clin Immunol 1998; 101(5): 602-5.

65. TALBOT ET AL. Mucociliary clearance and buffered saline hypertonic solution. Laryngoscope 1997; 197: 500-3.

66. Shoseyov D, Bibi H, Shai P, Shoseyov N, Shazberg G, HuRvitz H. Treatment with hypertonic saline versus normal saline nasal wash of pediatric chronic sinusitis. J Allergy Clin Immunol 1998; 101: 602-5.

67. Harvey R, Hannan SA, Badia L, Scadding G. Nasal saline irrigations for the symptoms of chronic rhinosinusitis. Cochrane Database of Systematic Reviews 2007, Issue 3. Art. No.: CD006394. DOI: 10.1002/14651858.CD006394.pub2.

68. Garavello W, Romagnoli M, Sordo L, Gaini RM, Di Berardino C, Angrisano A. Hypersaline nasal irrigation in children with symptomatic seasonal allergic rhinitis: A randomized study. Pediatr Allergy Immunol 2003; 14(2): 140-3.

69. Garavello W, Di Berardino F, Romagnoli M, Sambataro G, Gainl RM. Nasal rinsing with hypertonic solution: An adjunctive treatment for pediatric seasonal allergic rhinoconjunctivitis. Int Arch Allergy Immunol 2005; 137(4): 310-4.

70. Rabago D, Zgierska A, Mundt M, Barrett B, Bobula J, MaberRy R. Efficacy of daily hypertonic saline nasal irrigation among patients with sinusitis: A randomized controlled trial. J Fam Pract 2002; 51: 1049-55.

71. Heatley DG,McConnell KE, Kille TL, et al. Nasal irrigation for the alleviation of sinonasal symptoms. Otolaryngol Head Neck Surg 2001; 125: 44-8.

72. Rogkakou A, Guerra L, Massacane P, et al. Effects on symptoms and quality of life of hypertonic saline nasal spray added to antihistamine in persistent allergic rhinitis: A randomized controlled study. Allerg Immunol (Paris) 2005; 37: 353-6.

73. Cordray S, Harjo JB, Miner L. Comparison of intranasal hypertonic Dead Sea saline spray and intranasal aqueous triamcinolone spray in seasonal allergic rhinitis. Ear Nose Throat $J$ 2005; 84: 426-30.

74. Bachmann G, Hommel G, Michel 0. Effect of irrigation of the nose with isotonic salt solution on adult patients with chronic paranasal sinus disease. Eur Arch Otorhinolaryngol 2000; 257: 537-41.

75. Shoseyov D, Bibi H, Shai P, Shoseyov N, Shazberg G, HuRvitz $H$. Treatment with hypertonic saline versus normal saline nasal wash of pediatric chronic sinusitis. J Allergy Clin Immunol 1998; 101: 602-5.

76. McCarTY MS. Potential new avenues of treatment for chronic rhinosinusitis: An antiinflammatory approach. Otolaryngol Clin North Am 2005; 38: 1351-65.

77. Amrol D, Murray JJ. Curr Alternative medical treatment strategies for chronic hyperplastic eosinophilic sinusitis. Curr Opin Otolaryngol Head Neck Surg 2005; 1: 55-9.

78. KiefF DA, Busaba NY. Efficacy of montelukast in the treatment of nasal polyposis. Ann Otol Rhinol Laryngol 2005; 114(12): 941-5.

79. Stewart Ra, Ram B, Hamilton G, Weiner J, Kane KJ. Montelukast as an adjunct to oral and inhaled steroid therapy in chronic nasal polyposis. Otolaryngol Head Neck Surg 2008; 139(5): 682-7.

80. Dahlén B, Nizankowska E, Szczeklik a et al. Benefits from adding the 5-lipoxygenase inhibitor zileuton to conventional therapy in aspirin-intolerant asthmatics. Am J Respir Crit Care Med 1998; 157: 1187-94.

81. Ulualp S0, Toohill RJ, Hoffmann R, et al. Possible relationship of gastroesophagopharyngeal acid reflux with pathogenesis of chronic sinusitis. Am J Rhinol 1999; 13(3): 197-202. 


\title{
Mecanismos de resistencia antimicrobiana en patógenos respiratorios
}

\author{
Antimicrobial resistance mechanisms in respiratory pathogens
}

\author{
Claudia Moreno M', Rubén González E², Constanza Beltrán³.
}

\begin{abstract}
RESUMEN
Las infecciones del tracto respiratorio representan la indicación más frecuente de antibióticos en pacientes ambulatorios, lo cual se hace sobre bases empíricas. Una falla clínica al tratamiento puede explicarse por resistencia antimicrobiana, que últimamente ha aumentado en patógenos respiratorios. Los microorganismos desarrollan nuevos mecanismos de resistencia antibiótica y comparten virulencia por diversos sistemas. Este fenómeno representa un problema clínico y dificulta el manejo de patologías infecciosas, por lo cual es necesario utilizar nuevas estrategias para el uso adecuado de antimicrobianos. Patógenos respiratorios como S. pneumoniae y S. pyogenes presentan resistencia a betalactámicos por mutaciones en las uniones proteicas a penicilina $(P B P)$ y la resistencia a macrólidos se explica por dos mecanismos: metilación del ribosoma y expulsión del antibiótico por bombas de eflujo; $\mathrm{H}$. influenzae y M. catarrhalis expresan resistencia a betalactámicos debido a hidrólisis enzimática por b-lactamasas.

Palabras clave: Resistencia, antimicrobiana, transferencia horizontal de genes, patógenos, respiratorio.
\end{abstract}

\begin{abstract}
Respiratory tract infections are the most frequent indication of antibiotics in outpatient settings, based on empirical data. Clinical treatment failure can be explained by antimicrobial resistance, which has recently increased in respiratory pathogens. Microorganisms develop new antimicrobial resistance mechanisms and virulence is shared by different systems. This phenomenon represents a clinical problem and hampers the handling of infectious diseases. It is therefore necessary to utilize new strategies for the appropriate use of antimicrobials. Respiratory pathogens such as $S$. pneumoniae and $S$ pyogenes present antimicrobial resistance to beta-lactams by mutations in penicilin binding proteins (PBP); resistance to macrolides is explained by two mechanisms: ribosome methylation and antibiotic export by efflux pumps. $\mathrm{H}$. influenzae and $M$. catarrhalis express beta-lactam resistance due to enzymatic hydrolysis by $b$-lactamases.
\end{abstract}

Key words: Resistance, antimicrobial, horizontal gene transfer, pathogens, respiratory.

\footnotetext{
Médico de Microbiología, Facultad de Medicina, Universidad de Chile.

Médico del Departamento de Otorrinolaringología, Escuela de Medicina, Pontificia Universidad Católica de Chile.

Médico Otorrinolaringólogo, Escuela de Medicina, Pontificia Universidad Católica de Chile.
} 


\section{INTRODUCCIÓN}

Las infecciones del tracto respiratorio son la principal causa de consulta médica a nivel de atención primaria y representan la indicación más frecuente de antibióticos en pacientes ambulatorios, lo cual se hace sobre bases empíricas. Estas infecciones pueden presentar serias complicaciones si son tratadas de manera inefectiva ${ }^{1}$.

La resistencia antimicrobiana ha aumentado en patógenos respiratorios, constituyendo un importante problema para la elección de un antibiótico. Los microorganismos han desarrollado sistemas de resistencia a diversos agentes antimicrobianos ${ }^{2}$. Las bacterias han evolucionado, compartiendo información genética entre ellas. Existen interacciones recíprocas entre las bacterias y el huésped, generando un sistema en homeostasis ${ }^{3}$. Estas poblaciones bacterianas reciben el nombre de microbiota normal (conocida como flora bacteriana) localizada en la cavidad oral, nasofaringe, piel, mucosa intestinal y genitourinaria. La microbiota puede proteger de agentes patógenos ${ }^{4}$. La presencia y desarrollo de estos microorganismos se denomina colonización, sin expresión clínica ni detección de respuesta inmune en el huésped $^{6}$. Estas bacterias pueden producir infec- ción cuando disminuye el sistema inmune, frente a tratamiento inmunomodulador, uso de instrumentos invasivos o por un desbalance de la microbiota en el curso de un tratamiento antibiótico $0^{6}$.

Los microorganismos patógenos poseen genes de virulencia que les da la capacidad de producir daño a un huésped susceptible. La diseminación de esta virulencia entre especies bacterianas mediante transferencia horizontal de genes determina la evolución de patógenos emergentes ${ }^{7}$.

En este nuevo escenario, es relevante conocer los mecanismos principales de resistencia antimicrobiana y las opciones terapéuticas en el caso de los principales patógenos respiratorios.

\section{MECANISMOS DE RESISTENCIA BACTERIANA}

La resistencia antimicrobiana es un problema continuo y en aumento. Se hace aún mayor cuando un microorganismo presenta más de un mecanismo de resistencia y cuando tiene la facultad de transmitirlo, no sólo a su descendencia, sino también a otras bacterias de su misma 0 diferente especie ${ }^{8}$.

Los fenómenos de resistencia antimicrobiana son variados, destacando entre ellos cuatro mecanismos principales (Figura 1):

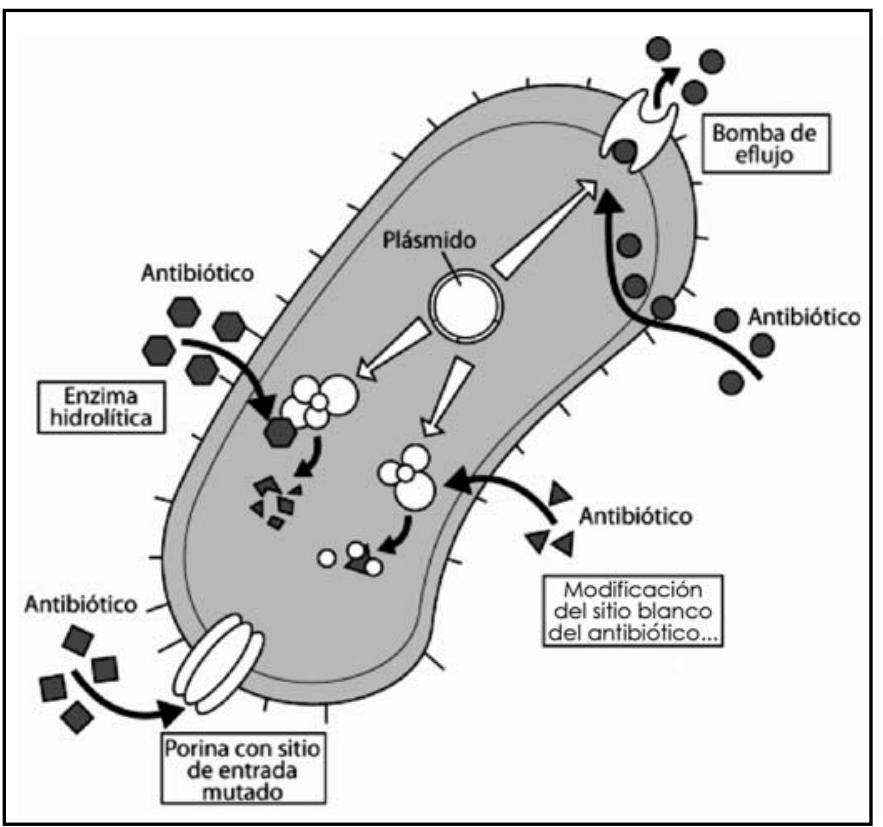

Figura 1. Mecanismos de resistencia antimicrobiana. 


\section{1) Enzimas hidrolíticas}

Las bacterias sintetizan enzimas que hidrolizan al antimicrobiano, destruyendo su acción antibacteriana, sin tener posibilidad de actuar sobre el microorganismo.

- Beta-lactamasas: son enzimas que hidrolizan la unión peptídica endocíclica del anillo betalactámico ${ }^{9}$. La producción de beta-lactamasas es el mecanismo más frecuente de resistencia antibiótica. Existen continuas mutaciones que producen expresión de beta-lactamasas de espectro extendido (BLEE), manifestándose como resistencia a cefalosporinas de $3^{\mathrm{a}}$ generación (ceftriaxona). Para combatir esta resistencia se utiliza un inhibidor enzimático que tiene mayor afinidad a la enzima e impide la destrucción del antimicrobiano y de esta manera permite su acción (clavulanato y sulbactam). Las BLEE se asocian a co-resistencia con aminoglicósidos y cotrimoxazol, dada la frecuencia de transferencia en el mismo plasmidio.

\section{2) Modificación del sitio activo}

La modificación de un aminoácido genera un blanco diferente y así disminuye la afinidad de unión por el antimicrobiano.

- Modificación de PBP: El PBP (penicillinbinding-protein) es un complejo enzimático que permite la síntesis del peptidoglicano, un compuesto de la pared celular en bacterias, principalmente en Gram positivas, si se produce mutación del sitio de unión al antimicrobiano como los beta-lactámicos, éstos no pueden actuar y se genera resistencia a ellos.

- Modificación ribosomal: Los genes erm A y erm $B$ producen modificación del sitio activo del ribosoma, mediante metilación. Este mecanismo es importante en la resistencia a macrólidos en $S$. pneumoniae y $S$. pyogenes ${ }^{10}$.

\section{3) Disminución de la permeabilidad de la pared celular al ingreso del antimicrobiano}

Cambios en el diámetro y/o número de porinas pueden bloquear el ingreso del antimicrobiano a la bacteria.
- Porinas: Existe disminución de la expresión de porinas (downregulation) lo que disminuye la susceptibilidad a betalactámicos y fluorquinolonas en Pseudomonas ${ }^{11}$.

\section{4) Bombas de eflujo}

Transporta al antimicrobiano hacia el exterior de la célula sin modificaciones, pero sin acción antimicrobiana. Existen bombas de eflujos multidrogas en la pared bacteriana que permiten la expulsión de drogas como los antimicrobianos. Los genes involucrados son MefA (Streptococcus pneumoniae), NorA (Staphylococcus aureus) y Mex (Pseudomonas aeruginosa). Estos genes explican la resistencia a macrólidos en estos patógenos $^{12}$ y a fluoroquinolonas. Para combatir este tipo de resistencia se encuentran en estudio la asociación de inhibidores de bombas de eflujo junto con el antimicrobiano ${ }^{13}$.

\section{TRANSFERENCIA HORIZONTAL DE GENES}

La transferencia horizontal de genes es el traspaso de información genética entre bacterias, proceso diferente a la replicación. Permite variabilidad genética y evolución bacteriana, generando la capacidad de adaptarse a las variaciones del medio. Las bacterias utilizan diversas vías para transferir información genética: conjugación, transducción y transformación (Figura 2). Estos mecanismos son el mayor determinante en la evolución bacteriana, diseminando genes de virulencia ${ }^{14}$. Es una transmisión dinámica que genera plasticidad en los genomas, dando propiedades patogénicas a muchos agentes infecciosos, previamente inocuos ${ }^{15}$.

\section{Conjugación}

Proceso mediado por plasmidios, elementos conjugativos, que tienen la propiedad de transferirse de una célula a otra gracias a un contacto cercano entre ambas células mediante un poro de conjugación o pili sexual. Los plasmidios son elementos genéticos móviles, de forma circular, poseen replicación propia, es decir, independiente de la duplicación bacteriana. Dentro de su información poseen casettes génicos que codifican para resistencia bacteriana. 


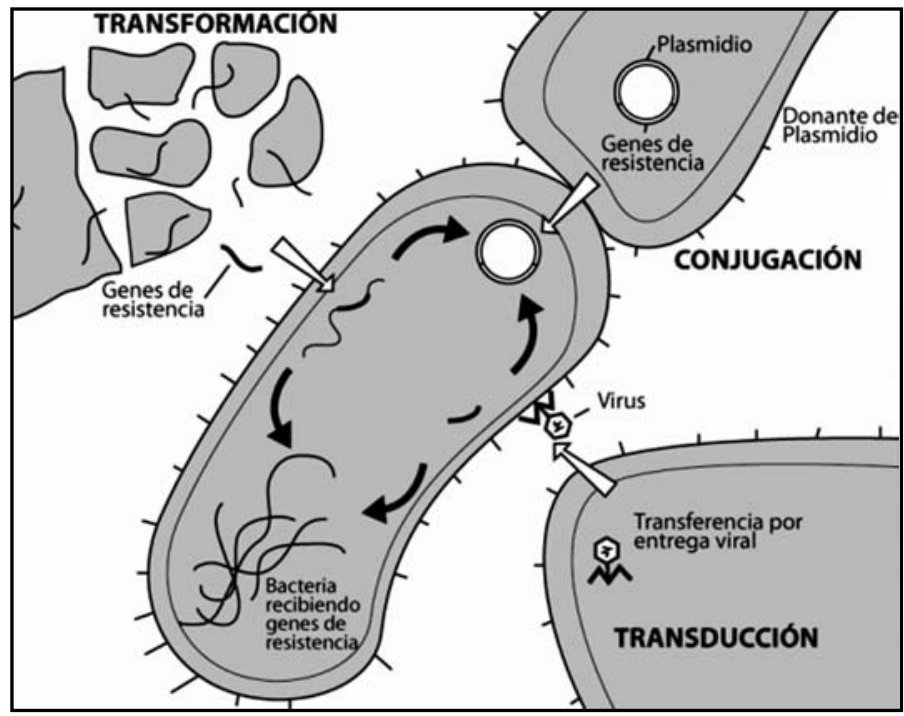

Figura 2. Transferencia horizontal de genes. Se adquiere material genético por conjugación, transducción y transformación. Además se producen deleciones y mutaciones genéticas, que optimizan los procesos bacterianos ${ }^{16}$.

\section{Transducción}

Es la transferencia de material genético de una bacteria a otra mediante un virus que infecta bacterias (bacteriófago). Este virus puede integrarse en el genoma bacteriano y al transferirse a otra célula puede llevar parte del genoma de esta bacteria y así trasferir genes, entre ellos genes de resistencia antimicrobiana.

\section{Transformación}

Es la captura de ADN extracelular del medio, que puede integrarse en el genoma y expresarse.

\section{BACTERIAS DE IMPORTANCIA EN ORL}

Las infecciones del tracto respiratorio representan la causa más frecuente de consulta médica y de prescripción antibiótica. El tracto respiratorio superior es más susceptible de infecciones bacterianas en individuos con cuadros alérgicos, infecciones virales, efectos del tabaquismo y la contaminación ambiental. Streptococcus pneumoniae, Haemophilus influenzae y Moraxella catarrhalis constituyen los principales agentes patógenos del tracto respiratorio que se adquieren en la comunidad ${ }^{17}$. Durante los últimos 20 años se ha observado un aumento de la resistencia antibiótica en muchas bacterias patógenas respiratorias, con modesto desarrollo de nuevos antimicrobianos para combatir este problema. La producción de beta-lactamasa es uno de los mecanismos principales de resistencia de estos organismos, otros mecanismos incluyen impermeabilidad a la membrana, bombas de eflujo, alteración del ribosoma ${ }^{18}$. Estudios en OMA muestran una resistencia a $S$. pneumoniae y $H$. influenzae, asociado a una disminución de la respuesta bacteriológica del tratamiento antimicrobiano, con impacto en la respuesta clínica. Esto sucede por el uso masivo y frecuente de Ios antimicrobianos, que selecciona cepas resistentes que luego son portadas en la cavidad nasofaríngea de niños y transmitidas a sus familiares y compañeros de escuela, creando un círculo vicioso, aumentando aún más la resistencia y disminuyendo la respuesta clínica, incrementando nuevamente el uso de antimicrobianos $^{19}$. Se ha observado que el tejido adenoideo de individuos sanos generalmente es colonizado por bacterias aeróbicas y anaeróbicas que interfieren el desarrollo de patógenos, esta protección no sucede en pacientes con infecciones recurrentes del tracto respiratorio. En consecuencia, es importante mantener los beneficios de la microbiota normal 
evitando la exposición innecesaria a los antimicrobianos y así prevenir la colonización de adenoides por potenciales patógenos ${ }^{20}$.

Algunas de las bacterias que dan grandes problemas de resistencia antimicrobiana en infecciones respiratorias son: Streptococcus pneumoniae, Haemophilus influenzae, Streptococcus pyogenes, Pseudomonas aeruginosa.

\section{Streptococcus pneumoniae}

Se describe resistencia a penicilina en 20\%-30\% y a cefotaximo en $15 \%$. Existen diferencias según grupo etario: la resistencia de alto nivel a penicilina es de $30 \%$ en niños menores de 5 años de edad y notablemente inferior (12\%-13\%) en niños sobre 5 años. Con cefotaximo se observa la misma diferencia siendo menos notable. Esta alta resistencia se puede atribuir al uso masivo de antimicrobianos en niños, el intercambio de microorganismos en los jardines infantiles, y otras situaciones que lleven a diseminación de las cepas ${ }^{21}$.

Los mecanismos de resistencia de $S$. pneumoniae a beta-lactámicos, son variados, siendo el más importante la alteración de PBP (penicillin binding protein) ${ }^{22}$, proteínas de síntesis de la pared celular (1a, 1b, 2a, 2b, 2x). Dentro de este grupo, 1a y $2 b$ son de alto nivel de resistencia a la penicilina y 1 a y $2 x$ para cefalosporinas de tercera generación (cefotaxima).

Se produce un interesante fenómeno de transferencia genética entre Streptococcus del grupo viridans con $S$. pneumoniae en la faringe al existir selección por el uso de antimicrobianos (especialmente ampicilina y amoxicilina).

La resistencia a macrólidos se describe en $25 \%$, los mecanismos de resistencia a macrólidos más frecuentes en $S$. pneumoniae son la metilación del ribosoma mediante el gen erm $B$ en $58 \%$ y sistemas de bombas de eflujo mediante el gen mef $A$ en $30 \%$ aproximadamente, existen cepas con ambos genes de resistencia, en $12 \%{ }^{23}$.

La resistencia a fluoroquinolonas respiratorias como levofloxacino y moxifloxacino es menos del $1 \%$. Los mecanismos de resistencia a fluororquinolonas son por mutación de enzimas como girasa y topoisomerasa, sitios donde actúa el antimicrobiano, y sistemas de eflujo, identificadas en el gen pmrA. Afortunadamente, las nuevas fluoroquinolonas no presentan altos grados de resistencia como el ciprofloxacino y disminuyen el riesgo de la emergencia de cepas resistentes ${ }^{24}$.

\section{Haemophylus influenzae}

La prevalencia ha disminuido en forma dramática, especialmente el serotipo b, debido a la incorporación de la vacuna en 1996 en el plan nacional de inmunizaciones. En el estudio LASER se han identificado cepas productoras de beta-lactamasa en Latinoamérica, desde 15\% (Brasil) -25\% (Panamá); Chile muestra una prevalencia de $18 \%$ de este mecanismo. La producción de beta-lactamasa es el mecanismo más importante de resistencia a las aminopenicilinas, presentando variación según la zona geográfica. La susceptibilidad antibiótica es superior al 95\% cuando se utilizan inhibidores de beta-lactamasa como es clavulanato o sulbactam, asociado al beta-lactámico ${ }^{25}$.

\section{Moraxella catarrhalis}

Existe alta prevalencia de producción de betalactamasa, cercana al $100 \%$, en muchos países a nivel mundial, lo que le confiere resistencia a amoxicilina en $80 \%-100 \%$. Otras resistencias antimicrobianas son: $5 \%$ a macrólidos, $14 \%$ para amoxicilina/ac. clavulánico, 20\% cefuroximo y $30 \%$ cotrimoxazol. Con respecto a fluoroquinolonas, se observó $100 \%$ de cepas sensibles.

\section{Streptococcus pyogenes}

Existen Streptococcus B-hemolíticos A, B, C, F, G y no agrupables. Algunos son estreptococos «piogénicos» con una variedad de mecanismos efectivos de virulencia que se traducen en su patogenicidad, mientras otros habitualmente forman parte de la microbiota comensal, aunque pueden aislarse en abscesos (Streptococcus milleri y Streptococcus anginosus) ${ }^{26}$.

La sensibilidad a penicilina no ha tenido cambios importantes, sin embargo, puede existir falla en la erradicación bacteriológica del $S$. pyogenes de la faringe, cercanas al 30\%, situación indispensable para la prevención de la enfermedad reumática.

Los macrólidos, muestran eficacia similar a la penicilina en pacientes con infecciones por $S$. 
pyogenes. Su uso indiscriminado ha generado la aparición de cepas resistentes, la resistencia a eritromicina es de $0,5 \%$ a $60 \%$, en Chile se ha descrito resistencia en $7,2 \%$.

Dentro de los mecanismos de resistencia descritos para los macrólidos destaca como más importante la alteración en el ribosoma, mediante una enzima metilasa dependiente del gen erm, de origen plasmidial 0 cromosomal ${ }^{27}$. El mecanismo de resistencia de eflujo se ubica en el gen $m e f A$, corresponde a cepas resistentes a eritromicina, pero susceptibles a clindamicina.

\section{Pseudomonas aureginosa}

Pseudomonas es responsable de muchas infecciones severas como otitis externa difusa, otitis externa maligna, OMC y pericondritis. Dentro de los beta-lactámicos, los únicos con acción antipseudomona son ceftazidima, cefoperazona y cefepime, la susceptibilidad a ceftazidima se mantiene en más del $90 \%$, sin embargo la resistencia a ciprofloxacino ha aumentado ${ }^{28}$. La resistencia antimicrobiana es una causa importante en la falla del tratamiento. Los mecanismos de resistencia se expresan por genes para bombas de eflujo, mutaciones que modifican el sitio de acción de los antimicrobianos, producción de $\beta$ lactamasas y disminución de la permeabilidad al antibiótico. La resistencia a fluoroquinolonas es de $25 \%$ y se explica por sistemas de eflujo. Este problema se soluciona aumentando las concentraciones en el sitio de acción para la erradicación efectiva y la prevención de cepas resistentes. La disminución de la expresión de porinas a nivel de la membrana externa, genera resistencia a imipenem y meropenem ${ }^{29}$.

\section{DISCUSIÓN}

El tratamiento antibiótico se realiza de manera empírica en la práctica clínica otorrinolaringológica, sin embargo el fracaso a los tratamientos obliga a identificar las cepas bacterianas y su patrón de resistencia antibiótica.

La elección de un tratamiento antimicrobiano para otitis y sinusitis se ha vuelto más compleja debido al incremento en las tasas de resistencia antimicrobiana en los patógenos respiratorios. Entre las opciones terapéuticas siguen destacando beta-lactámicos como amoxicilina, amoxicilinaclavulánico; macrólidos y fluoroquinolonas. Las cefalosporinas orales como cefuroximo son una buena alternativa para casos complejos.

Asociado a la resistencia antimicrobiana existen pacientes más susceptibles a las infecciones bacterianas, debido a la disminución o ineficiencia de la respuesta inmune, es el caso de pacientes diabéticos, inmunosuprimidos (VIH, cáncer), drogas inmunomoduladoras (trasplantes), edades extremas, entre otras, lo que genera un problema mayor.

El control de la prescripción de antimicrobianos permite cambiar patrones de resistencia, es fundamental mantener indicaciones correctas de acuerdo al diagnóstico planteado, seleccionando un tratamiento adecuado. Esta estrategia puede disminuir el problema de resistencia.

Conocer los mecanismos de resistencia permite investigar nuevos blancos de acción para blo-

Tabla 1. Mecanismos de resistencia antimicrobiana en los principales patógenos respiratorios ${ }^{30}$

\begin{tabular}{|lll|}
\hline Patógeno respiratorio & Antimicrobiano & Mecanismo de resistencia \\
\hline S. pneumoniae & Betalactámicos & Mutación de PBP \\
& Macrólidos & Metilación del ribosoma (genes erm) \\
& & Bombas de eflujo (genes mefA) \\
H. influenzae y M. catarrhalis & Betalactámicos & Hidrólisis enzimática por betalactamasas \\
S. pyogenes & Betalactámicos & Sin resistencia \\
& Macrólidos & Metilación del ribosoma (genes erm) \\
& & Bombas de eflujo (genes mefA) \\
\hline
\end{tabular}


quear estos mecanismos, y así permitir la acción antimicrobiana deseada, como sucede con inhibidores de beta-lactamasas. En el futuro, pueden ser importantes los inhibidores de bombas de eflujo, como ya se está estudiando para cepas resistentes en Pseudomonas, importante en el manejo de otitis externa maligna.

\section{Agradecimientos}

Sabina Lorca M, Neurobiology, Houston, Texas. USA Sebastián Aravena 0, diseñador gráfico.

\section{BIBLIOGRAFÍA}

1. Nicolau D. Clinical and economic implications of antimicrobial resistance for the management of community-acquired respiratory tract infections. J Antimicrob Chemother 2002; 50 Suppl S1: 61-70.

2. Martínez JL, Baquero F, Andersson DI. Predicting antibiotic resistance. Nat Rev Microbiol 2007; 5(12): 958-65.

3. VIRGIN HW. In vivo veritas: pathogenesis of infection as it actually happens. Nat Immunol 2007; 8(11): 1143-7.

4. Stecher B, HaRdt WD. The role of microbiota in infectious disease. Trends Microbiol 2008; 16(3): 107-14. Epub 2008 Feb 14.

5. JARVIS WR. The epidemiology of colonization. Infect Control Hosp Epidemiol 1996; 17(1): 4752.

6. Jarvis WR. The epidemiology of colonization. Infect Control Hosp Epidemiol 1996; 17(1): 47-52.

7. Groisman EA, Casadesús J. The origin and evolution of human pathogens. Mol Microbiol 2005; 56(1): 1-7.

8. Valenzuela, M Teresa, Prat, M Soledad, Santolaya, M Elena et al. Starting a national surveillance network of antibiotic resistance classified by clinical síndromes. Rev Chil Infect (2003); 20 (2): 119-25.

9. Viswanatha T, Marrone L, Goodfellow V, DMITRIENKo Gl. Assays for beta-lactamase activity and inhibition. Methods Mol Med 2008; 142: 239-60.

10. Wierzbowski AK, Hoban DJ, Hisanaga T, Decorby M, Zhanel GG. The Use of Macrolides in
Treatment of Upper Respiratory Tract Infections. Curr Infect Dis Rep 2005; 7(3): 17584.

11. Driscoll JA, Brody SL, Kollef MH. The epidemiology, pathogenesis and treatment of Pseudomonas aeruginosa infections. Drugs 2007; 67(3): 351-68.

12. Gотон N. Antibiotic resistance caused by membrane impermeability and multidrug efflux systems. Nippon Rinsho 2001; 59(4): 712-8.

13. Zhanel GG, Hoban DJ, Schurek K, Karlowsky JA. Role of efflux mechanisms on fluoroquinolone resistance in Streptococcus pneumoniae and Pseudomonas aeruginosa. Int I Antimicrob Agents 2004; 24(6): 529-35.

14. BG Kelly A, A Vespermann, DJ Bolton. The role of horizontal gene transfer in the evolution of selected foodborne bacterial pathogens. Food Chem Toxicol 2008; Feb 14.

15. Ahmed N, Dobrindt U, Hacker J, Hasnain SE. Genomic fluidity and pathogenic bacteria: applications in diagnostics, epidemiology and intervention. Nat Rev Microbiol 2008; 6(5): 387-94.

16. BG Kelly A, A. Vespermann, DJ Bolton. The role of horizontal gene transfer in the evolution of selected foodborne bacterial pathogens. Food Chem Toxicol 2008; Feb 14.

17. BRook I. Effects of antimicrobial therapy on the microbial flora of the adenoids. J Antimicrob Chemother 2003; 51(6): 1331-7.

18. Cappelletty D. Microbiology of bacterial respiratory infections. Pediatr Infect Dis $J$ 1998; 17(8 Suppl): S55-61.

19. Dagan R. Treatment of acute otitis media challenges in the era of antibiotic resistance. Vaccine 2000; 19 Suppl 1: S9-S16.

20. BRook I. Effects of antimicrobial therapy on the microbial flora of the adenoids. $J$ Antimicrob Chemother 2003; 51(6): 1331-7.

21. M. Pinto. Antimicrobial agents resistance in Chile nowdays. Rev Chil Infect (2002); 19 (Supl 3): S213-S218.

22. ChIOU CC, HseiH KS. Pneumococcal infection in children: rational antibiotic choice for drugresistant Streptococcus pneumoniae. Acta Paediatr Taiwan 2003; 44(2): 67-74.

23. Felmingham D, Cantón R, Jenkins SG. Regional trends in beta-lactam, macrolide, fluoroqui- 
nolone and telithromycin resistance among Streptococcus pneumoniae isolates 20012004. J Infect 2007; 55(2): 111-8. Epub 2007 Jun 12.

24. Zhanel GG, Hoban DJ, Schurek K, Karlowsky JA. Role of efflux mechanisms on fluoroquinolone resistance in Streptococcus pneumoniae and Pseudomonas aeruginosa. Int $J$ Antimicrob Agents 2004; 24(6): 529-35.

25. Alpuche C, Garau J, Lim V. Global and local variations in antimicrobial susceptibilities and resistance development in the major respiratory pathogens. Int $J$ Antimicrob Agents 2007; 30 Suppl 2: S135-8. Epub 2007 Oct 22.

26. Rossanna Camponovo. Antimicrobial resistance in Streptococcus pyogenes. Rev Chil Infectol v.19 supl. 2 Santiago 2002.
27. Claudia Vinagre, Marcela Cifuentes, Francisca Valdivieso, Alicia OJeda, Valeria Prado. Emergence of macrolide resistant Streptococcus pyogenes strains. Rev Méd Chile v.127 n.12 Santiago dic. 1999.

28. ELIES W. Current therapeutical management, new antibiotics and treatment of Pseudomonas aeruginosa in bacterial ENT-infections. Laryngorhinootologie 2002; 81(1): 40-5.

29. Farra A, Islam S, Strålforos A, Sörberg M, WRETLIND B. Role of outer membrane protein OprD and penicillin-binding proteins in resistance of Pseudomonas aeruginosa to imipenem and meropenem. Int $J$ Antimicrob Agents 2008; 31(5): 427-33.

30. Baquero y col. Clin Microb Infect 1998; 4 ( supl 2): $19-26$. 


\section{REVISTA DE REVISTAS}

TRATAMIENTO DE LA HIPOACUSIA SÚBITA. I. UNA REVISIÓN SISTEMÁTICA

Treatment of Sudden Sensorineural Hearing Loss. I. A Systematic Review

Anne Elizabeth Conlin, BA\&Sc, MD; Lorne S. Parnes, MD, FRCSC. Arch Otolaryngol Head Neck Surg. 2007; 133: 573-581

Introducción: Uno de los tópicos más controvertidos en la otorrinolaringología es el tratamiento de la Hipoacusia Súbita (HS). El Instituto Nacional de Ios EE.UU. para la Sordera y Trastornos de la Comunicación (NICDC) la define como una pérdida auditiva sensorioneural aguda, unilateral, de más de $30 \mathrm{~dB}$, en tres frecuencias vecinas, y de evolución no superior a tres días (72 horas). Se estima una incidencia global de 5 a 20/100.000 habitantes por año.

Su tratamiento es ampliamente variable, tanto en la forma y en la dosificación; es más, algunos especialistas optan por no tratar a algunos pacientes, dado que se reportan tasas de recuperación espontánea de $32 \%$ a $70 \%$. Sin embargo, el tratamiento más utilizado en norteamérica son los esteroides sistémicos, usados por algunos autores como gold standard, pese a que la evidencia es de discutible calidad metodológica.

Objetivo: Identificar, evaluar y revisar estudios clínicos randomizados, en el tratamiento de la HS.

Métodos: Búsqueda manual y en MEDLINE en idioma inglés, de estudios clínicos randomizados (ECR), en el tratamiento de la HS, publicados entre enero de 1966 y febrero de 2006. Los términos de búsqueda fueron hearing loss, sensorineural (término MeSH), sensorineural hearing loss y sudden deafness.

Se seleccionaron ECR prospectivos en el tratamiento de pacientes con diagnóstico de HS. Los datos fueron extraídos por un observador independiente; la validez fue evaluada utilizando criterios estándar. Características y resultados fueron revisados sistemáticamente.
Resultados: Se encontraron $21 \mathrm{ECR}$, referentes a diversos tratamientos como esteroides sistémicos e intratimpánicos, terapias vasoactivas y de hemodilución (pentoxifilina, dextrán, Ginkgo biloba, y nifedipino), antivirales, minerales, vitaminas, preparaciones a base de hierbas, batroxobina, carbógeno y oxígeno hiperbárico. Todos los estudios utilizaron como outcome mediciones audiométricas.

Sólo 2 estudios utilizaron criterios idénticos para definir HS. El método de randomización fue descrito en 2 estudios. Los puntajes de validez estuvieron entre 2 y 8 puntos, de un máximo de 9 . Se reportaron resultados favorables con el uso de esteroides sistémicos, intratimpánicos, batroxobina, magnesio, vitamina $\mathrm{E}$, y con oxígeno hiperbárico, aunque existían serias limitaciones metodológicas en todos estos estudios.

No hubo diferencia estadísticamente significativa entre los resultados audiométricos obtenidos en los estudios que usaron antivirales y terapias vasoactivas y de hemodilución, como tampoco en uno de los 2 estudios que compararon esteroides sistémicos versus placebo (Cinamon U, Bendet E, Kronenberg J. Steroids, carbogen or placebo for sudden hearing Ioss: a prospective double-blind study. Eur Arch Otorhinolaryngol 2001; 258(9): 477-80).

Conclusiones: Existen muy pocos ECR válidos, y ninguno concluyente que nos permita dilucidar la terapia más apropiada y eficaz para el tratamiento de la HS. A la luz de tan sólo 2 estudios que evalúan con una metodología aceptable a los esteroides sistémicos versus placebo, y con resultados disímiles, éstos no deberían ser considerados como gold standard para el tratamiento de la HS. Sin embargo, dado que no existen terapias más efectivas, es recomendable continuar su uso en el tratamiento de la HS.

Dra. Carolina Aranís J. Hospital Clínico, Pontificia Universidad Católica de Chile 
RESULTADOS A LARGO PLAZO EN DACRIOCISTORRINOSTOMÍA ENDOSCÓPICA: ¿ES LA INTUBACIÓN NECESARIA?

LONG-TERM RESULTS IN ENDOSCOPIC DACRYOCYSTORHINOSTOMY: IS INTUBATION REALLY REQUIRED?

Otolaryngology - Head \& Neck Surgery 140(4): 589-595, April 2009.

En este estudio compararon los resultados a largo plazo de pacientes sometidos a dacriocistorrinostomía endoscópica, en donde la variable fue el uso de cánulas de silicona para la intubación de la vía lagrimal.

El diseño es prospectivo en donde realizaron un seguimiento a 38 pacientes sometidos a esta cirugía por estenosis postsacular de la vía lagrimal. En 19 de estos pacientes no se colocó una sonda de silicona en la vía lagrimal, en la otra mitad sí fue usada. Los grupos fueron randomizados y eran equivalentes. En los que usaron sonda ésta se dejó por ocho semanas.

La técnica quirúrgica usada en ambos grupos fue bisturí frío para flap de mucosa y para la apertura de saco, para el hueso se usó cincel y martillo.

El seguimiento promedio de los pacientes fue de 8,1 años, el mínimo fue de 7 años.

El éxito quirúrgico anatómico y funcional fue evaluado subjetiva y objetivamente. El $84,4 \%$ de los pacientes del grupo que usó la sonda presentaron mejoría de sus molestias, mientras que 94,7\% del grupo que no usó sonda presentó mejoría. Se les solicitó que valoraran la epifora dándole un puntaje de 1 a 5. En donde 1 es sin epifora, 2 mejoría significativa, 3 mejoría parcial, 4 sin cambios y 5 deterioro de la epifora. De 1 a 3 se consideró mejoría de sus molestias.

La evaluación endoscópica mostró que la apertura del saco lagrimal fue visible en $89,5 \%$ de los que usaron sonda y $94,7 \%$ de los que no usaron sonda.

Concluyen que los resultados de éxito son similares en los dos grupos. Colocar una sonda en la vía lagrimal tiene algunas desventajas: formación de tejido de granulación, incomodidad para el paciente y gastos asociados a la cánula.

Recomiendan no dejar sonda en la vía lagrimal a los pacientes sometidos a dacriocistorrinostomía endoscópica por obstrucción postsacular.

Dr. Santiago Cornejo Sch. Hospital Clínico, Pontificia Universidad Católica de Chile
ROL DE LA VITAMINA A EN LA EVOLUCIÓN DEL COLESTEATOMA

Role of Vitamin A in the eVolution of cholesteatoma U.S. Vishal Rao, D.R. Srinivas, Rajendra S. Humbarwadi, Bharat Kumar Malhotra Indian J Otolaryngol Head Neck Surg 2009; 61: 150-2.

A pesar de la gran cantidad de estudios realizados, el colesteatoma sigue siendo una entidad no completamente comprendida. Existen muchas teorías para explicar el origen y la evolución de esta enfermedad pero ninguna explica con exactitud como esto ocurre.

Existen varios estudios que demuestran la importancia de la vitamina A en la integridad epitelial, así como la deficiencia de esta vitamina es un conocido factor de riesgo para el desarrollo de la otitis media.

Estudios en animales y cultivos celulares demuestran que la deficiencia de vitamina $A$ induce la metaplasia del epitelio del oído medio hacia un epitelio escamoso queratinizante, como una forma de adaptación del epitelio a un ambiente desfavorable. En estos estudios, se ha demostrado la existencia de un marcador genético (cornifin- $\alpha$ ) que actúa como regulador en la diferenciación hacia este epitelio escamoso, y su posterior desaparición al recibir tratamiento con vitamina $A$.

En el presente estudio, los autores presentan cinco casos de pacientes con colesteatomas primarios adquiridos, los cuales fueron tratados solamente con suplementos orales de vitamina A $(25,000 \mathrm{UI}$ diarias por 14 días), sin otro tratamiento tópico ni sistémico; encontrando una resolución significativa de la enfermedad en cuatro pacientes, con la completa resolución del colesteatoma y la persistencia del bolsillo de retracción en estos cuatro casos.

Aunque la deficiencia de vitamina A no permite explicar completamente la patogénesis del colesteatoma, este estudio muestra que existe un subgrupo de pacientes que se podría ver beneficiado con esta simple indicación médica.

Finalmente, los autores extrapolan que la deficiencia materna de vitamina A podría tener algún rol en el desarrollo del colesteatoma congénito.

\author{
Dr. Rodrigo Cabezón A. \\ Hospital Clínico, \\ Pontificia Universidad Católica de Chile
}




\section{¿UNA TEORÍA UNIFICADA PARA LA DISFUNCIÓN VESTIBULAR?}

A UNIFIED HYPOTHESIS FOR VESTIBULAR DYSFUNCTION? Phillips JS, Prinsley PR

Otolaryngol Head Neck Surg 2009; 140: 477-9.

La etiopatogenia subyacente a distintas enfermedades que asocian disfunción vestibular (como enfermedad de Ménière, parálisis vestibular súbita, neuronitis vestibular) aún no está completamente dilucidada. Tradicionalmente se ha considerado la etiología de cada una de estas patologías como distintas 0 independientes.

Los autores presentan en este trabajo una nueva teoría única para explicar las distintas patologías vestibulares, basados en el concepto de partículas libres flotantes (PLFs). Estas han ganado aceptación como el mecanismo tras el vértigo posicional paroxístico benigno (VPPB).

Las PLFs serían el resultado de la condensación y precipitación de detritos originados por otoconias en degeneración y otros fragmentos celulares. En la teoría de canalolitiasis en el VPPB, estas partículas generan movimientos endolinfáticos por arrastre provocando el vértigo postural. Las PLFs han sido observadas intraoperatoriamente.

Existe gran acuerdo en que la enfermedad de Ménière es secundaria a un hidrops endolinfático. Sin embargo se ha demostrado hidrops endolinfático en pacientes sin síntomas de Ménière.

Los autores proponen que PLFs podrían viajar más allá del laberinto vestibular, hacia el aparato coclear. Dependiendo del tamaño, cantidad, solvencia, precipitabilidad y lugar de depósito dentro del laberinto vestíbulo-coclear de las PLFs, estas podrían explicar la obstrucción del saco endolinfático (con el subsecuente hidrops), el daño de la membrana de Reissner y propiciar corrientes iónicas endolinfáticas (con la subsecuente crisis vértigo e hipoacusia). El predominio de tonalidades bajas en la hipoacusia y tinnitus del Ménière se corresponderían con la disminución del diatro del conducto coclear y la mayor facilidad de impactación de PLFs en esta zona. Además existe evidencia de una correlación fuerte entre enfermedad de Ménière y la posibilidad de desarrollar VPPB.

Fenómenos semejantes de compresión, obstrucción y daño mecánico reversible o irreversible podría explicar (considerando la existencia de PLFs de mayor tamaño) la sintomatología de una parálisis vestibular súbita 0 neuronitis vestibular. Los autores enfatizan cómo esta hipótesis explica el inicio súbito de los síntomas tras una supuesta impactación de las PLFs, mientras que una causa viral (siendo la más aceptada tradicionalmente) debiese expresarse con un inicio algo más gradual.

Tratamientos como la osilación mastoidea y la modulación de presión de oído medio pudiesen ser efectivos mediante un efecto "litotriptor" disolviendo por vibración las PLFs. En cuanto al efecto de la disminución de ingesta de sal, este mineral podría estar implicado en la cristalización y precipitabilidad de las PLFs.

Finalmente los autores reconocen la dificultad de probar esta teoría, especialmente por la transitoriedad de la precipitación de estas partículas. Esperan que el avance de técnicas imagenológicas permita en el futuro descubrir PLFs en crisis de enfermedad de Ménière, neuronitis vestibular, 0 parálisis vestibular súbita.

$$
\begin{array}{r}
\text { Dr. Hayo Breinbauer K. } \\
\text { Hospital Clínico, } \\
\text { Pontificia Universidad Católica de Chile }
\end{array}
$$

ROL DE LA RESONANCIA MAGNÉTICA EN PACIENTES CON SOSPECHA DE NEURINOMA DEL ACÚSTICO: UNA REVISIÓN SISTEMÁTICA DE LA COSTO-EFECTIVIDAD CLÍNICA Y LA HISTORIA NATURAL

THe ROLE OF MAgnetic Resonance IMAging IN the IDENTIFICATION OF SUSPECTED ACOUSTIC NEUROMA: A SYSTEMATIC REVIEW OF CLINICAL AND COST-EFFECTIVENESS AND NATURAL HISTORY

H Fortnum,C O'Neill, R Taylor, R Lenthall, T Nikolopoulos, G Lightfoot, G O'Donoghue, S Mason, D Baguley, H Jones and C Mulvaney.

Health Technology Assessment 2009; Vol. 13: No. 18; pp 1-176

El programa de la Health Technology Assessment (HTA) es parte del Instituto Nacional para la Investigación en Salud (NIHR), cuya función es generar investigación de alta calidad con respecto a la efectividad, costos e impacto de diversas interven- 
ciones en salud, dirigida a aquellos que trabajan en el Sistema Nacional de Salud de Reino Unido. En este contexto se desarrolló el presente trabajo con el objetivo de evaluar la efectividad clínica y costoefectividad de distintos métodos diagnósticos para el estudio de pacientes con hipoacusia sensorioneural unilateral y/o tinnitus con sospecha de neurinoma del acústico, y además describir la historia natural de esta enfermedad. Se buscaron trabajos en bases de datos electrónicas entre enero de 1980 y agosto de 2008. Se evaluó la calidad de los estudios encontrados y se extrajeron los datos para su análisis siguiendo las normas vigentes de medicina basada en evidencias. Se excluyeron aquellos casos de neurofibromatosis tipo 2 .

La sensibilidad del PEAT es alta al compararla con la RM pero sólo para los tumores de más de 1 $\mathrm{cm}$. Al comparar la sensibilidad de los estudios de RM sin uso de gadolineo (estudiando las secuencias T2) versus los estudios de RM con gadolineo (con estudio de las secuencias T2 y T1, tomando este último como patrón de referencia) se encontró que los estudios sin gadolineo tienen una sensibilidad de $98 \%$ (intervalo de confianza 94\%-99\%) y una especificidad de $90 \%$ a $100 \%$ con respecto a los estudios con gadolineo.

Respecto a los estudios de costo-efectividad, se encontró que es más costo-efectivo el uso de la RM de forma inmediata o junto con el PEAT, sin la realización de exámenes previos como la tomografía computada y la electronistagmografía. Al comparar la costo-efectividad de solicitar RM sin contraste versus RM con contraste se encontró que es mejor pedir estudios de RM sin contraste.

Respecto a la incidencia y prevalencia de la enfermedad se encontró que ha aumentado su frecuencia de 5 por millón de habitantes en 1976 a 20 por millón de habitantes en el 2001, sin cambios en la edad promedio de diagnóstico (55 años), y con aumento de los tumores pequeños y medianos y reducción de los tumores grandes. Esto probablemente se relaciona con las mejoras en los métodos diagnósticos.

La sintomatología no se reporta claramente en la literatura, pero en general tienen hipoacusia unilateral, tinnitus y/o vértigo de instalación insidiosa.

Los estudios respecto al crecimiento del tumor tienen varias fallas metodológicas. El patrón de crecimiento es altamente variable y actualmente impredecible. Al menos $50 \%$ no crece por unos años desde el diagnóstico. El crecimiento promedio es de 1-2 mm/año, pero si se toman sólo aquellos que crecen se encuentran valores de 2-4 $\mathrm{mm} / \mathrm{año}$ (pero puede llegar a $18 \mathrm{~mm} / \mathrm{año}$ ). La regresión ocurre en $5 \%$.

La RM sin gadolineo puede permitir una adecuada visualización del VII y VIII par en el ángulo pontocerebeloso y CAI, además visualizar bien la cóclea y el laberinto. Cuando todas estas estructuras se logran identificar en forma segura, es muy poco probable que la adición de las secuencias con gadolineo aporten información que altere el manejo de los pacientes. Sin embargo esto será altamente dependiente de la calidad y confiabilidad del resonador, tecnólogos que tomen el examen y experiencia el radiólogo que lo informe, por lo que se debe analizar cuidadosamente la aplicabilidad de los hallazgos de este estudio a la realidad nacional. Las mejoras en los métodos diagnósticos permitirán diagnosticar tumores cada vez más pequeños, que pueden plantear nuevos desafíos en términos del mejor manejo para estos pacientes.

$$
\begin{array}{r}
\text { Dr. Rubén González E. } \\
\text { Hospital Clínico, }
\end{array}
$$

¿ES LA HIPERTROFIA AMIGDALINA UNILATERAL POR SÍ SOLA UNA INDICACIÓN DE AMIGDALECTOMÍA?

IS UNILATERAL TONSILLAR ENLARGEMENT ALONE AN INDICATION FOR TONSILLECTOMY?

Sunkaraneni VS, Jones SE, Prasai A, Fish BM.

J Laryngol Otol 2006 Jul;120(7):E21.

Department of Ear, Nose and Throat, Addenbrooke's Hospital, Cambridge, UK.

Introducción: Actualmente existe controversia en la literatura respecto del examen histopatológico de rutina de las amígdalas extirpadas. El aumento amigdalino unilateral (AAU) es visto con cierta frecuencia en la práctica diaria, emergiendo el dilema si representa o no una neoplasia subyacente. Existen ciertas características clínicas que au- 
mentan el grado de sospecha al respecto. Sin embargo, la dificultad aparece cuando sólo existe una hipertrofia unilateral, sin otros hallazgos al examen físico. ¿Es correcto someter a estos pacientes a una cirugía con los riesgos inherentes al procedimiento (Ej: hemorragia) y a la anestesia general? El objetivo de este estudio es clarificar este dilema, determinando la prevalencia de malignidad en pacientes con AAU con y sin otras características clínicas.

Método: Se analizaron los registros de todos los pacientes de este centro sometidos a amigdalectomía y enviados a estudio histopatológico, desde el $1^{\circ}$ de junio de 1998 hasta 30 de mayo de 2003. Los criterios de exclusión fueron: pacientes sin antecedentes preoperatorios en ficha clínica, muestras de tejido amigdalino derivadas desde otros hospitales, pacientes ya diagnosticados de neoplasia y los casos en que la amigdalectomía fue efectuada por otras especialidades. Luego del total se seleccionaron todos los pacientes con antecedente previo de AAU como único hallazgo clínico y aquellos con ciertas características (historia de dolor crónico, disfagia, mucosa amigdalina y periamigdalina anormal y adenopatías cervicales). El análisis estadístico se realizó con el programa SPSS (v. 11.0.2 para Mac).

Resultados: Durante este periodo se realizaron 1.475 amigdalectomías, de las cuales 181 fueron enviadas a anatomía patológica. Luego de aplicar los criterios de exclusión quedó un total de 105 pacientes. De estos últimos, sólo 53 tenían AAU. Todos los pacientes fueron sometidos a amigdalectomía bilateral. De los 53, 33 casos (edad promedio $=25$ años) tenían sólo AAU y 20 (edad promedio =49,5 años) presentaban los hallazgos clínicos descritos previamente. No hubo diferencias por género. Ninguno de Ios 33 pacientes con sólo AAU tuvo diagnóstico de malignidad. En el otro grupo de 20 pacientes, hubo confirmación histológica de neoplasia en el $45 \%$ (edad promedio $=65$ años). La diferencia entre ambos grupos fue estadísticamente significativa ( $p$ $<0,001)$. Cabe destacar que en el segundo grupo, las características clínicas relacionadas con el diagnóstico de malignidad incluyeron: mucosa ulcerada, adenopatías cervicales, antecedente de hábito tabáquico y alcohólico, linfoma testicular previo, masa 0 nódulo cervical, quiste 0 papiloma amigdalino y odinofagia crónica.
Discusión: El AAU puede ser causado por tumores primarios como linfoma (generalmente no Hodgkin de células B) 0 carcinoma celular escamoso, más raramente producto de metástasis. Los hallazgos relevantes de este estudio aparte del hecho que no se encontró signos de malignidad en pacientes que sólo tenían AAU, es que el $45 \%$ de los casos de neoplasia pertenecientes al segundo grupo con ciertas características clínicas, muestra que dichos hallazgos al examen físico constituyen un indicador más sensible de malignidad respecto al AAU por sí solo. Según otros estudios la diferencia de tamaño amigdalino, tanto en adultos como en niños, es a menudo debido a asimetría de los pilares 0 variaciones en la profundidad de las fosas amigdalinas. Lo que sugiere que la impresión clínica muchas veces es errónea. Además, de acuerdo a varios autores el estudio histológico de rutina de las amígdalas extirpadas no es costoefectiva. Finalmente, podemos concluir que en muchas ocasiones es la clínica lo que nos puede sugerir malignidad. Asimismo, los autores concuerdan con la literatura, que la conducta de observar y esperar por un periodo de 6 semanas en casos de AAU es más apropiado. Sin embargo, según los resultados del presente estudio el índice de sospecha debiera ser enfocado al grupo de 65 ó más años sobretodo cuando existen signos clínicos que orientan a malignidad.

$$
\begin{array}{r}
\text { Dr. Marcelo Raín H. } \\
\text { Hospital Clínico, } \\
\text { Pontificia Universidad Católica de Chile }
\end{array}
$$

TERAPIA TÓPICA EN ANOSMIA: PERTINENCIA DE RESPUESTA DE LOS ESTEROIDES

Topical Therapy in Anosmia: Relevance of SteroldRESPONSIVENESS

Laryngoscope 118: 1681-1686, sept. 2008.

Se sabe que $5,8 \%$ de la población sufre de anosmia y $19,1 \%$ sufre de alguna disfunción olfatoria en general. Lo cual afecta seriamente la calidad de vida de estos pacientes. El uso de los corticoides ya sea por vía sistémica o tópica es conocido como una terapia común en estos pacientes, sin embar- 
go las investigaciones que prueben el beneficio de la terapia tópica son muy escasas, además no se conocen los factores pronósticos. En este estudio se busca evaluar el efecto adicional de la terapia tópica no sólo con corticoides sino además asociado a antibióticos después del uso del tratamiento convencional con corticoides orales, además de establecer la pertinencia de la respuesta a corticoides como un factor pronóstico.

Para lograr lo anterior se evaluaron 299 pacientes con disfunción olfatoria. En 89 pacientes en que se indicó inicialmente tratamiento con corticoides sistémicos se logró tener suficientes datos como para realizar un seguimiento en el tiempo. En un segundo paso todos estos pacientes recibieron tratamiento tópico, siendo entrenados en la correcta forma de aplicación nasal, ya sea sólo con budesonida o en combinación de esta con neomicina. Como parámetro principal de resultado se utilizó el resultado de umbral de identificación y discriminación olfatoria (TDI).

En los resultados en la respuesta a la terapia inicial con corticoides orales el cambio en el TDI fue de 15,5 a 18,7 en promedio ( $p<.001)$. Ahora dividiendo a los pacientes en aquellos que tuvieron una buena respuesta con la terapia oral (SRA); y los que no mostraron beneficio (no-SRA), en este último grupo el beneficio del tratamiento tópico resultó ser estadísticamente significativo (p $<.001$ ); además en este grupo se encontró mejores resultados en la asociación de corticoides más antibióticos tópicos (neomicina), con una elevación del TDI +2,1 puntos, por sobre los corticoides solos con una elevación de sólo $+1,0$ puntos.

En conclusión la respuesta a corticoides sistémicos en anosmia demostró ser un factor pronóstico indicador relevante del beneficio de la terapia tópica en general. En todos los pacientes los efectos de una terapia inicial corticoidal sistémica debería ser mantenida con la suma de la terapia tópica, la cual es aún más efectiva en los pacientes con baja respuesta a los primeros, más aún la adición de antibióticos tópicos. En este último grupo se demostró un efecto adicional en la mejora de su resultado de olfato. Diferentes razones se han discutido para explicar este efecto, ya sea la resistencia a los esteroides por la suma del efecto antiinflamatorio de los antibióticos o la inhibición de la apoptosis podría jugar un rol importante, por lo cual se hacen necesarios estudios a nivel molecular que determinen el rol de los antibióticos como la neomicina en el tratamiento de la disfunción olfatoria.

$$
\begin{array}{r}
\text { Dr. Ricardo Valdés S. } \\
\text { Hospital Clínico, }
\end{array}
$$

SINUPLASTÍA CON BALÓN PARA EL TRATAMIENTO QUIRÚRGICO DE RINOSINUSITIS AGUDA EN PACIENTES CRÍTICOS Y/O INMUNOCOMPROMETIDOS

BALLOON SINUPLASTY FOR THE SURGICAL MANAGEMENT OF IMMUNOCOMPROMISED AND CRITICALLY ILL PATIENTS WITH ACUTE RHINOSINUSITIS

Maria L. Wittkopf, MD, Samuel S. Becker, MD, James A. Duncavage, MD and Paul T. Russell, MD, Nashville, TN

Otolaryngology-Head and Neck Surgery (2009) 140, 596-598.

Introducción: La sinuplastía con balón se define por la técnica endoscópica de dilatación del seno paranasal y la conservación relativa de su mucosa. Consecuentemente la pérdida sanguínea puede ser frecuentemente minimizada. Esta disminución en la pérdida sanguínea convierte a la sinuplastía en una buena opción para el tratamiento de rinosinusitis aguda en pacientes críticos y/0 inmunocomprometidos. Estos pacientes tienen frecuentemente alteraciones hematológicas y tienen una pequeña reserva de sangre en caso de pérdidas en una cirugía endoscópica nasal clásica para tratar una sinusitis aguda. Desafortunadamente, en estos pacientes, una sinusitis aguda puede evolucionar a una enfermedad crítica sin una intervención quirúrgica. Es así que está clara la necesidad de encontrar una intervención quirúrgica con una mínima morbilidad asociada. El propósito de este estudio fue revisar la experiencia del grupo de Nashville de 6 meses usando la sinuplastía con balón para el tratamiento de sinusitis aguda en pacientes críticos y/o inmunocomprometidos.

Métodos: Se identificaron los pacientes a quienes se les realizó sinuplastía con balón entre octubre de 2007 y marzo de 2008 . Se revisaron y analizaron las fichas del subgrupo de pacientes críticos y/o inmunocomprometidos. 
Resultados: Treinta y un pacientes fueron sometidos a sinuplastía con balón en la institución entre octubre de 2007 y marzo de 2008. Se identificaron cinco pacientes críticamente enfermos con sinusitis aguda de este grupo. Las edades de los pacientes oscilaban entre los 15 a 51 años, sin preponderancia por sexo. Todos los pacientes tenían hallazgos focales en una tomografía computarizada del seno. En todos los casos, se observó drenaje purulento intraoperatoriamente. Todos los pacientes regresaron a su estado basal de salud, obteniendo criterios de alta médica después del tratamiento.

Conclusión: Los pacientes críticos y/o inmunocomprometidos con sinusitis aguda están expuestos a complicaciones potencialmente mórbidas. Estos pacientes, en quienes falla el tratamiento médico y requieren cirugía, a menudo son pobres candidatos quirúrgicos. La sinuplastía con balón representa potencialmente una técnica quirúrgica menos invasiva a la opción estándar de cirugía endoscópica nasal clásica y debe considerarse en enfermos críticos y/o inmunocomprometidos.

Dr. Francisco De la Paz P. Hospital Clínico, Pontificia Universidad Católica de Chile

ANÁLISIS DE LOS SÍNTOMAS RESIDUALES DESPUÉS DEL TRATAMIENTO DEL VÉRTIGO POSTURAL PAROXÍSTICO BENIGNO UTILIZANDO UN CUESTIONARIO

ANALYSIS OF RESIDUAL SYMPTOMS AFTER TREATMENT IN BENIGN PAROXYSMAL POSITIONAL VERTIGO USING QUESTIONNAIRE No Hee Lee, Hee Jun Kwon, Jae Ho Ban. Otolaryngol Head Neck Surg 2009; 141(2): 232-6.

Introducción: El Vértigo Postural Paroxístico Benigno (VPPB) es una de las alteraciones vestibulares más frecuentes, presentando vértigo y nistagmus en respuesta a los cambios de posición de la cabeza.

Fisiopatológicamente, se produciría por un desplazamiento de otoconias utriculares hacia los canales semicirculares, lo cual produciría un flujo de endolinfa que explicaría la sintomatología.
Dependiendo de canal semicircular afectado, existen diferentes maniobras de reposicionamiento de partículas que pueden ser utilizadas para su tratamiento, las cuales han probado ser útiles mediante metaanálisis.

Sin embargo, existe $22 \%-38 \%$ de pacientes que presentan molestias residuales posteriores a las maniobras de reposicionamiento, como disconfort y ansiedad, las cuales son difíciles de objetivar con los métodos clásicos de evaluación vestibular. Es así como se han desarrollado cuestionarios para poder objetivar dichas molestias, dentro de los cuales se encuentra el DHI (Dizziness Handicap Inventory), introducido en 1990 para evaluar la autopercepción del impedimento que producen las enfermedades vestibulares. Consiste en 25 ítemes divididos en 3 grupos, que evalúan el impacto en las áreas funcionales, emocionales y físicas de los pacientes.

Objetivos: Evaluar los síntomas residuales después de las maniobras de reposicionamiento de partículas en pacientes con VPPB, mediante el uso de un cuestionario.

Materiales y Métodos: Se diseñó un estudio prospectivo, controlado. Se seleccionaron 328 pacientes con VPPB que consultaron entre septiembre 2004 y abril 2006, a los cuales se le aplicó el DHI. Un total de 193 pacientes fueron excluidos por: asociación a otras patologías vestibulares, compromiso de más de 1 canal semicircular, falta de resolución de síntomas en 2 semanas a pesar de múltiples maniobras de reposicionamiento, y cuestionario incompleto.

De este modo, 135 pacientes fueron reclutados en forma definitiva, a los cuales se aplicó el DHI antes de las maniobras de reposicionamiento, y 5 a 7 días posterior a éstas. Se utilizó la maniobra de Epley para los VPPB del canal semicircular posterior y la maniobra de Barbacoa para los del canal lateral, las cuales se aplicaron en forma diaria hasta la resolución del vértigo y el nistagmus.

Luego se reclutaron 135 pacientes controles voluntarios sin enfermedad vestibular, con características demográficas similares, a los cuales también se les aplicó el DHI.

Se compararon los valores obtenidos por el DHI antes y después de las maniobras de reposicionamiento, y con el grupo control. Se utilizó t-test pareado, definiendo significancia estadística con $p<0,05$. 
Resultados: La edad promedio de los pacientes estudiados fue de $5,2 \pm 12,7$ años. La mayoría de los pacientes tuvieron VPPB generado en los canales posteriores $(60,7 \%)$, correspondiendo el resto a los canales laterales.

No existió diferencia en los puntajes de $\mathrm{DHI}$ entre los pacientes mayores y menores de 65 años con VPPB, tanto previo como posterior a las maniobras de reposicionamiento.

Existió una mejoría significativa de los puntajes del DHI al comparar el grupo estudiado antes y después de las maniobras de reposicionamiento. Sin embargo, hubo 6 ítemes en los cuales no hubo mejoría, de los cuales 5 estaban destinados a evaluar el área emocional de los pacientes. Por otra parte, los puntajes posterior a las maniobras fueron significativamente mayores que los del grupo control, lo cual estuvo dado por diferencias en 5 ítemes, de los cuales 4 también pertenecieron al área emocional.

Discusión: A pesar de un rol aceptado del desplazamiento de otoconias en la génesis del VPPB, existen autores que plantean que otros mecanismos fisiopatológicos complementarios, como degeneración neuronal, neurolaberintitis viral u otras alteraciones vestibulares concurrentes. Esto se manifestaría clínicamente como la presencia de algunos síntomas subjetivos a pesar de la resolución del vértigo y nistagmus. Es por esto que se diseñó el presente estudio, para así poder objetivar dichas molestias.

Al analizar el $\mathrm{DHI}$ previo y posterior a las maniobras de reposicionamiento, se aprecia una disminución significativa de la discapacidad de los pacientes, pero que no alcanza la normalidad del grupo control, lo cual se ve reflejado predominantemente en el área emocional de los pacientes. Esto se explica por la falta de predictibilidad de las crisis, lo cual generaría una ansiedad importante en los pacientes. Debido a esto se debería considerar algún tipo de apoyo emocional en este grupo de pacientes.

Por otra parte, en este estudio la edad de los pacientes no tuvo relación con la incapacidad percibida tanto previo como posterior a las maniobras de reposicionamiento.

Conclusiones: Las maniobras de reposicionamiento de partículas son útiles para el tratamiento de pacientes con VPPB, pero no siempre logran resolver la totalidad de los síntomas, particularmente los emocionales. Es por esto que se debe considerar rehabilitación vestibular y seguimiento en este grupo de pacientes.

\author{
Dr. Andrés Finkelstein K. \\ Hospital Clínico, \\ Pontificia Universidad Católica de Chile
}




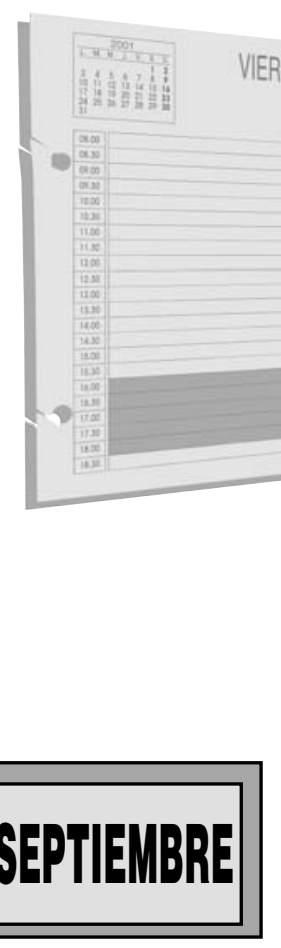

\section{CALENDARIO CEPE AÑO 2009}

25 de septiembre Hospital Clínico Universidad de Chile

16 de octubre Hospital Clínico Universidad Católica de Chile

\section{CURSOS Y CONGRESOS AÑO 2009}

SEPTIEMBRE 10 al 12

VIII Congreso Hispano-Alemán de Otorrinolaringología y Patología Cérvico Facial San Sebastián, España.

Contacto: orlcongresos@seorl.net.chao

\section{OCTUBRE 1 y 2}

II Curso de Técnicas Endoscópicas en Neurocirugía

Auditorio Alta Complejidad Hospital Clínico UC

Organiza: Pontificia Universidad Católica de Chile

Directores del Curso: Dr. Francisco Santorcuato, Dr. Ricardo Rojas

Información e Inscripciones: Dirección de Extensión, Facultad de Medicina, Lira 44, primer piso. Santiago. Teléfonos: 3546430 - 3546425

inscrip@med.puc.cl - http://contacto.med.puc.cl

\section{OCTUBRE 4 al 7}

American Academy of Otolaryngology-Head and Neck Surgery Annual Meeting \& OTO EXPO,

San Diego, California, USA.

www.entnet.org

\section{OCTUBRE 17}

Olimpiadas $\mathrm{ORL}$

Estadio Las Condes, Santiago. Av. Las Condes 11755, Las Condes

Director: Dr. Claudio Bustos Fernández

Participan: Socios SOCHIORL, esposa (o) e hijo (s)

Asado de Camaradería

\section{OCTUBRE 31}

Jornadas Andinas 2009

Hotel Regal Pacific

Director: Dr. Gonzalo Bonilla 
NOVIEMBRE 4 al 7

LXVI Congreso Chileno de Otorrinolaringología y II Reunión Conjunta con la Academia Americana de Otorrinolaringología - Coquimbo, Chile.

Presidente: $\quad$ Dr. Andrés Rosenblüt Ratinoff

Vicepresidente: Dra. Edda Pruzzo Chandía

Secretaria: Dra. Virginia Murillo Sayago

Tesorero: $\quad$ Dr. Luis Villarroel Nieto

Pro Tesorero: $\quad$ Dr. José San Martín Prieto

Comité Científico: Dr. José Miguel Contreras Retamales

Comité Audio Visual: $\quad$ Dr. Pedro Badía Venti

Comité Eventos Sociales: Dra. Claudia Corssen Janssen

Profesores Internacionales Invitados:

- Diego Preciado, MD., PhD Dept. of Pediatric Otolaryngology Children's National Medical Center. Assistant Professor, The George Washington University Medical Center, Pediatric Otolaryngology and Airway Management.

- Ehab Hanna, MD., FACS Professor and Vice Chairman Director of Skull Base Surgery Medical. Director of Head and Neck Center, Deparment of Head and Neck Surgery, University of Texas, MD Anderson Cancer Center.

- Joseph B. Nadol Jr. MD. Professor and Chairman, Otology. Harvard Medical School, Massachusetts. Eye and Ear Infirmary.

- David Sherris, MD Professor and Chairman. Facial Plastic Surgery and Rhinology, Dpto Otolaryngology University of Buffalo, NY.

- Miguel Moscovicz Médico de Staff de Rinosinusología, Hospital de Clínicas, Buenos Aires. Argentina.

Envío de trabajos libres: comitecientifico@sochiorl.cl

Plazo máximo para envío de trabajos: 13 de septiembre de 2009

\section{NOVIEMBRE 26 al 28}

I Curso Internacional de Cirugía de Cabeza y Cuello

Centro de Cáncer y Dirección Académica, Clínica Las Condes

Auditorio Mauricio Wainer Norman

Directores: Dr. Gustavo Vial, Dr. Carlos Ferrada, Dr. Gonzalo Nazar

Invitados: Dr. Patrick Gullane (Canadá), Dr. Jesús Medina (EE.UU.), Dr. Óscar

Guillamondegui (Argentina), Dr. Claudio Cernea (Brasil), Dr. Pedro Sánchez (Perú), Dr. Gabrielle Materazzi (Italia)

Contacto: Dirección Académica Clínica Las Condes

\section{BREVES DE INTERÉS}

- Se informa a los socios que el Concurso Anual de Investigación de la Sociedad Chilena de Otorrinolaringología se encuentra abierto. El plazo de recepción de los trabajos vence el 30 de septiembre. Las bases están disponibles en la página web de la Sociedad. Se les recomienda a los interesados revisarlas pues éstas han sufrido modificaciones recientemente.

- Se invita a todos los socios a proponer temas que les gustaría que fueran tratados en la editorial de nuestro informativo.

Esperamos sus ideas en el mail secretaria@sochiorl.cl 
Los trabajos enviados para publicación en la Revista de Otorrinolaringología y Cirugía de Cabeza y Cuello deberán ajustarse a las siguientes instrucciones preparadas considerando el estilo y naturaleza de la Revista y "Requisitos uniformes para los manuscritos sometidos a Revistas Biomédicas" establecidos por International Committee of Medical Journals Editors (Annals of Internal Medicine 1997; 126: 36-47 y http://www.icmje.org):

1. RECEPCION DE TRABAJOS: La Revista Chilena de Otorrinolaringología recibe trabajos a publicar en alguna de las siguientes secciones:

- Artículos de Investigación

- Artículos de Ética

- Artículos de Revisión

- Casos clínicos

- Cómo lo hago

- Revista de Revistas

- Cartas al Editor

Las secciones Historia de la Medicina, Imágenes Históricas, Revista de Revistas, Desafío, Cómo lo Hago e Informativo son responsabilidad del Editor, quien recibe y puede solicitar colaboraciones a miembros de la Sociedad.

No obstante, todas las colaboraciones son bienvenidas y agradecemos, de antemano, el envío.

Los trabajos deben enviarse con el texto mecanografiado e impreso a doble espacio en hojas tamaño carta, dejando un margen no menor de $3 \mathrm{~cm}$ de los bordes. La extensión del texto no debe sobrepasar 10 páginas, excepto en los trabajos de Revisión Bibliográfica, en los que la extensión puede ser mayor. Se debe enviar un original y dos fotocopias o copias de impresora.

Los trabajos preparados en computadores pueden ocupar cualquier familia de letra, de preferencia helvética, en caracteres de tamaño 12 y enviar junto al ejemplar original, dos copias y el diskette 0 CD indicando el programa utilizado.

\section{LOS ARTÍCULOS DE INVESTIGACIÓN DEBEN CONSIDE- RAR LAS SIGUIENTES SECCIONES}

\subsection{Página del Título debe contener}

a) El título del trabajo, el que debe ser conciso, pero informador del contenido del trabajo; b) Identificación de los autores: Debe incluir nombre de pila, el apellido paterno y la inicial del materno, su calidad profesional y su lugar de trabajo.

c) Identificación del lugar en que fue realizado el trabajo: nombre de las Secciones, Servicios, Departamentos e Instituciones.

d) Identificación del contacto, nombre, dirección y email del autor principal.

e) Fuente de apoyo: Indicar fuente de apoyo económico, si la hubo.

\subsection{Página de Resumen}

a) Resumen de no más de 200 palabras ordenado según el siguiente esquema para los artículos de investigación:

\section{Introducción}

Objetivo

Material y método

Resultados

Discusión

Conclusiones.

No es necesario una traducción al inglés.

b) Palabras clave. Al final del resumen se deberá indicar algunas palabras en castellano que sirvan para ubicar computacionalmente el contenido del texto, dentro de una base de datos.

2.3. Introducción. Debe contener una breve revisión del tema y el propósito y objetivo de la investigación.

2.4. Material y método. Describa claramente la selección de los sujetos en observación. Identifique los métodos y señale los instrumentos con la precisión necesaria para que otros investigadores puedan reproducir sus resultados. Indique las marcas comerciales entre paréntesis. Si se trata de métodos conocidos y establecidos de uso frecuente, basta nombrarlos 0 dar la referencia respectiva.

Si la experiencia se desarrolló con participación de pacientes 0 sujetos, señale si los procedimientos satisfacen las normas éticas establecidas de antemano, revisadas por un comité ad hoc de la institución en que se hizo el estudio, 0 concordantes con la declaración de Helsinski (1975). Identifique los pacientes por números correlativos, pero no use sus 
nombres, iniciales verdaderas, número de la observación 0 ficha clínica.

Registre los fármacos empleados por su nombre genérico e indique las dosis, vías de administración y esquemas aplicados.

Mencione, si es necesario, el método estadístico empleado, así como su nivel de significación.

2.5. Resultados. Presente sus resultados con una secuencia lógica. Esta secuencia debe aparecer concordante en el texto, las Tablas y Figuras. Los datos pueden presentarse en Tablas 0 en Figuras, pero no simultáneamente en ambas. No repita en el texto todos los datos que se presentan en una Figura 0 en una Tabla, sino aquello más relevante. No mezcle los resultados con la discusión, ya que ésta se hace en la sección siguiente.

2.6. Discusión. Se trata de una discusión de los resultados obtenidos en este trabajo y no de una revisión del tema. Discuta y destaque sólo los aspectos nuevos e importantes que aporta su trabajo, y las conclusiones que se desprenden de ellos. No repita con detalle los datos que aparecen en Resultados. Haga explícitas en esta sección las implicaciones de sus hallazgos, y relacione estas observaciones con otros estudios publicados con la cita bibliográfica respectiva. Vincule sus conclusiones con los propósitos y objetivos indicados en Introducción, pero evite proponer conclusiones que no estén sólidamente respaldadas por su trabajo, o por otros por terminar. Si le parece adecuado puede sugerir nuevas hipótesis 0 recomendaciones.

2.7. Conclusiones. Describir claramente las conclusiones del trabajo las que deben tener relación directa con los objetivos planteados los que deben ser avalados por los resultados y las pruebas estadísticas si proceden.

2.8. Agradecimientos. Exprese su reconocimiento sólo a personas 0 instituciones que hicieron contribuciones sustantivas a su trabajo.

2.9. Referencias. Los autores son responsables de la exactitud de sus referencias.

Numere las referencias consecutivamente de acuerdo al orden en que se mencionan en el texto, figuras, cuadros y/0 ilustraciones identificándolas, entre paréntesis, con números arábigos.

Emplee el estilo de los ejemplos que aparecen más adelante, los cuales están basados en el formato que la Biblioteca Nacional de Medicina de los Estados Unidos usa en el Index Medicus. Los títulos de las revistas deben abreviarse de acuerdo con el estilo utilizado en esta publicación. Consulte List of Journals Indexed in Index Medicus (Lista de revistas indexadas en Index Medicus).

Procure abstenerse de utilizar como referencias los resúmenes y las "comunicaciones personales".

Puede insertarse (entre paréntesis) en el texto las referencias a comunicaciones escritas, no verbales.

De igual forma puede incluirse entre las referencias los artículos aceptados para publicación, aunque todavía no hayan sido publicados; indique la revista y agregue "en prensa" (entre paréntesis). La información sobre manuscritos sometidos a la consideración de una revista, pero que aún no han sido aceptados, debe citarse en el texto como "observaciones inéditas" (entre paréntesis).

Los autores deben verificar las referencias cotejándolas contra los documentos originales.

A continuación se dan ejemplos de formas correctas de referencias.

a) Revistas

1) Artículo de revistas. Incluya el nombre de todos los autores separados por coma cuando sean seis o menos; si son siete 0 más, anote sólo el de los tres primeros y agregue "et al". Sigue el título del artículo en su idioma original. A continuación el nombre de la Revista según el estilo utilizado por Index Medicus y año de publicación, volumen de la revista, página inicial y final del artículo.

Ejemplo: You CH, Lee KY, Chey RY, Menguy R. Electrogastrographic study of patients with unexplained nausea, bloating and vomiting. Gastroenterology 1980; 79: 3114-5.

2) Autor corporativo

The Royal Marsden Hospital Bone-Marrow Transplantation Team. Failure of syngeneic bonemarrow graft without preconditioning in posthepatitis marrow aplasia. Lancet 1977; 2: 2424.

3) Anónimo. Coffee drinking and cancer of the pancreas (Editorial). Br Med J 1981; 283: 628.

4) Suplemento de revista

Frumin AM, Nussbaum J. Espodito M. Fuctional asplenia: Demonstration of splenic activity by bone marrow scan (Resumen). Blood 1979; 54 (supll): 26a

5) Revista con paginación discontinua (por número).

Seaman WB. The case the pancreatic pseudocyst. Hosp Pract 1981; 16 (sep): 245.

6) Libros y otras monografías.

b) Autor(es) personal(es)

Eisen HN. Immunology: An introduction to molecular and cellular principles of the immune response. Sa ed. Nueva York: Harper and Row 1974:406. 
c) Editor, compilador o presidente como autor

Dausset J. Colombani J. eds. Histocompatibility testing 1972.

Copenhague: Munksgaard, 1973: 128.

d) Capítulo de libro

Weinstein L, Swartz MN. Pathogenic properties of invading microorganisms. En: Sodeman WA Jr, Sodeman WA, eds, Pathologic physiology: Mechanisms of disease. Filadelfia: WB Saunders, 1974; 457-72.

e) Artículo incluido en las actas publicadas de una reunión

DuPont B. Bone marrow transplantation in severe combined immunodeficiency with an unrelated MLC compatible donor. En: White HJ, Smith R. eds.

Proceedings of the third annual meeting of the International Society for Experimental Hematology: Houston: International Society for Experimental Hematology, 1974: 446.

\section{f) Monografía que forma parte de una serie.}

Hunnighake GW, Gadek JE, Szapiel SV, et al. The human alveolar macrophage. En: Harris CC, ed. Cultured human cells and tissues in biomedical research. Nueva York: Academic Press, 1980: 546, (Stoner GD, ed. Methods and perspectives in cell biology; vol 1).

g) Publicación de un organismo.

Ranofsky AL. Surgical operations in shortstay hospitals: United States-1975.

Hyattsville, Maryland: National Center for Health Statistics, 1978; DHEW publication núm (PHS) 78-1785. (Vital and health statistics; serie 13, núm 34). h) Tesis

Cairns RB. Infrared spectroscopic studies of solid exigen (Tesis doctoral). Berkeley, California: University of California, 1965. $156 \mathrm{pp}$.

i) Para las referencias electrónicas, deben citarse primero los autores, el título del artículo, la revista de origen en caso que el trabajo estuviese publicado en ellas, y después el sitio electrónico donde se obtuvo la cita y la fecha en que se hizo esta consulta, teniendo en consideración que esta referencia pudiese eventualmente tener una modificación posterior de los autores; para ello debe anteponerse a la cita del sitio electrónico las palabras: Disponible en: y al finalizar la cita electrónica las palabras: Consultado el: (fecha).

j) Otros artículos

1) Artículos de periódico

Shaffer RA. Advances in chemistry are starting to unlock mysteries of the brain: Discoveries could help cure alcoholism and insomnia, explain mental illness.

How the messengers work. Wall Street Journal 1977 ago 12: 1 (col 1).

2) Artículo de revista periodística (magazine)
Rouche B. Annals of medicine: The Santa Claus culture. The New Yorker 1971 sep 4:66-81.

$\begin{array}{lll}\begin{array}{l}\text { 2.10.Símbolos } \\ \text { error estándar } \\ \text { promedio } \\ \text { número de observaciones }\end{array} & & \mathrm{EE} \\ \text { desviación estándar } & \mathrm{X} \\ \text { anticuerpo } & \mathrm{n} \\ \text { antígeno } & & \mathrm{DE} \\ \text { bell } & & \mathrm{AC} \\ \text { decibel } & \mathrm{Ag} \\ \text { electrocardiograma } & & \mathrm{B} \\ \text { electroencefalograma } & & \mathrm{dB} \\ \text { nano } & 10^{-9} & \mathrm{ECG} \\ \text { micro } & 10^{-6} & \mathrm{nEG} \\ \text { mili } & 10^{-3} & \mathrm{~m} \\ \text { centi } & 10^{-2} & \mathrm{C} \\ \text { deci } & 10^{-1} & \mathrm{~d}\end{array}$

2.11. Tablas. Presente las tablas en hoja aparte, escrita a máquina y a doble espacio. No envíe diapositivas 0 fotografía de las tablas. Numere las tablas en orden consecutivo y coloque un título breve encabezando cada tabla. Sobre cada columna coloque un encabezamiento corto y abreviado. Separe con líneas sólo los encabezamientos de las columnas y títulos principales. Las columnas deben separarse por espacios y no por líneas verticales. Coloque notas aclaratorias cuando proceda y explique las abreviaturas no convencionales al pie de la tabla.

2.12. Figuras. Se denomina Figura a cualquier tipo de ilustración que no es Tabla (fotografía, dibujo, esquema, radiografía, gráfico, ECG, ENG, etc.). Cualquiera sea su tipo deben ser numeradas de acuerdo a su aparición en el texto. En caso de dibujos o gráficos es preferible que sean hechos por profesionales. En este caso envíe una fotografía del mismo en blanco y negro del tamaño $9 \times 12 \mathrm{~cm}$. Los números o símbolos deben verse nítidos en toda la superficie de la fotografía, tomando en cuenta la posible reducción de tamaño en la publicación. Los títulos y leyendas deben ir en hojas aparte. En el reverso de las figuras, con lápiz de mina, debe anotarse el número de la figura como aparece en el texto, el nombre del autor principal y una flecha cuya punta se dirija a la parte superior de la figura. Si una figura es reproducción de material ya publicado, indique su fuente de origen y obtenga permiso escrito del autor o editor para reproducirla en su trabajo.

La publicación de ilustraciones en color debe ser consultada a la Dirección de la Revista y será de costo del autor. 
3. APARTADOS. La Revista podrá imprimir apartados a solicitud de los autores. Estos serán costeados por ellos y sólo se hará si la solicitud es materializada antes de la impresión del número. El mínimo de apartados es 30 ejemplares.

\section{RECORDATORIO}

Se sugiere leer detenidamente las Instrucciones a los autores, que se incluyen en las páginas finales de cada ejemplar de Revista de Otorrinolaringología y Cirugía de Cabeza y Cuello.

Título del trabajo.

Autores.
La identificación de los autores es Nombre, Primer Apellido, e Inicial del segundo Apellido.

Lugar de trabajo y calidad profesional de los autores

Se cita con números arábigos a la izquierda de la inicial del segundo apellido. Se debe indicar al pie de la página las Secciones, Servicios, Departamentos e Instituciones donde fue realizado el trabajo.

Resumen y palabras clave.

Referencias.

Los autores son responsables de la exactitud de sus referencias. 